\title{
WISH4Campus: Evaluating College Food Insecurity and Promoting Solutions for Student Wellbeing
}

\author{
Rebecca L. Hagedorn \\ West Virginia University, rlhagedorn@mix.wvu.edu
}

Follow this and additional works at: https://researchrepository.wvu.edu/etd

Part of the Food Security Commons, Nutrition Commons, and the Social Work Commons

\section{Recommended Citation}

Hagedorn, Rebecca L., "WISH4Campus: Evaluating College Food Insecurity and Promoting Solutions for Student Wellbeing" (2019). Graduate Theses, Dissertations, and Problem Reports. 3905.

https://researchrepository.wvu.edu/etd/3905

This Dissertation is protected by copyright and/or related rights. It has been brought to you by the The Research Repository @ WVU with permission from the rights-holder(s). You are free to use this Dissertation in any way that is permitted by the copyright and related rights legislation that applies to your use. For other uses you must obtain permission from the rights-holder(s) directly, unless additional rights are indicated by a Creative Commons license in the record and/ or on the work itself. This Dissertation has been accepted for inclusion in WVU Graduate Theses, Dissertations, and Problem Reports collection by an authorized administrator of The Research Repository @ WVU.

For more information, please contact researchrepository@mail.wvu.edu. 


\title{
WISH4Campus: Evaluating College Food Insecurity and Promoting Solutions for Student Wellbeing
}

\section{Rebecca Lee Hagedorn}

\author{
Dissertation submitted \\ To the Davis College of Agriculture, Natural Resources, and Design \\ at West Virginia University
}

In Partial Fulfillment of the requirements for the degree of Doctor of Philosophy in Animal and Food Science

\author{
Melissa D Olfert, DrPH, RDN, Chair \\ Deana Morrow, Ph.D. \\ Catherine Yura, Ed.D. \\ Lanae Hood, Ph.D.
}

Department of Animal and Nutritional Sciences

\author{
Morgantown, West Virginia \\ 2019
}

Keywords: Higher Education, College, University, Student, Food Insecurity, Wellbeing

(C) Copyright 2019 Rebecca L. Hagedorn 


\section{Abstract \\ WISH4Campus: Evaluating College Food Insecurity and Promoting Solutions for Student Wellbeing \\ Rebecca L. Hagedorn}

Introduction: Interest in college food insecurity has increased in previous years, however, little research focuses on the Appalachian and Southeastern regions of the United States resulting in limited understanding of food insecurity's impact on college students in these regions.

Additionally, resources to help food insecure students are often sparse with universities lacking evidence-based programming to implement for student benefit.

Aims: This dissertation aims to (1) investigate the correlates and behavioral consequences of food insecurity on college students at an Appalachian university, (2) expand college food insecurity research to a regional investigation in the Appalachian and Southeastern regions, and (3) develop and evaluate a toolkit of food insecurity initiatives that can assist higher education institutions in providing adequate resources for food insecure students.

Methods: A 56 item, cross sectional survey was utilized for aims 1 and 2. Surveys were distributed to students attending 10 public universities in the Appalachian and Southeastern Regions between Spring 2016 and Spring 2018. Food security status was measured using the United States Department of Agriculture Adult Food Security Screener (USDA AFSS). This survey also included demographic, behavioral, health, and economic independent variables. Forward selection logistic regression was used to determine variables that increased the likelihood of being food insecure. Aim 3 used online survey data collection to capture feedback on the WISH4Campus (Wellbeing Increased by Security from Hunger) toolkit. Experts $(n=126)$ from land-grant universities were sent a 27-question survey to determine perceptions of food insecurity and evaluation of specific toolkit components. Descriptive statistics and frequency analyses were performed on quantitative data and thematic analysis was used to analyze qualitative data.

Results: Students at an Appalachian university ( $\mathrm{n}=692)$ reported food insecurity prevalence at $36.6 \%$. Results of the forward selection logistic regression showed money expenditure (MES), coping strategies (CSS), health, and academic year were significant predictors of food insecurity in college students. When expanded to a regional investigation of 13,642 college students, prevalence of food insecurity at the universities ranged from 22.4-51.8\% with an average prevalence of $30.5 \%$. From the forward selection logistic regression model, MES, CSS, academic performance (APS), grade point average (GPA), academic year, perceived health status, race/ethnicity, financial aid, cooking frequency, and health insurance were significant predictors of food security status. For aim 3, thirty experts completed the toolkit evaluation survey. Evaluation feedback covered four main topics: layout, overall content, initiatives, and application. Eight themes emerged from the coding and categorization of responses: visual appeal, organization, value, provoking, comprehensive, barriers, collaboration, and efficiency.

Conclusion: Limited research has focused on college food insecurity in the Appalachian and Southeastern regions. Findings from these studies suggest food insecurity is a public health problem among college students in this region, and that continuing efforts are needed to assist affected students in getting greater access to safe, nutritious food. The developed toolkit is suggested to be a potential tool to help university personnel provide resources to students. Future research should aim to implement and evaluate food insecurity initiatives. 


\section{Table of Contents}

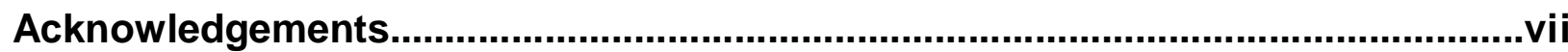

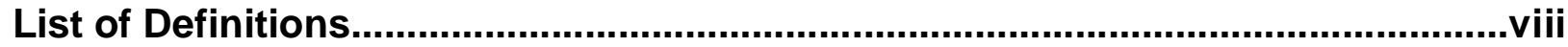

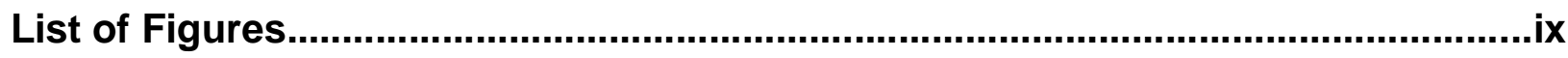

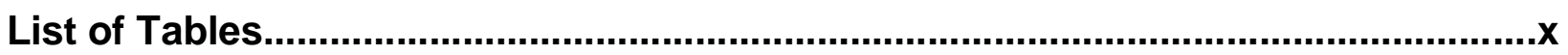

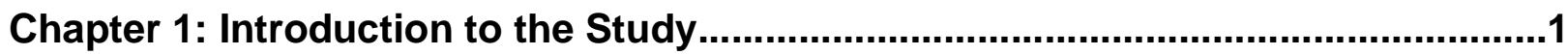

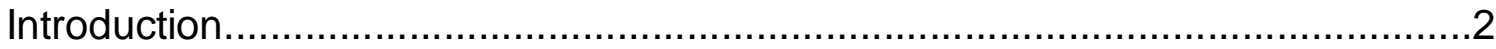

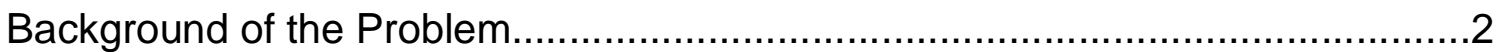

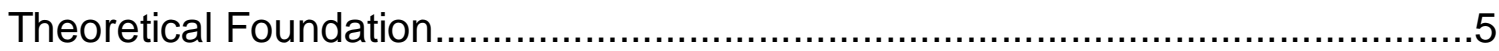

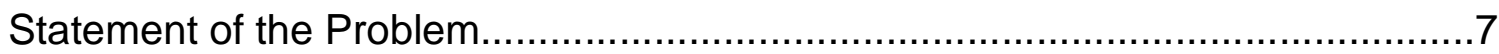

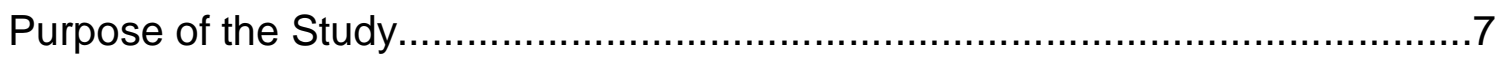

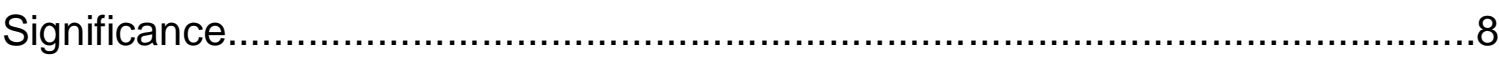

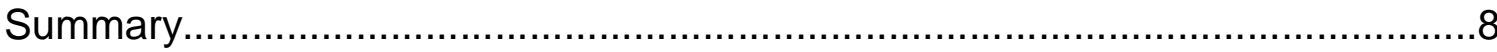

Chapter 2: Additional Background and Literature Review........................................9

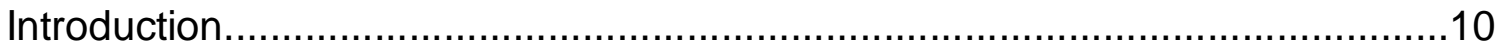

Food Insecurity: A National Problem..........................................................

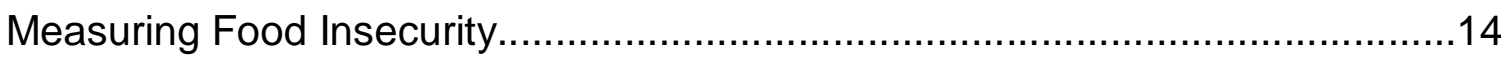

At Risk Populations and a Focus on Appalachia.............................................17

College Student Demographics and Lifestyle..............................................19

Food Insecurity Among College Students in the United States.........................21

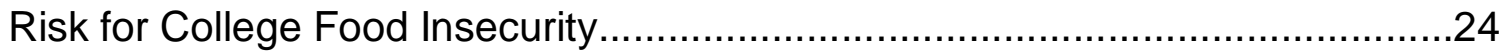

Impacts of Food Insecurity on College Students............................................27

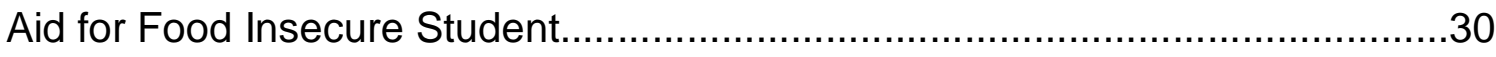

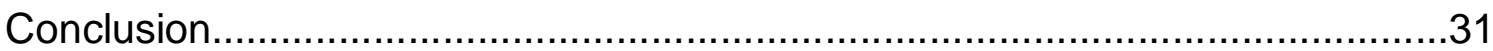

Chapter 3: Study Design and Statistical Analyses..................................................32

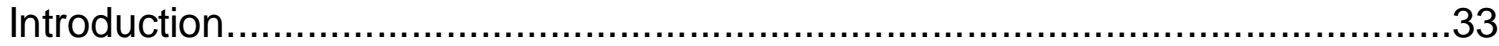

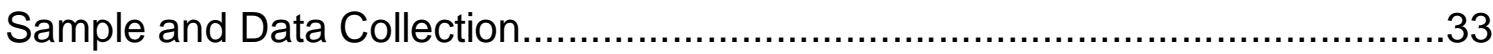

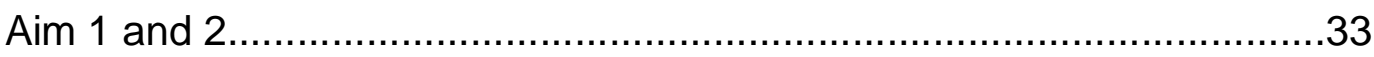

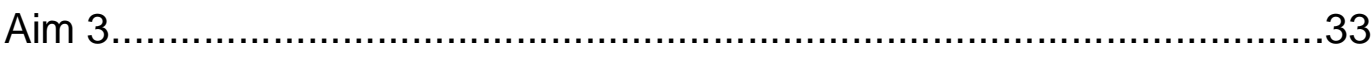

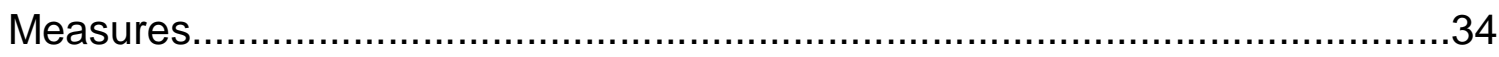

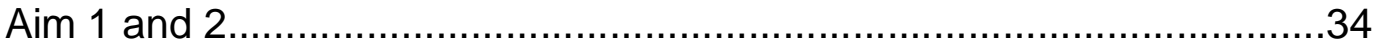


USDA Adult Food Security Screener..........................................34

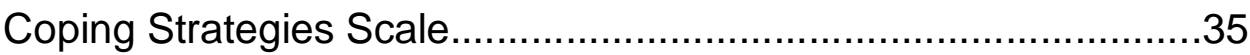

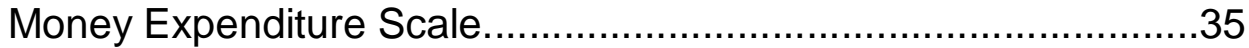

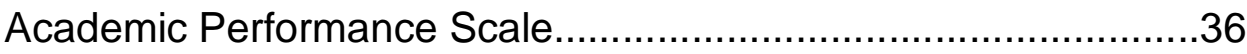

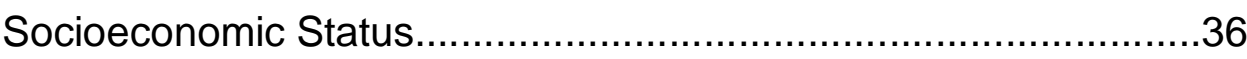

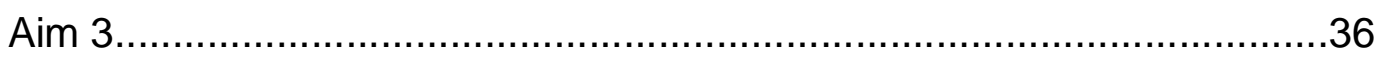

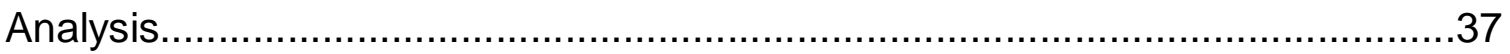

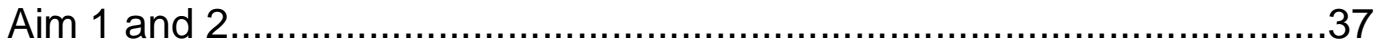

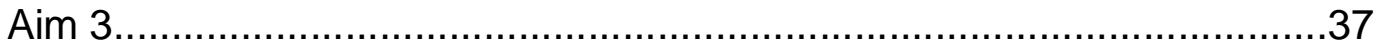

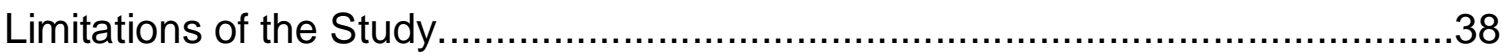

Chapter 4: Food Insecurity and Behavioral Characteristics for Academic Success in Young Adults Attending an Appalachian University.........................................39

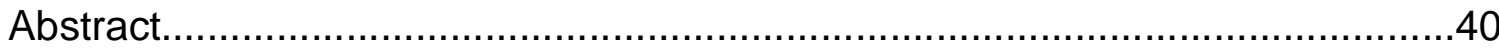

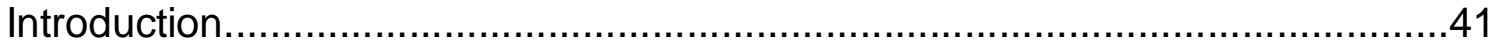

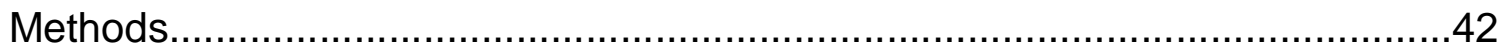

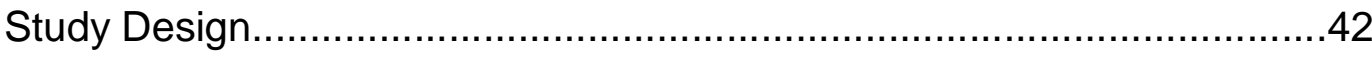

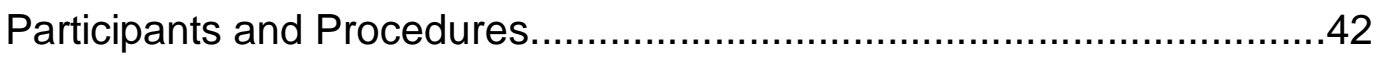

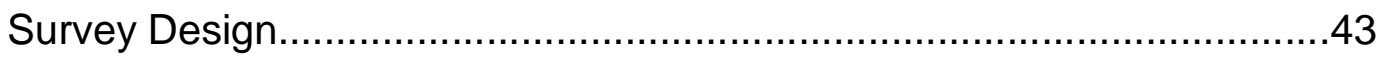

Dependent Variable ............................................................. 43

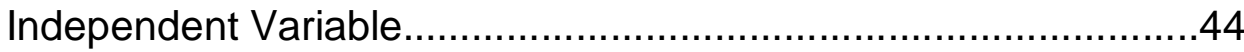

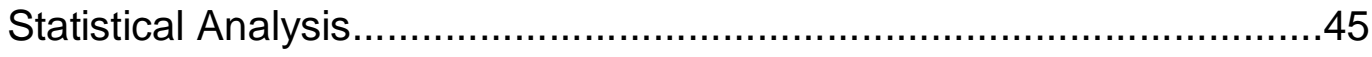

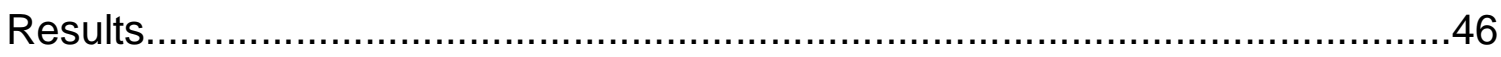

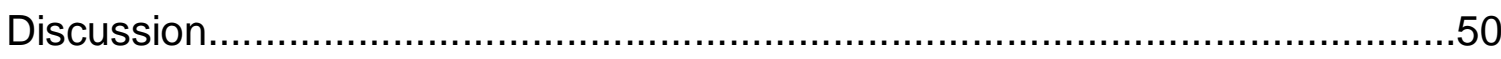

Limitations

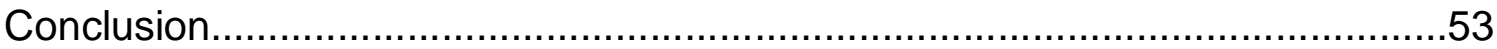

Chapter 5: Food Insecurity Impacts Behavior of College Students at 10 Higher Education Institutions in the Appalachian and Southeastern Regions...................54

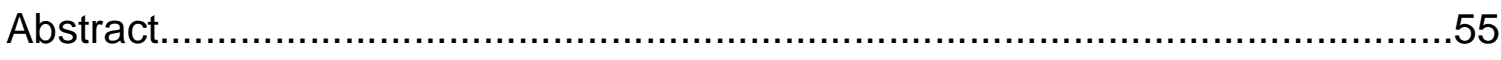

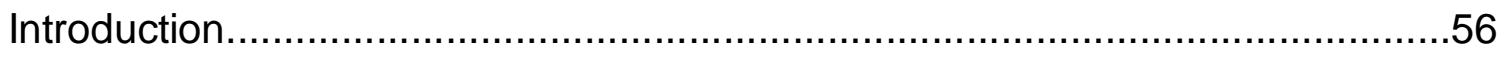

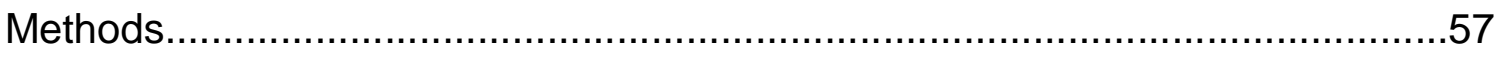

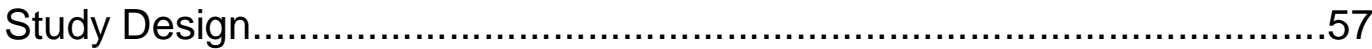

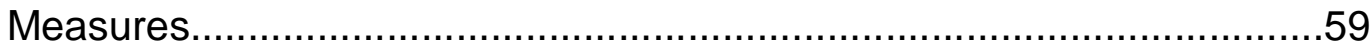

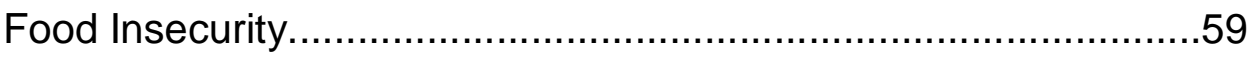




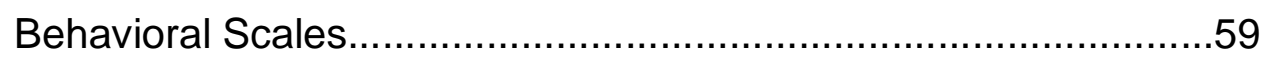

Sociodemographic and Health Characteristics...........................61

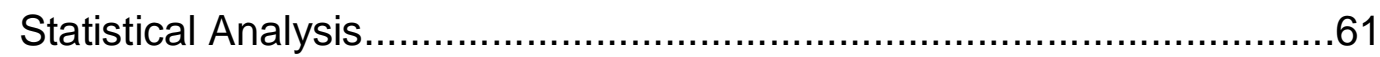

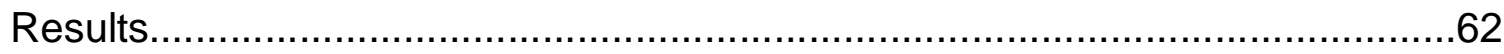

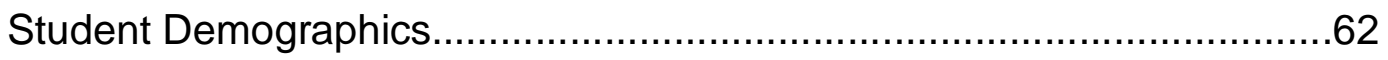

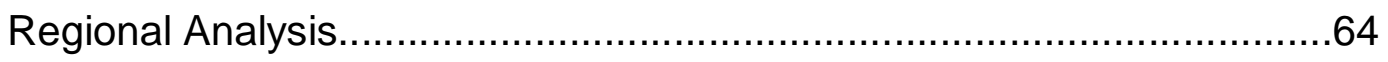

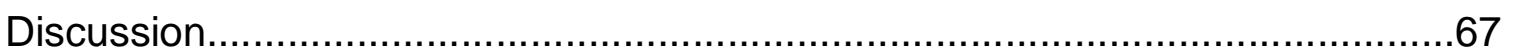

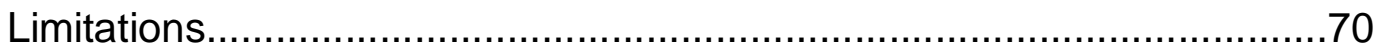

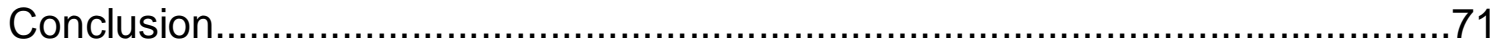

Chapter 6: Development and Evaluation of a Higher Education Food Security Toolkit to Provide Ideas of Initiatives for Student Wellbeing...................................72

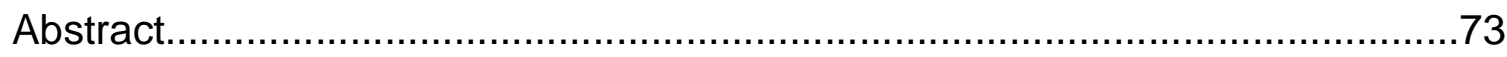

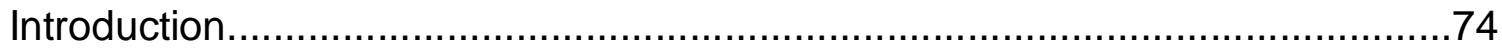

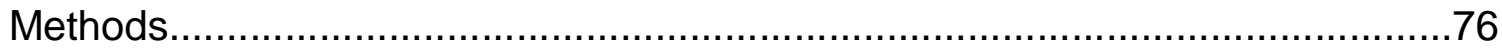

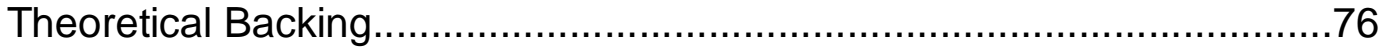

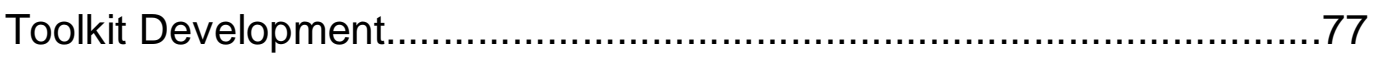

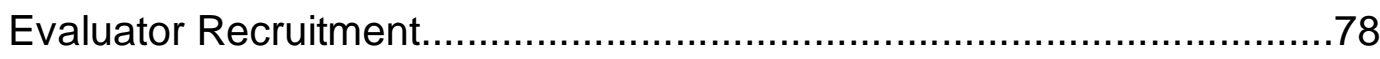

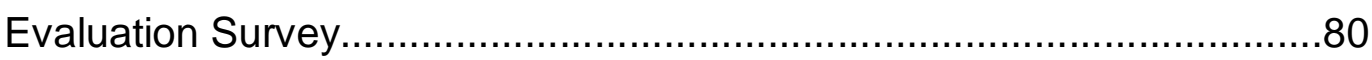

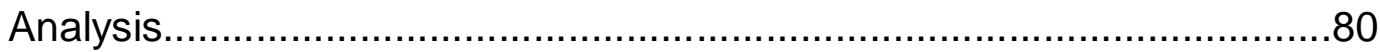

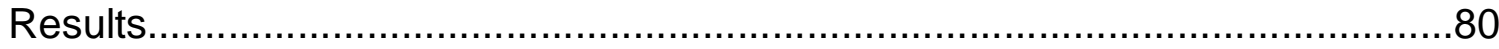

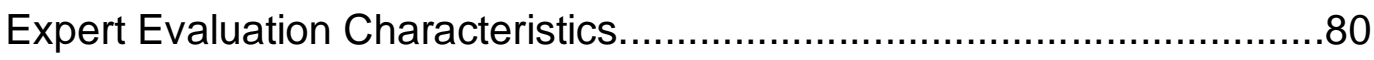

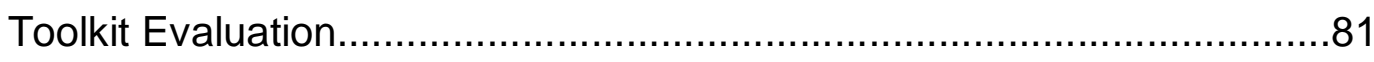

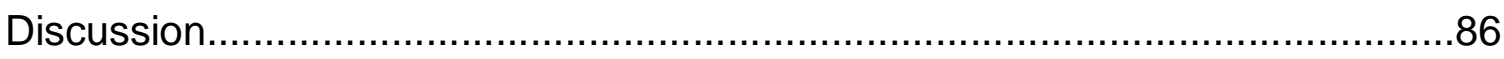

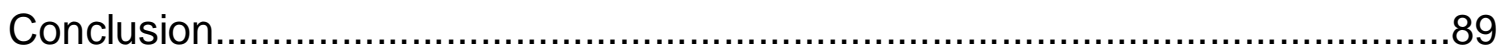

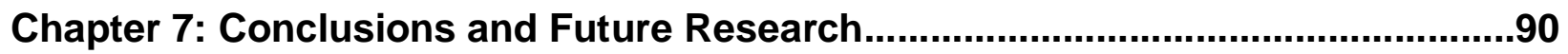

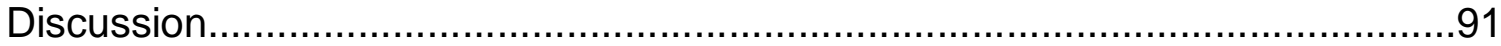

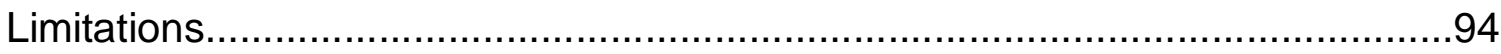

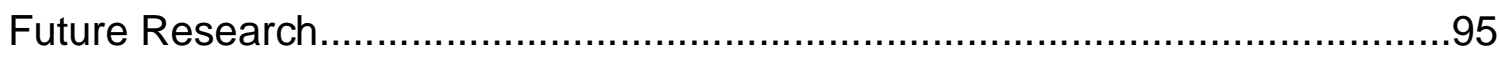

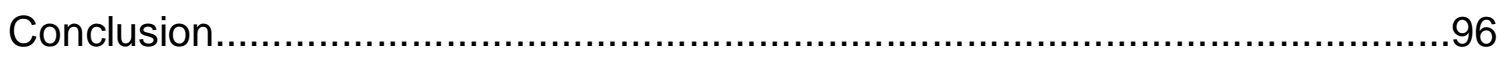

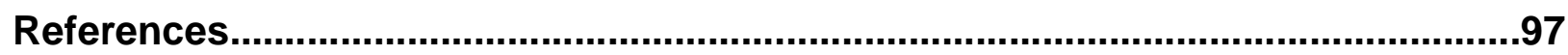

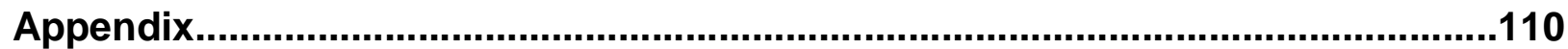

Appendix A: Institutional Review Board Approval..........................................111

Appendix B: Aim 1 and 2 Survey ...........................................................113 


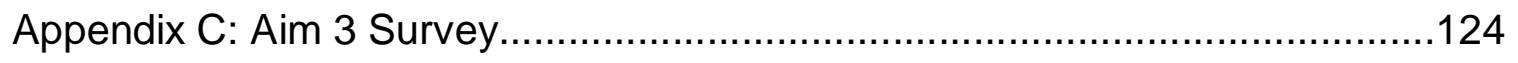

Appendix D: College Food Insecurity Screener Paper..................................128

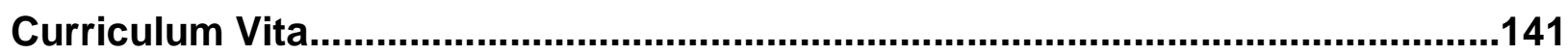




\section{Acknowledgements}

I can't believe this incredible journey is coming to an end and am beyond thankful for the people who offered love and support along the way. Dr. Melissa Olfert, thank you for your guidance, mentorship, and professional and personal advice all these years. I can't thank you enough for putting countless opportunities in front of me and always encouraging me to always take a chance which has opened so many doors for me. You have made me a confident researcher ready to tackle public health issues and can forge a path of my own knowing I have trained under such a passionate mentor. Thank you for taking a chance on me, I am forever grateful.

To my committee members. Dr. Lanae Hood, Dr. Catherine Yura, and Dr. Deana Morrow, thank you for stepping into this role and providing me with your support and guidance. Dr. Hood, thank you for always passing along opportunities for me to expand or share our research. Your passion for improving the well-being of individuals in the Appalachian region is inspiring. Dr. Yura, you bring so much joy to every room you are in and I am honored that you agreed to serve on this committee. Everyone deserves to know someone as supportive as you and I thank you for your countless words of encouragement. Dr. Morrow, I'm so appreciative for your willingness to serve on this committee. Although our relationship is just beginning, your kind words have made this an enjoyable process and I look forward to continuing to collaborate with you in the future.

To my friends, thank you for the endless love and support. Kenz, I'm so grateful graduate school brought us together. l've whined to you and wined with you - both of which have helped my mental health endure this process. You are also one of the few people who will read this dissertation from top to bottom, so thank you for always being willing to edit for me. Morgan, you're the most supportive person I know and I'm so blessed God made you my best friend. Thanks for always taking my mind off the stress of graduate school. Angie, from infants to college graduates, you've been by my side through it all. You make every accomplishment a huge deal and I'm so grateful to have you as my cheerleader through this process. Again, you all mean the world to me and I hope I'm half the friend you are all to me.

To John, thank you for sticking with me through this process. You could probably give a lecture or two on food insecurity from all the times I have made you listen to me practice for talks. Thank you for enduring the good days and the bad, providing advice, listening to me, or just offering a shoulder to lean on when needed. I am grateful for your love and support, you truly are my best friend.

To my family, Nan, Larry and Maria, thank you for keeping me grounded. I am grateful for the support over the years and the tough love at times. I am blessed to have family like you.

To my Mom, this is for you. Thank you for dreaming big for me and willing me to get an education. You have been my motivation! I wish you were here to see this but know you have been here in spirit every step of the way. I love you. 


\section{List of Definitions}

WISH4Campus: Well-being Increased by Security from Hunger for Campus is a research project conducted in the Lifestyle Intervention Research Lab that focuses on investigating campus food insecurity and promoting solutions for student well-being.

United States Department of Agriculture (USDA): The USDA is a government agency that strives to support food, agriculture, natural resources, rural development, nutrition, and related issues based on public policy, the best available science, and effective management.

Economic Research Center (ERS): Within the USDA, the ERS conducts objective economic research on issues in agriculture, food, the environment, and rural America to inform and enhance public and private decision making.

Government Accountability Office (GAO): Nonpartisan agency that provides evidencebased reports to Congress to support objective, reliable justification for how the government can save money and work more efficiently.

Food Insecurity (FI): An economic and social condition of limited or uncertain access to adequate food for a healthy lifestyle.

Appalachian Region: Defined by the Appalachian Regional Commission to consist of parts of 13 states: New York, Pennsylvania, Ohio, West Virginia, Kentucky, North Carolina, South Carolina, Maryland, Virginia, Tennessee, Georgia, Alabama, and Mississippi.

Southeastern Region: Defined by the American Association of Geographers to include 12 states: Alabama, Florida, Georgia, Kentucky, Mississippi, North Carolina, South Carolina, Tennessee, Maryland, Virginia, and West Virginia. 


\section{List of Figures}

\section{Chapter 1:}

Figure 1: Map of Appalachian and Southeastern Regions 3

Figure 2: Average Prevalence of Food Insecurity in the United States

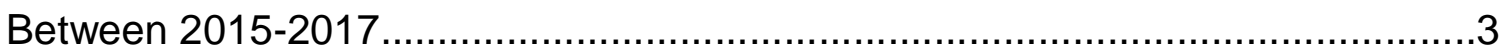

Figure 3: Normalization Process Theory Framework .......................................6

\section{Chapter 2:}

Figure 1: Dimensions of Food Security 10

Figure 2: Trends in Prevalence Rates of Food Insecurity and Very Low Food Security in United States Households form 1995-2017..... 11

Figure 3: Variance in Average Prevalence Rates of Food Insecurity by Census Region in 2017.

Figure 4: Trends in Tuition and Fees at Higher Education Institutions between 1988-2019 .20

\section{Chapter 4:}

Figure 1: Percent of Health Status Category by Food Security Status among Students. 49 


\section{List of Tables}

\section{Chapter 2:}

Table 1: United States Department of Agriculture (USDA) Household Food

Security Survey Module (HFSSM) Questions and Response Options. 15

\section{Chapter 3:}

Table 1: United States Department of Agriculture (USDA) Labels to Describe the

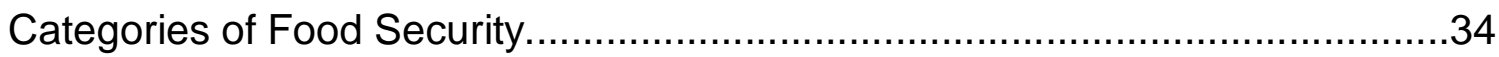

\section{Chapter 4:}

Table 1: Characteristics of Respondents and Correlations with Food Security Status

Table 2: Logistic Regression Model Predicting Food Insecurity in Students.......50

\section{Chapter 5:}

Table 1: Methodologies used for Student Recruitment at 10 Universities .58

Table 2: Characteristics of Student Respondents at 10 Universities .63

Table 3: Food Security Status Categorization for Students at 10 Universities....64

Table 4: Characteristic of Respondents for Regional Analysis and Correlations with Food Security Status

Table 5: Logistic Regression Model Predicting Food Insecurity in Regional

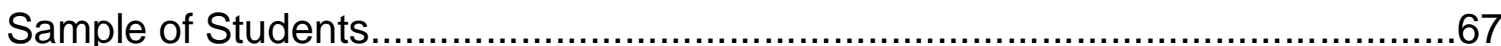

\section{Chapter 6:}

Table 1: Thematic Analysis of Evaluator Feedback with Related Quotes 83

Table 2: Recommendations for Topics within the WISH4Campus Toolkit and Related Quotes. 


\section{Chapter I: Introduction to the Study}




\section{Introduction}

Maslow's Hierarchy of Needs highlights the core concepts essential to life. At the foundation is food; a basic necessity for human success and survival [1]. Accordingly, individuals with uncertain or limited access, availability, and variety of food would be considered at greater risk for poor quality of life and, consequently, shorter life expectancy. Sadly, these individuals, termed food insecure, make up an alarming portion of the American population. Each year, the United States Department of Agriculture (USDA) Economic Research Service (ERS) measures the prevalence of food insecurity among households in America. In the most recent data of 2017, 11.8 percent of American households were food insecure, which equates to roughly 15 million households not having a secure source of food [2].

Food insecurity can be present in all populations throughout the United States, although certain populations are reported at higher risk. College students are one such population that has sparked national attention due to reports of food insecurity prevalence far higher than the national average [3]. The dissertation will delve into the issues of food insecurity among a college population. Specifically, this document will focus on college populations in the Appalachian and Southeastern regions of the United States, due to the fact that poor health outcomes in these regions often supersede that of the national averages $[4,5]$. This document encompasses the beginning of the WISH4Campus - Wellbeing Increased by Security from Hunger - project. The entirety of this dissertation explores the background of food insecurity literature, with close focus on college students in the Appalachian and Southeastern regions and aims to provide solutions to promote student well-being.

\section{Background of the Problem}

Within the United States, habitation within difference regions can play an impact on the health of its residents [6,7]. Appalachia, a region consisting of parts of New York, Pennsylvania, Ohio, Kentucky, North Carolina, South Carolina, Maryland, Virginia, Tennessee, Georgia, Alabama, Mississippi and the entirety of West Virginia, is consistently regarded as a health disparate region $[4,8]$. Similarly, the Southeastern region of the United States, which overlaps with parts of Appalachia and contains 11 
Figure 1: Map of Appalachian and Southeastern Regions

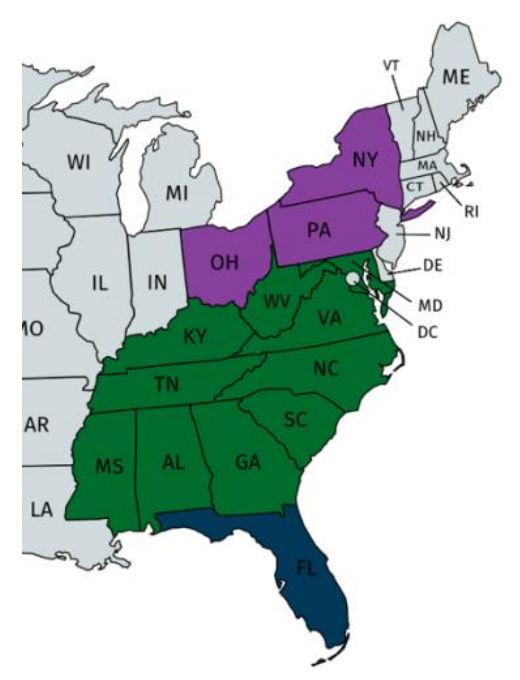

states according to the American Association of Geographers, is also a frequent flyer for poor health outcomes [9]. The Appalachian and Southeastern regions are highlighted in Figure 1, with green representing states encompassed in both regions, purple representing states only in Appalachia and blue representing only being part of the Southeastern region. Inhabitants of Appalachian and the Southeastern regions are prone to higher rates of obesity [10], diabetes [11], cancers [12], heart disease and other comorbidities [13] when compared to other populations throughout the nation. Overall, this makes

the mortality and morbidity rates within these areas subsequently higher than that of national average [14].

Further, the residents of these regions are often subject to poor socioeconomic status that can contribute to poor quality of life. Both the Appalachian and Southeastern regions are home to residents who have lower income [15] and poorer educational attainment [15] that can lead to detriments in the household environment. One disadvantage that stems from these disparities is a heightened risk for food insecurity. Exact prevalence of food insecurity for the entirety of Appalachian and United States Between 2015-2017

Southeastern populations is not known, however state level data shows prevalence within these regions higher than the national average [16, 17], as represented by the dark teal states in Figure 2. Additionally, smaller scale studies within these regions have also highlighted an increased food insecurity prevalence among this

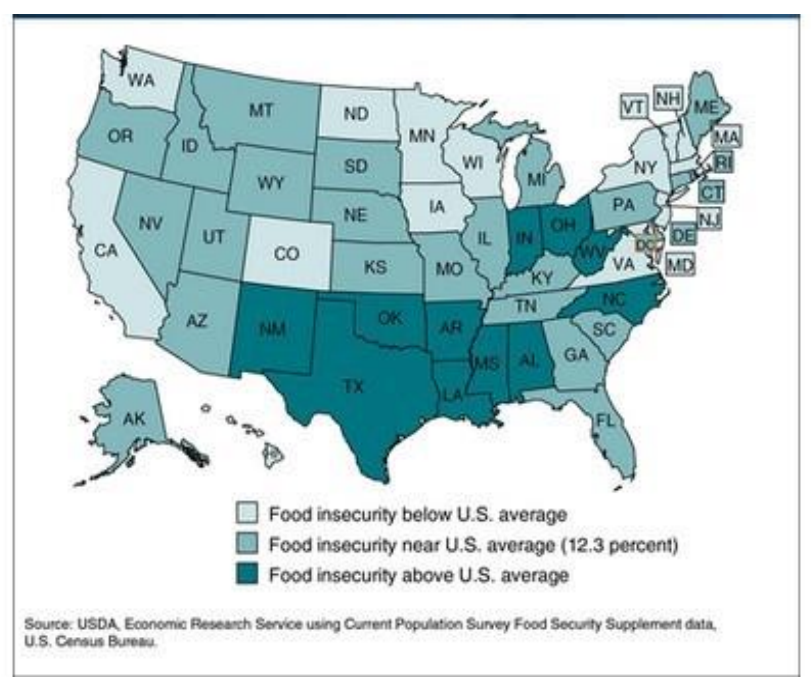


population [18]. From these findings we can identify a relationship exists between regional disparities within the Appalachian and Southeastern regions, making it essential that research targets these at risk populations.

Regional organizations, such as the Appalachian Regional Commission [8], have been developed to illustrate need and drive forward policy change to aid in improving health equity for residents. However, while these organizations are monumental in shedding light on the problems of a region as a whole, they often overlook micro-level populations. For example, prevalence data reports are available for poverty, unemployment, education, income, and population estimates for the region as a whole as well as state level breakdown [19]. However, there is no breakdown for specific level populations such as college attending young adults. What programs that do collect data on college level populations, such as the American College Health Assessment [20], fail to capture robust data on health disparities, particularly food insecurity. Therefore, the food insecurity prevalence in college populations within the Appalachian and Southeastern regions is relatively unknown.

Three systematic reviews have highlighted the heightened food insecurity prevalence for college students in the United States [3, 21, 22]. This is worrisome as food insecurity among college students has been associated with inadequate diet quality [23-25], poor self-reported health [23, 26-30], decreased academic performance [23, 26, 29, 31-33], and reliance on unhealthy coping behaviors [26, 34, 35]. Therefore, food insecurity is detrimental to a college students physical and mental well-being and can potentially impact successful degree attainment. However, these reviews largely lacked colleges and universities from the Appalachian and Southeastern regions [3], again overlooking a population that is at risk. Therefore, there is a need to investigate the prevalence and correlates of food insecurity in these health disparate regions to ensure college students are provided the supports they need to succeed.

Some colleges and universities are tackling the issue of food insecurity on campus by implementing food security programming. These initiatives are nascent and include campus food pantries, meal share programs, and on-campus gardens and farmers markers [36]. These emergency food programs are essential, especially as more upstream solutions, such as expanding SNAP assistance, are deliberated in 
today's uncertain political environment. However, even when knowledgeable of the food insecure issues on campus, university personnel may struggle to understand how to implement food security programming to help students. This can in part be due to the lack of evidence-based literature on the development and implementation of support programs for food insecure college students, which would allow for replication on other campuses. What programming that is available is often highlighted in local or university based media without peer-reviewed manuscript. Thus, university personnel could benefit from comprehensive documentation that highlights multiple food security initiative options and available resources to foster the development programming on campus.

\section{Theoretical Foundation}

This dissertation includes the development and evaluation of the WISH4Campus Toolkit, a collection of previous food security initiatives that have been started on college campuses. The toolkit is built on the basis of the Normalization Process Theory (NPT), a theory aids in understanding the social processes that can occur to promote or inhibit implementation of new programming [37, 38]. Co-developed and described by Dr. Carl May, the NPT focuses on "the social organization of the work (implementation), of making practices routine elements of everyday life (embedding) and of sustaining embedded practiced in their social contexts (integration)" [37]. Therefore, utilization of this theory is intending to improve program implementation success.

The four main constructs of this theory, shown in Figure 3, help implementers understanding what is work, who does the work, how does the work get done and how is the work understood [39]. 
Figure 3: Normalization Process Theory Framework

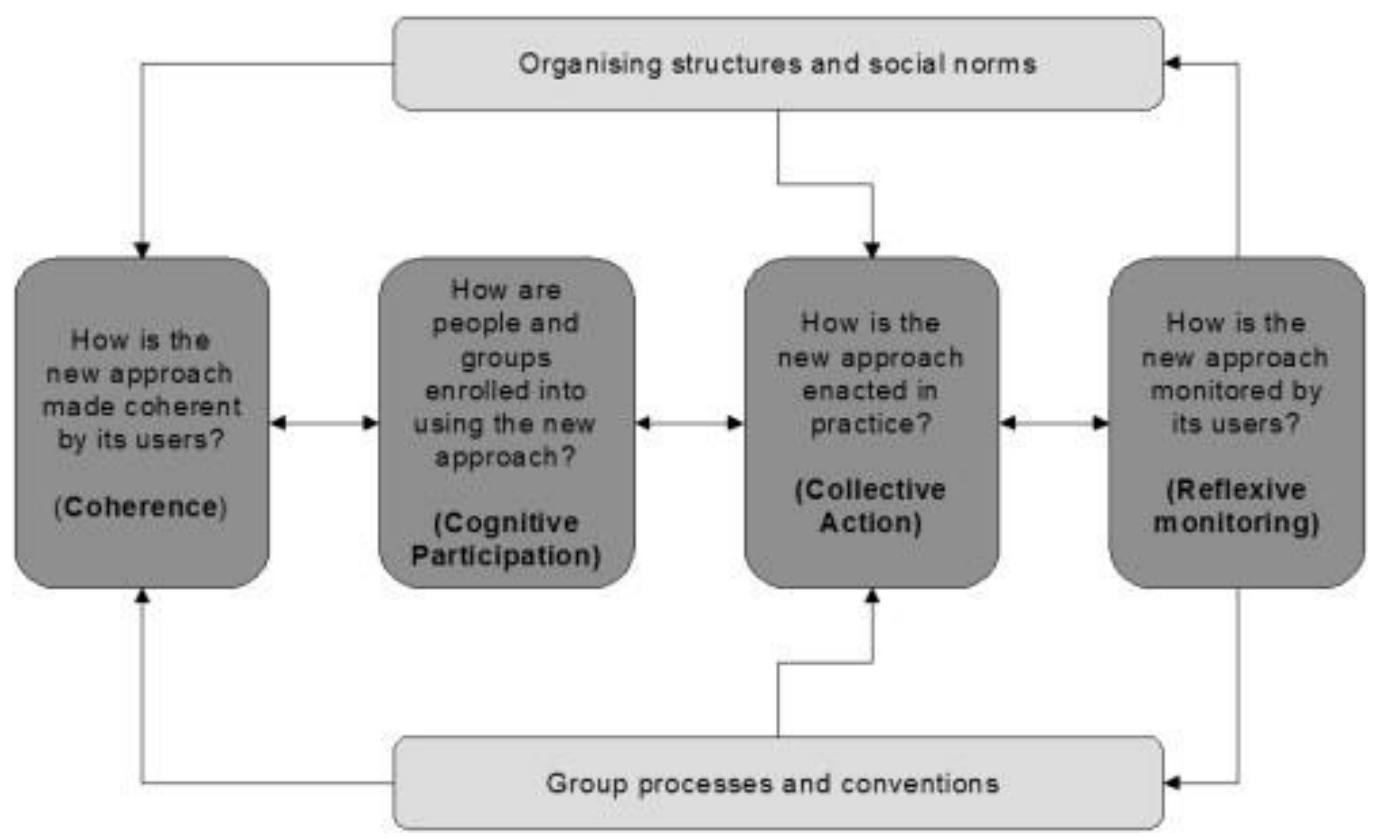

Source: Ong, Bie Nio, et al. "Changing policy and practice: making sense of national guidelines for osteoarthritis." Social Science \& Medicine 106 (2014): 101-109.

This theory has previously been used in toolkit development and evaluation with success. For example, Murrary, May and Mair (2010) developed a toolkit of e-Health initiatives to synthesize emerging literature and guide the implementation process [40]. This toolkit written from currently e-Health programs with the NPT constructs as a coding framework to ensure the toolkit encompasses the potential of an initiative to become successfully implemented. Results suggested that the use of NPT allowed for the toolkit to highlight the factors that could promote or inhibit a program from being implemented.

For the WISH4Campus Toolkit, this theory allows the toolkit to highlight factors that could promote or inhibit college campuses from making sustainable initiatives on their campus. The toolkit is written to encompass recommendations developed from the NPT constructs and expert evaluation of the document uses the NPT to understand expert's opinion on how the toolkit can be used to overcome barriers and empower campus communities to invoke change for food insecure students. This aids in the revision of the toolkit to ensure all components of the NPT are covered in the toolkit and the chances for successful implementation are maximized. 


\section{Statement of the Problem}

While interest in college food insecurity has increased in previous years, much of the Appalachian and Southeastern regions of the United States have yet to be fully explored [3]. Despite the growing body of literature on the correlates and outcomes associated with food insecurity in college students, there is limited understanding of food insecurity's impact on college students in this region. Food insecure college students are at a disadvantage and often develop behavioral differences due to their food insecure situation, including poor money expenditure and negative coping behaviors as well as lowered academic performance [26, 41]. Additionally, resources to help food insecure students are often sparse with universities lacking evidence-based programming to put in place for student benefit.

This dissertation aims to provide insight on the characteristics and behavioral differences of food insecure students to promote an understanding of this population in the literature for future targeted interventions. Further, to aid universities in providing resources for students, this dissertation strives to capture food insecurity programming, that is being implemented on campuses nationwide, into a toolkit to help prompt colleges and universities to employ programming to help students succeed.

\section{Purpose of the Study}

The aims of the current dissertation are to (1) investigate the correlates and behavioral consequences of food insecurity on college students in the Appalachian region, (2) expand college food insecurity research to a regional investigation in the Appalachian and Southeastern regions of the United States, and (3) develop and evaluate a toolkit that can assist higher education institutions in promoting a campus environment that provides adequate resources for food insecure students. The overarching goal will be to provide a snapshot of the characteristics of food insecure college students in regions of need and promote solutions for student well-being. Institutional Review Board (IRB) approval for this study is available in Appendix A and survey tools to achieve these aims are available in Appendix B and Appendix C. 


\section{Significance}

Food insecurity among college students has become a public health concern, with impacts on college students' academic aspirations. As research continues to confirm the high rates of food insecurity among the college population, it is imperative to provide assistance to ensure students are able to succeed with their college aspirations and translate into the educated workforce of today's society. The Appalachian and Southeastern regions remain at the top of the list for poor health outcomes and although a plethora of literature is available on the health disparities in these regions, very little is focused on college students. More specifically, as college food insecurity in these regions is overlooked and geographical variances occur, understanding college food insecurity among students in at risk regions of the United States is essential. This dissertation is the first to examine the characteristics of food insecurity students throughout two at risk regions of the United States.

\section{Summary}

Within this document, Chapter 2 provides an in-depth review of the literature to provide background that will justify the necessity for this dissertation. Chapter 3 covers the research design and statistical analyses utilized within this dissertation to provide insight on the methodological processes of this study. Following, Chapters 4-6 include three manuscripts that aim to fill the gap in literature addressed. These manuscripts include: Food Insecurity and Behavioral Characteristics for Academic Success in Young Adults Attending an Appalachian University (Ch. 4), Food Insecurity Impacts Behavior of College Students at 10 Higher Education Institutes in the Appalachian and Southeastern Regions (Ch. 5), and Development and Evaluation of a Higher Education Food Security Toolkit to Provide Ideas of Initiatives for Student Wellbeing (Ch. 6). These manuscripts together will provide a glimpse of the issue of food insecurity among college students in the Appalachian and Southeastern regions and further promote solutions to improve the well-being of these students. Chapter 7 will conclude the document with a discussion of the findings and recommendations for future research. Additional research on this topic is available in the Appendix. 
Chapter II: Additional Background \& Literature Review 


\section{Introduction}

This chapter provides a comprehensive review of food insecurity, not only in the college population, but also the history of this public health issue in the United States. West Virginia University Libraries were utilized to collect literature. Databases accessed included PubMed, Google Scholar, CINAHL, ScienceDirect, and WorldCat.org. West Virginia University's InterLibrary Loan Internet Accessible Database (Illiad) was utilized when published literature was not available through other databases. No year restrictions were placed on literature review however, food insecurity prevalence and health outcomes were restricted to the most recent years for comparison. Systematic reviews were reviewed when available.

The aim of this review is to provide an in-depth understanding of the copious amounts of food insecurity literature, including the prevalence, correlates, and impacts of being food insecure, as well as identify gaps in the literature to gauge future research. Further, this review will provide justification for the WISH4Campus Study. Additional literature review is provided for each manuscript introduction, presented in Chapters 4-6.

\section{Food Insecurity: A National Problem}

The ability to acquire enough food to sustain a healthy, active life is a fundamental right for all individuals. Maslow's Pyramid of Human Needs includes a secure source of food as a basic necessity for human success and survival [42]. However, a consistent source of food is not reality for many and these individuals with an uncertain or limited access to enough food to sustain a healthy lifestyle are termed food insecure [2].

Globally, food security is suggested to Figure 1: Dimensions of Food Security

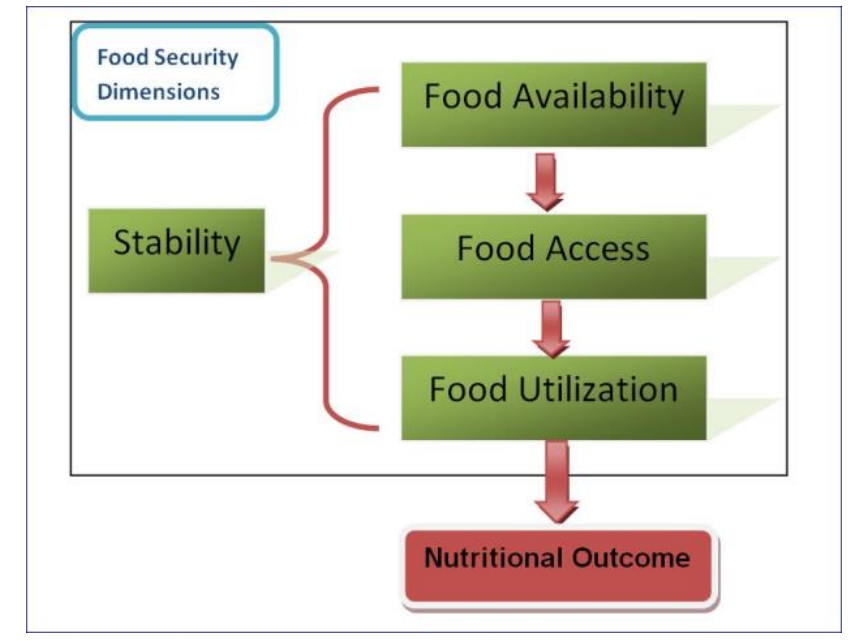
encompass four dimensions as shown in Figure 1. These dimensions are availability, access, utilization, and stability [43]. Food availability embodies having sufficient 
quantity of appropriate food obtainable and can be included by food production and demand in a given area. Food access describes the physical and economic access to a sufficient amount of food. This can be influenced by income and employment or transportation. Food utilization addresses the ability to achieve an adequate dietary intake and is inclusive of the food preparation, food safety and food diversity within a household. Lastly, stability is an umbrella dimension that includes the other three

Figure 2: Trends in Prevalence Rates of Food Insecurity and Very Low Food Security in United States Households form 1995-2017

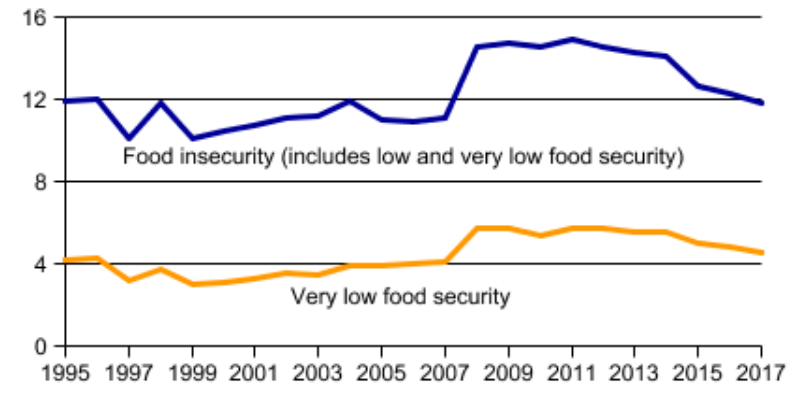

Note: Prevalence rates for 1996 and 1997 were adjusted for the estimated effects of differences in data collection screening protocols used in those years.

Source: USDA, Economic Research Service, using data from Current Population Survey Food Security Supplement. dimension and ensures stability of individual and household food access, availability, and utilization across time.

Within United States food insecurity literature and public health efforts, food access is a primary focus [44] and the main construct measured regarding food insecurity [45] (see Measuring Food Insecurity section). Thus, ensuring that all individuals have adequate resources to obtain the food

they need to maintain a healthy lifestyle is essential for the millions of food insecurity households in the United States [2]. In 2017, $11.8 \%$ or what equates to 15 million households were food insecure sometime during the year [2]. Fortunately, the prevalence of food insecurity has trended down in recent years as shown in Figure 2. Although some scholars contribute the decline to inaccurate measurement and lack of representation of some food insecure groups, the decline may also be attributed in part to the multifaceted solutions being implemented to address this issue and the continued research into to this topic. Further, increased efforts have been made to promote public and health policy change to tackle this preventable public health concern [46].

However, despite the heightened awareness, food insecurity is still a reality for many people and comes with several detrimental nutrition and health outcomes across the lifespan. At the household level, food insecurity is associated with an increased likelihood of poor dietary patterns including lower intake of fruit, vegetables, and fiber, and increased intake of energy dense foods [46]. The Academy of Nutrition and 
Dietetics attributes this to food expenditures, with food secure households being able to spend more on food [46]. Further, many food insecure households rely on emergency or charitable food sources, such as food pantries which often lack diverse food options, making it difficult to access more nutritious foods [47].

A systematic review of food insecurity and dietary quality identified 26 articles identified relationships in both children and adults [48]. For youth, 16 articles were examined and found an adverse relationship between food insecurity and overall diet quality in both young children and adolescents $[49,50]$. The association between food insecurity and vegetable consumption is mixed in research, however, fruit consumption is reported to have an inverse relationship with food insecurity [48]. Additionally, there is limited evidence regarding a clear relationship between food insecurity and childhood consumption of grains, sweets, sugar-sweetened beverages, or added sugar. Further, there is only evidence of a relationship between dairy intake and food insecurity in 8-11 year old boys [48, 51]. However, regarding specific vitamin and mineral intake in children, an inverse association has been reported for iron consumption in adolescents [52] and young children as well as vitamin B-6 in young children [48, 53].

Stronger interactions have been identified for food insecure adults. Of 13 reviewed articles, an inverse relationship was identified between food insecurity and dietary quality $[49,54,55]$. Although not definitive in the childhood population as mentioned before, there is sufficient evidence on the relationship between lower fruit and vegetable consumption among food insecure adults, as well as dairy consumption among working-age adults, but not older ( $>60$ years) adults $[48,56]$. No connection is shown for grain intake, however limited research indicates an unfavorable relationship between food insecurity and fiber [57]. More specifically, food insecure adults had lower intakes of vitamins A and B-6 as well as calcium, magnesium, and zinc [48]. Therefore, it can be concluded that food insecurity plays a detrimental role in the nutritional quality of both youth and adults and could be a detriment to health.

Food insecure youth and adults are subject to a myriad of other problems, including cognitive, behavioral, mental and physical impairments. For youth, Gundersen and Zaliak (2014) reviewed the vast quantity of research and concluded that food insecurity is associated with higher risk of anemia, hospitalization, asthma, poorer 
general health, and reduced oral health [58]. Further, food insecurity hampers children's mental wellbeing with associations found between food insecure youth and increases in anxiety, depression, and suicidal ideation [59-61]. Additionally, food insecurity can cause cognitive and behavioral issues for youth, with many food insecurity youth displaying poor academic outcomes and aggression towards others in school [62-64]. This is stated to be true during all childhood years, from infancy throughout adolescence [65]. Therefore, children growing in food insecure situations face an uphill battle to succeed, with further possibility that food insecurity and the associated outcomes will translate into adulthood.

Similarly, studies show strong relationships between food insecurity and adult health outcomes. As with youth, food insecure adults are at risk for developing mental health illnesses [58, 66]. For example, mothers who are food insecure are more than twice as likely to develop a mental health illness [62]. Unlike children though, adults are more likely to develop a chronic disease in conjunction with food insecurity. From a 2018 systematic review, food insecurity has been shown in the literature to be associated with chronic disease outcomes [67]. Of 51 studies, $82 \%(n=42)$ reported a positive association between increase in food insecurity and chronic disease occurrence [67]. This includes increased likelihood of diabetes, hypertension, heart disease, metabolic syndrome and chronic kidney disease among food insecure populations [67]. However, only 15 studies investigated the relationship between food insecurity and chronic disease independent of obesity. As obesity is a contributor to the development of chronic disease, it is essential to control for this within analysis of food insecurity and chronic disease. When controlling for obesity, chronic disease and food insecurity still demonstrate relationship, consequently, justifying the need to improve food security status among populations to aid in the prevention of chronic disease. However, this relationship is often bidirectional with poor health being both an outcome and risk factor for food insecurity [68].

Concluding from the current research, we summarize that food insecurity can have crimpling effects on the well-being of both youth and adults. Although prevalence has trended down in recent years, for the 15 million American households face food insecurity as part of their daily live, this is still a public health issue of dire importance. 


\section{Measuring Food Insecurity}

The issue of hunger in the United States has been of national concern for many years, with government assistance programs being implemented as early as the 1930s with the start of the Food Stamp Program. It wasn't until the mid-1980's, however, that the government first attempted to measure the prevalence of food insecurity, using a single question on the Nationwide Food Consumption Survey $[69,70]$. The attempt at quantifying the issue of food insecurity was expanded with the addition of the food insecurity questions in the Nutrition Examination Survey (NHANES III), although there was little consensus on the accuracy of the survey measure [70].

The development of valid food insecurity measurement was triggered with the enactment of the National Nutrition Monitoring and Related Research (NNMRR) Act in 1990. This act required the United States Department of Agriculture (USDA) and Department of Health and Human Services (DHHS) to implement a ten-year comprehensive plan and included a recommendation for "a standardized mechanism and instrument(s) for defining and obtaining data on the prevalence of 'food insecurity' or 'food insufficiency' in the United States and methodologies that can be used across the NNMRR Program and at State and local levels." In conjunction with representatives from federal agencies, academic institutes, and private organizations, the USDA and DHHS identified the conceptual basis for the first national survey of food insecurity, the Food Security Supplement (FSS). The FSS, introduced in 1995, was first administered as part of the Current Population Survey (CPS) and measured not only food insecurity, but also variables regarding food sufficiency, food expenditures, use of food programs, and other ways of coping with food insecurity.

Within the FSS is one of the most commonly known measures of food insecurity, the Household Food Security Survey Module (HFSSM) [71]. This survey tool includes 18-items for households with children, or a 10-item option (also termed the Adult Food Security Survey) for households without children [72]. Questions in the HFSSM are shown in Table 1. In 2006, the USDA introduced ranges of food insecurity that are 
commonly used today and include four categories, high food security, marginal food security, low food security, and very low food security. These are defined as follows:

- High food security-Households have no problems, or anxiety about, consistently accessing adequate food

- Marginal food security-Households have problems at times, or anxiety about, accessing adequate food, but the quality, variety, and quantity of their food intake were not substantially reduced

- Low food security - Households reduce the quality, variety, and desirability of their diets, but the quantity of food intake and normal eating patterns were not substantially disrupted

- Very low food security-At times during the year, eating patterns of one or more household members were disrupted and food intake reduced because the household lacked money and other resources for food.

Within these classifications, households that are characterized as high food security or marginal food security are deemed food secure and those characterized as low or very low food security are regarded as food insecure. The USDA has also introduced other modifications to their original survey [72]. These variations include a 6item short form of the food security survey module which helps ease respondent burden, a self-administered food security survey module for youth ages 12 and older which allows researchers to measure food insecurity among children without reliance on parental input, as well as translation into a Spanish format for use in more diverse populations [72-74].

Table 1: United States Department of Agriculture (USDA) Household Food Security Survey Module (HFSSM) Questions and Response Options

\begin{tabular}{|c|c|c|}
\hline Item & Question & Response Option \\
\hline $\mathrm{HH} 2$ & $\begin{array}{l}\text { (I/We) worried whether (my/our) food would run out before } \\
(\mathrm{I} / \mathrm{we}) \text { got money to buy more. }\end{array}$ & $\begin{array}{ll}\text { 1. } & \text { Often true } \\
\text { 2. Sometimes true } \\
\text { 3. Never true }\end{array}$ \\
\hline $\mathrm{HH} 3$ & $\begin{array}{l}\text { The food that (I/we) bought just didn't last, and (I/we) didn't } \\
\text { have money to get more. }\end{array}$ & $\begin{array}{ll}\text { 1. } & \text { Often true } \\
\text { 2. } & \text { Sometimes true } \\
\text { 3. } & \text { Never true }\end{array}$ \\
\hline $\mathrm{HH} 4$ & (I/we) couldn't afford to eat balanced meals. & $\begin{array}{l}\text { 1. Often true } \\
\text { 2. Sometimes true } \\
\text { 3. Never true }\end{array}$ \\
\hline
\end{tabular}




\begin{tabular}{|c|c|c|}
\hline AD1 & $\begin{array}{l}\text { In the last } 12 \text { months, did (you/you or other adults in your } \\
\text { household) ever cut the size of your meals or skip meals } \\
\text { because there wasn't enough money for food? }\end{array}$ & $\begin{array}{l}\text { 1. Yes } \\
\text { 2. No (Skip AD1a) }\end{array}$ \\
\hline AD1a & If yes above, how often did this happen? & $\begin{array}{l}\text { 1. Almost every month } \\
\text { 2. Some months but not } \\
\text { every month } \\
\text { 3. Only } 1 \text { or } 2 \text { months }\end{array}$ \\
\hline AD2 & $\begin{array}{l}\text { In the last } 12 \text { months, did you ever eat less than you felt you } \\
\text { should because there wasn't enough money for food? }\end{array}$ & $\begin{array}{l}\text { 1. Yes } \\
\text { 2. No }\end{array}$ \\
\hline AD3 & $\begin{array}{l}\text { In the last } 12 \text { months, were you every hungry but didn't eat } \\
\text { because there wasn't enough money for food? }\end{array}$ & $\begin{array}{ll}\text { 1. Yes } \\
\text { 2. No }\end{array}$ \\
\hline AD4 & $\begin{array}{l}\text { In the last } 12 \text { months, did you lose weight because there } \\
\text { wasn't enough money for food? }\end{array}$ & $\begin{array}{l}\text { 1. Yes } \\
\text { 2. No }\end{array}$ \\
\hline AD5 & $\begin{array}{l}\text { In the last } 12 \text { months, did (you/you or other adults in your } \\
\text { household) ever not eat for a whole day because there } \\
\text { wasn't enough money for food? }\end{array}$ & $\begin{array}{l}\text { 1. Yes } \\
\text { 2. No (Skip AD5a) }\end{array}$ \\
\hline AD5a & If yes above, how often did this happen? & $\begin{array}{l}\text { 1. Almost every month } \\
\text { 2. Some months but not } \\
\text { every month } \\
\text { 3. Only } 1 \text { or } 2 \text { months }\end{array}$ \\
\hline $\mathrm{CH} 1$ & $\begin{array}{l}\text { (I/we) relied on only a few kinds of low-cost food to feed } \\
\text { (my/our) child/the children) because (I was/we were) running } \\
\text { out of money to buy food. }\end{array}$ & $\begin{array}{l}\text { 1. Often true } \\
\text { 2. Sometimes true } \\
\text { 3. Never true }\end{array}$ \\
\hline $\mathrm{CH} 2$ & $\begin{array}{l}\text { (I/We) couldn't feed (my/our) child/the children) a balanced } \\
\text { meal, because (I/we) couldn't afford that. }\end{array}$ & $\begin{array}{ll}\text { 1. } & \text { Often true } \\
\text { 2. Sometimes true } \\
\text { 3. Never true }\end{array}$ \\
\hline $\mathrm{CH} 3$ & $\begin{array}{l}\text { (My/Our child was/The children were) not eating enough } \\
\text { because (I/we) just couldn't afford enough food. }\end{array}$ & $\begin{array}{ll}\text { 1. } & \text { Often true } \\
\text { 2. Sometimes true } \\
\text { 3. } & \text { Never true } \\
\end{array}$ \\
\hline $\mathrm{CH} 4$ & $\begin{array}{l}\text { In the last } 12 \text { months, since (current month) of last year, did } \\
\text { you ever cut the size of (your child's/any of the children's) } \\
\text { meals because there wasn't enough money for food? }\end{array}$ & $\begin{array}{l}\text { 1. Yes } \\
\text { 2. No }\end{array}$ \\
\hline $\mathrm{CH} 5$ & $\begin{array}{l}\text { In the last } 12 \text { months, did (CHILD'S NAME/any of the } \\
\text { children) ever skip meals because there wasn't enough } \\
\text { money for food? }\end{array}$ & $\begin{array}{l}\text { 1. Yes } \\
\text { 2. No (Skip CH5a) }\end{array}$ \\
\hline $\mathrm{CH} 5 \mathrm{a}$ & If yes above, how often did this happen? & $\begin{array}{l}\text { 1. Almost every month } \\
\text { 2. Some months but not } \\
\text { every month } \\
\text { 3. Only } 1 \text { or } 2 \text { months }\end{array}$ \\
\hline $\mathrm{CH} 6$ & $\begin{array}{l}\text { In the last } 12 \text { months, (was your child/were the children) ever } \\
\text { hungry but you just couldn't afford more food? }\end{array}$ & $\begin{array}{l}\text { 1. Yes } \\
\text { 2. No }\end{array}$ \\
\hline
\end{tabular}




\begin{tabular}{|l|l|l|}
\hline $\mathrm{CH} 7$ & $\begin{array}{l}\text { In the last } 12 \text { months, did (your child/any of the children) ever } \\
\text { not eat for a whole day because there wasn't enough money } \\
\text { for food? }\end{array}$ & $\begin{array}{l}1 . \text { Yes } \\
2 . \text { No }\end{array}$ \\
\hline
\end{tabular}

The USDA tools are the only available survey measurements that have undergone rigorous testing and evaluation of psychometric properties [75]. However, there are other tools available to measure food insecurity, and encompass the other dimensions of this issue, that are used within the literature. A 2016 systematic review of food insecurity measurement identified 9 other survey tools [76]. Only one survey measured the dimension of food utilization, the Radimer/Cornell Scale [77]. This survey measures individual level food insecurity and is validated for use in an elderly population [77]. Similarly, only one survey measure captures the dimension of stability. The Kuyper past food insecurity survey instrument measures household food insecurity for a retrospective recall period of "as a child" $[78,79]$. The remaining six tools measure access and include the Cornell Child Food Security Survey [80], Community Childhood Hunger Identification Project (CCHIP) tool [81], Hager two-item screener [82, 83], Girard four-point tool [84], Household Food Insecurity Access Scale (HFIAS) [85-87], and Townsend Food Behaviour Checklist [88]. These tools measure either household or individuals level food insecurity, except the Girard four-point tool which assess both levels of food insecurity. All tools rely on self-reported data and were developing using populations that were at risk for food insecurity (i.e. older adults, low-income families, adults with HIV).

All the aforementioned tools contain variations of food security questions but focus primarily on the financial constraints associated with obtaining food. Consequently, it is suggested that these tools may fail to identify the associated anxieties or detriments to diet quality and thus may underestimate the true prevalence of food insecurity. Further, the lack of validated survey tools in specific populations limits the understanding of the validity of these estimates. Different populations experience food insecurity in different manners and, as proposed by Wolfe, Frongillo and Valois when investigating food insecurity in the elderly [24], there is a need to fully conceptualize the food insecurity experience of a given population. Given these 
findings, future research can help to validate these tools across diverse populations and different geographical regions.

\section{At Risk Populations and a Focus on Appalachia}

Food insecurity is distributed disproportionately throughout the regions of the United States. Populations prone to food insecurity include households with children headed by singlefemales, households that fall under $185 \%$ of the federal poverty line, and minority households [89]. Many Figure 3: Variance in Average Prevalence Rates of Food Insecurity by Census Region in 2017

factors can contribute to the

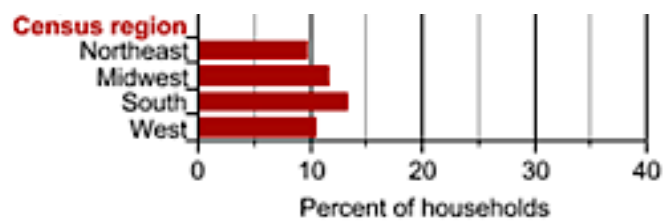

Source: USDA, Economic Research Service, using data from the December 2017 Current Population Survey Food Security Supplement.

development of food insecurity among these populations including low educational attainment, poverty, and cost of living [89]. It has been reported that geographical regions, such as the Mississippi Delta and Appalachia, are subject to many of these factors and report higher prevalence of food insecurity among inhabitants [90].Further, as shown in Figure 3, and reported by the ERS, food insecurity prevalence is highest in the South region of the United States. Further, it has been reported that geographical regions, such as the Mississippi Delta and Appalachia, report higher prevalence of food insecurity among inhabitants [90]. Thus, inhabitants of these areas are subject to higher risk of food insecurity. Appalachia, in particular, is a region that has lagged behind the rest of the country in economic, social and health outcomes.

Food insecurity in Appalachia has been understudied, with limited peer review literature available. A preliminary Appalachian study of food security and perceived health in 2002 identified that $23 \%(n=1,006)$ of surveyed households were food insecure, compared to $10 \%$ national prevalence at the time [91]. Further study, in a Head Start program in Appalachia, found similar results with prevalence rates higher than the national average. Holben et al. surveyed 710 parents with a child in a Head Start program in 2004 and found that $48.8 \%$ of households were food insecure, which was three times higher than national average at the time (16.1\%) [92]. As aforementioned, high levels of food insecurity can have consequences on the health of 
population, and this remains true in this study of Appalachians. Pheley, Holben, Graham and Simpson (2002) reported that food insecurity, even minimal levels, was a strong predictor of health within this population and most common within the young adult (2039 years) population [91]. Holben and Pheley (2006) further investigated this relationship between food insecurity and chronic disease risks [93]. Among food insecurity participants, higher BMls, rates of obesity, and self-reported rates of diabetes were observed compared to those from food-secure households [93]. This is of specific importance for the Appalachian region as prevalence of these chronic disease including diabetes and obesity are consistently higher than that of the national average. If food insecurity is a mediating factor in chronic disease development, it is imperative to provide aid to this population to improve the health of the region.

The geographical differences in food insecurity may be attributed to the fact that some food insecure populations reside within food deserts. A food desert is an area with limited access to affordable nutritious foods, and while not always a determinant with food insecurity, heightens the risk for food insecurity situations [94, 95]. One of the main barriers presented for those who reside in a food desert is the increased distance required to access food [96]. This is of concern as previous research has shown that households residing a greater distance from a grocery store are at higher risk for food insecurity [97]. This situation may be particularly true for rural areas, which commonly have limited access to public transportation systems and greater distances to food supplies [98]. This relationship may be indicated in a 2018 study, by Hege et al., where Appalachian residents were asked to identity health issues in their community. From three focus groups, consisting of 24 participants in total, poor nutrition was identified as pressing health issue within Appalachian communities [99]. Participants stressed that access to nutritious food was included by the food environment, economic status, transportation, lack of cooking/gardening skills, and challenges with receiving government assistance [99]. Many of these factors identified are consistent with issues of living in a food desert.

Overall, this geographical variance makes these "at risk" regions and need to understand the challenges faced by residents within these regions and provide support for better outcomes. To overcome the systemic barriers these populations have faced 
including poverty and low educational attainment, populations are also seeking opportunities to better themselves. One of the commonly perceived ideas to improve socioeconomic standing in today's society is college degree attainment.

\section{College Student Demographics and Lifestyle}

Enrollment in higher education declined slightly (1.7\%) in 2018, however, enrollment numbers are still sizeable with an estimated 17,510,928 million students attending a 2- or 4-year institution [100]. Of those students, majority (70\%) attend a 4year institution, although many no longer encompass the traditional student demographics thought to make up a 4-year college student [101]. In recent history, most traditional students (described as one who enrolls in college full time immediately after graduating from high school, is financially dependent on parents of guardians, and either does not hold a fulltime job while in college) would enroll at a 4-year institution, with non-traditional students enrolling at 2-year or community colleges [102]. However, students from disadvantaged socioeconomic backgrounds are starting to make up a large portion of the college demographic at both community colleges and 4-year institutions. For example, enrollment of students from households with an income at or below 130 percent of the federal poverty line has grown $11 \%$ in the past decade [101]. Therefore, the environment and student demographics at a 4-year institution are no longer what they used to be, and with this being the primary educational option of students, study of lifestyles among college students at 4-year institutions is imperative.

The financial burden of attending college has also changed throughout the years with increases in campus tuition and fees, cost of living, books and supplies, reliance of federal loans, and diminished funding for higher education assistance [101, 103-105]. Between 1984 and 2014, average tuition and fees for in-state students rose by $\$ 6,335$ for students attending public, 4-year institutions [103]. This trend has continued with cost of tuition continuing to rise in recent years, as shown in Figure 4 from the "Trends in Higher Education" reports [106]. 
While this trend can be detrimental to the financial situation of all students, those from limited socioeconomic standing or student who are financially independent are especially at risk. Although the federal government provides resources for financially disadvantaged students, such as the Federal Pell Grant Program, these financial allotments are less than the average cost to attend college [107]. The disproportion causes many students to be financially limited and a need to rely on financial management skills. However, young adults transitioning into college are often not equipped with the skills to maintain financial security [108]. Consequently, many students struggle to maintain financial balance that encompasses education costs, living expenses, and food. In qualitative studies with students, high cost of attendance has been identified as the primary cause of food insecurity [109]. Overall, the increasing cost of postsecondary education has shaped of an environment in which students struggle to obtain enough financial resources to maintain food security. Thus, food insecurity has become a harmful element in the lives of college students.

\section{Food Insecurity among College Students in the United States}

The first peer-reviewed study of college food insecurity was published a decade ago and sparked interest in this public health issue. In 2009, Chaparro, Zaghloul, Holck, and Dobbs published their results from a 2006 study on the food insecurity prevalence among students at the University of Hawaii at Manoa [110]. Shockingly, the findings

Figure 4: Trends in Tuition and Fees at Higher Education Institutions between 1988-2019

showed that student food insecurity prevalence was $21 \%$; a rate higher than the national average at the time of $11 \%$ [111] and nearly three times higher than the average prevalence in the state of Hawaii (7.8\%) [112]. This first study was monumental in establishing that food insecurity might be a challenge many college students face and set forth the precedence for investigation on other

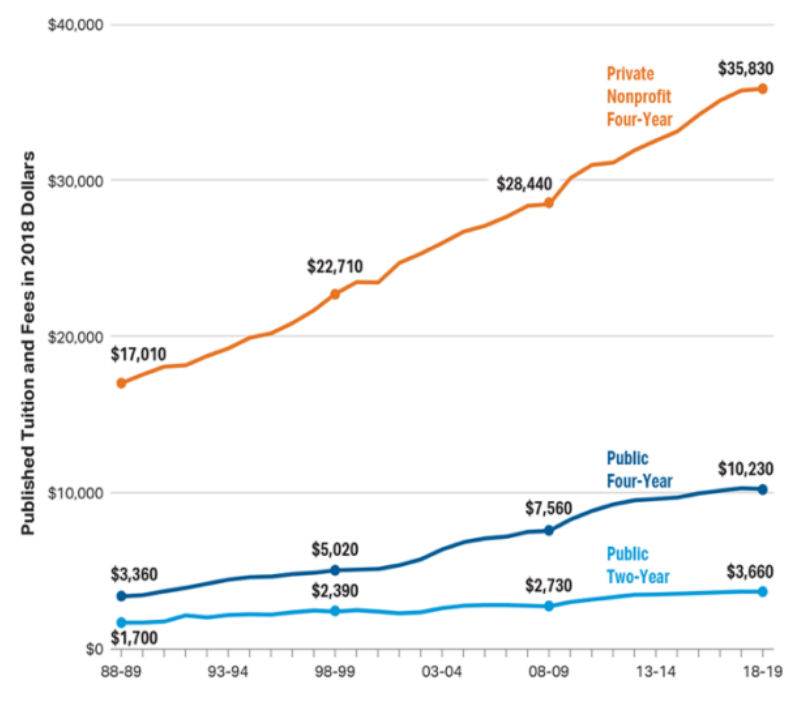


college campuses to follow. Since then, over 30 peer-reviewed articles have been published from across the United States on the issue of college food insecurity.

The prevalence of college food insecurity has been displayed in three systematic reviews to date, all with varying estimates based on inclusion criterion. The first systematic review, published in 2017 by Bruening, Argo, Payne-Surges, and Laska [3], reviewed both peer-reviewed and grey literature that assessed the prevalence of food insecurity among students in higher education. Authors of this review utilized all available literature published between January 2001 and August 2016, resulting in 18 peer-reviewed (9 United States and 9 International universities) and 41 grey literature (37 United States and 4 International) sources for review. Average food insecurity prevalence among peer reviewed studies was $42.0 \%$ and ranged from $12.5 \%$ at the University of KwaZulu-Natal [113] to 84\% at the University of the Free State [114]. However, these outliers are from outside the United States, therefore, when including only peer-reviewed studies from the United States, prevalence ranged from $14.1 \%$ at the University of Alabama [115] to 58.8\% at Western Oregon University [28], with an average of $33.2 \%$ for eight studies. This is similar to the grey literature average of $35 \%$ prevalence.

A following review on food insecurity was published in February of 2018 by Lee et al [21]. Authors took a narrative approach and provided additional insight on the quality of studies, using the Quality Assessment Tool for Quantitative Studies [116]. Similar to Bruening et al., this review included both domestic and international studies but did not specify between their definition of peer-reviewed and grey literature. Food insecurity prevalence of the 37 studies included demonstrated a wide margin in estimates ranging from $9-89 \%$. When excluding international studies, prevalence from 21 studies showed an average food insecurity prevalence of $40.4 \%$ and ranged from $15 \%$ at the University of Maryland [29] to $61.9 \%$ at the City University of New York [117]. All studies included in this review were rated weak on the quality assessment, which took into account selection bias, study design, confounders, blinding, data collection methods and withdrawals/drop-outs.

The most recent review, June 2018 , by Nazmi et al. aimed to synthesize the prevalence of food insecurity among students attending higher education institutions 
and utilized strict inclusion criteria to capture only higher quality studies. Included studies must have collected primary data on food security prevalence, utilized random or representative sampling strategies, and utilize a USDA food security assessment tool, thus the number of included studies was reduced to eight studies. Unweighted mean prevalence of food insecurity was $43.5 \%$ across the eight studies included and ranged from $21 \%$ at the University of Hawaii at Manoa [110] to $58.8 \%$ at Western Oregon University [28].

Due to the variance in these reviews, it is difficult to get an exact estimate of the prevalence of food insecurity among college students, although it is clear the food insecurity rate is consistently higher than the national average. These reviews are limited for the purpose of this dissertation due to a few factors. First, the prevalence is often inclusive of community colleges, which as mentioned previously, may represent a different population compared to students at 4-year institutions. Further, the mix between peer-reviewed and grey literature weakens the validity of the studies included. Lastly, a large portion of the peer-reviewed food insecurity literature has been published in 2017 and 2018 and not included within these reviews.

To gauge a more accurate estimate that encompasses all currently published peer-reviewed studies, a current literature review was completed for this dissertation to include all studies that measured food insecurity at a 4-year institution. One peerreviewed study was not included in this estimate as the qualitative study methods were not adequate for comparison against quantitative studies [118]. Of 31 published studies, the average food insecurity prevalence is calculated to be $36.1 \%$. Similar to previous reviews, the highest prevalence again at Western Oregon University (58.8\%). The lowest prevalence, $11 \%$, was in recent manuscript on the prevalence of food insecurity among college athletes at the University of Mississippi [119]. This average estimate is lower than that of the previous reviews, suggesting that prevalence among students at 4-year institutes may be lower than that of community college students. However, it is vital to note that a few of these studies utilize singular populations on campus (those using the campus food pantry, student athletes, etc.) and differing survey methods that may fluctuate the food insecurity estimate and further may not generalize to the student population as a whole. Additionally, as mentioned above, validated survey tools are 
lacking in specific populations. Particularly, in the college population, there is limited understanding of college student's interpretation of the USDA food security questions to gauge survey validity among college students. Current research is targeting this issue, see Appendix $D$, and trying to fill the gaps in survey tools for the college population.

Further, these studies fail to encompass all regions of the United States. Current peer-reviewed college food insecurity literature contains data from students in 19 states, including Alabama [27, 115], Arizona [25, 120], California [109, 118, 121, 122], Florida [123], Hawaii [110], Illinois [124], Maryland [29], Massachusetts [125], Michigan [24], Mississippi [119], New Hampshire [126], North Carolina [26, 127], Ohio [128-130], Oregon [28, 131], Tennessee [132], Texas [108, 133, 134], Wisconsin [135, 136], and West Virginia [137]. Other states have been represented in grey literature including Alaska [138], Arkansas [139], Minnesota [140] and New York [117]. However, only five of these studies have been conducted in the Appalachian region [26, 27, 115, 132, 137], consequently making the Appalachian region well represented in college food insecurity literature. As mentioned above, the Appalachian region is subject to poor health outcomes and prone to higher rates of food insecurity, therefore investigate of college food insecurity in this region is pertinent and should be targeted moving forward.

\section{Risk for College Food Insecurity}

Previous research has taken an interest on understanding the determinants of food insecurity among the college population. The Government Accountability Office (GAO) released a report to congressional requestors, entitled "Food Insecurity: Better Information Could Help Eligible College Students Access Federal Food Assistance Benefits" in December 2018 [141]. Authors of this report identified key risk factors to include when studying food insecurity; these being disability status, first generation student, former foster youth, housing insecurity, income, single parent status, and SNAP enrollment [141]. These risk factors encompass much of what has been expressed in the college food insecurity literature [28, 29, 108, 126, 129, 131, 142]. However, other variables have been identified that may be of interest, despite not being included in the GAO analysis. 
A demographic variable identified as a potential risk factor for college food insecurity, similar to national food insecurity, is race/ethnicity. College students that classify as minority status have been identified in multiple studies to have higher prevalence of food insecurity $[24,29,110,115,123,124,129,131,136,143]$. Specifically, African American students have been identified as more likely to be food insecure than students from other races or ethnicities [29, 124], with Phillips, McDaniel, and Croft (2018) reporting that African American students had 2.9 times higher odds of being food insecure compared to their White counterparts [129]. Students who identify as Hispanic [108, 131, 143] and Pacific Islander [110] have also been reported to have increased risk for food insecurity. Lastly, El Zein, Mathews, House, and Shelnutt (2018) reported that international students are more likely to be food insecure compared to both in-state and out-of-state students in Florida [123]. Therefore, students of minority status may require additional assistance to prevent food insecurity during college.

In addition to minority status, some recent literature suggests that students raised in food insecure households are more likely to be food insecure in college [132, 136, 143]. Martinez, Webb, Frongillo, and Ritchie (2018) reported that in a sample of 8,705 students, about one fifth reported food insecurity during childhood. Of those students with experience of childhood food insecurity, a significant proportion of students were currently food insecure (43\%). Broton, Weaver, and Mai (2018) corroborated this finding between childhood food insecurity and experiences during college, stating that those who grew up food insecure had a $40 \%$ chance of experiencing food insecurity during college [136]. When engaging qualitatively with students, authors reported that growing up where "there wasn't food in the house" contributed to complex relationships with food, including appetite changes and anxiety, for college students once on their own. Lastly, Wooten, Spence, Colby and Anderson Steeves (2018) found that history of food insecurity as a child was the strongest predictors of food insecurity among college students [132]. In a study of 4842 students, those with previous food insecurity were 4.78 times more likely to be food insecure compared to students who did not experience food insecurity before college [132]. Thus, it may be important to screen college students entering college for history of food insecurity to identify at risk students in college. 
Financial aid could be thought to provide support against food insecurity by affording students a source of financial support, however, the literature suggests that receiving financial aid increases the likelihood that a student will become food insecure $[26,29,115,120,123,124,126,132,142,143]$. Some studies only investigate whether a student receives financial aid or not [26, 29, 115, 143], with Davidson and Morrell (2018) indicating that students who receive financial aid are 1.8 times more likely to be food insecure. Other studies look more in-depth, indicating that loans that require repayment may specifically increase risk $[124,132,142]$. Wooten et al. (2018) indicated that students with loans requiring repayment were 1.4 times more likely to be food insecure. Knol, Robb, McKinley, and Wood (2018) stated that the amount owed also plays a role in food insecurity risk, with students who owe between $\$ 1,000-\$ 9,999$ being 1.4 times more likely to be food insecure and those who owe $\$ 10,000$ or more being 2.9 times more likely to be food insecure compared to students who do not have financial aid debt. Other forms of financial aid, such as needs based assistance (i.e. Pell Grant), have been indicated to increase risk of food insecurity among students $[120,123]$. Overall, this suggests that students who receive financial aid may require additional resources to prevent food insecurity during their college career.

The prevalence of food insecurity throughout the academic years has also been studied. Undergraduates have be reported in multiple studies to have increased likelihood of food insecurity compared to graduate students [24, 123, 132]. Mirabitur et al. (2016) first reported this relationship and found that undergraduate students were 3.13 times more likely to be food insecure compared to graduate level students. This relationship has been confirmed by El Zein et al. (2018) and Wooten et al. (2018), both stating that when compared to graduate students, undergraduate students are significantly more likely to be food insecure. Specific academic years have been identified within studies, although they are not consistent, highlighting significant differences between freshman [144] and senior [26, 132] standing students compared to graduate level students. However, Chaparro et al. (2009) found no significant difference between academic year (undergraduate vs graduate) [110], indicating that this relationship might not be present on every campus. 
College students living arrangements have also been speculated to impact student food security status. Multiple studies have found relationship between living on or off campus and risk of food insecurity $[110,123,129,134,136]$. Specifically, students living off campus have been reported to have higher risk of food insecurity compared to those living on campus $[123,134,136]$, with the exception of those who live off campus with their parents or guardians $[110,124]$. The proximity housing is to campus is reported to play a role, as Phillips et al (2018) reported that students that live within walking distance were 2.9 times more likely to be food insecure compared to those who live on campus but those who live outside of walking distance had lower odds of 2.4 times greater risk compared to those on campus [129]. Additionally, students who live in housing that does not provide food provision (i.e. dining hall, fraternity house, etc.) are more likely to be food insecure. These studies indicate that it may be warranted to provide additional resources and investigation to students who live off campus.

Other variables have been identified as having a significant association with college student food security status but are much more inconsistent within the literature. These variables include age [129, 143], gender [24, 26, 131], cooking and food purchasing behaviors [26, 133], having a meal plan [132, 134], and level of employment $[28,132,145]$. As there is no clear consensus within the literature, more research is needed before it is understood if a relationship exists among these variables and college students who experience food insecurity.

\section{Impacts of Food Insecurity on College Students}

The impact food insecurity has on college student well-being has been studied and includes detriments on physical and mental health, coping behaviors, academic outcomes and dietary intakes.

Health among college students is heavily studied, but studies particularly focused on food insecurity's impact on college student health outcomes are more limited. Patton-Lopez, Lopez-Cevallos, Cancel-Tirado, and Vazquez (2014) reported that students reporting their health to be fair or poor were 2.1 times more likely to be food insecurity [28]. This finding was reiterated by McArthur, Ball, Danek, and Holbert (2018) who stated that fair and poor health responses were 3 times greater among food 
insecure students [26]. These authors also described that food insecure students were more likely to be categorized as overweight and obese[26], which may contribute to their poor health perceptions. The mental health of food insecure college students is also a concern, with food insecure college students exhibiting signs of depression and anxiety [25, 29, 122, 137]. Bruening et al. (2016) reported that food insecure freshman were 3 times more likely to report signs of depression [25]. Wattick, Hagedorn, and Olfert (2018) found similar results with food insecurity increasing the odds of depression in male and female college students [137]. Additionally, food insecurity was reported to increase the odds of anxiety in both genders of college students [137]. It is further suggested that this poor mental health status may be a mediating factor between food insecurity and other negative outcomes, including poor academic performance [122].

Several studies have examined the relationship between food insecurity and college student academic accomplishments. It has been reported that food insecure college students are more likely to have lower GPA's compared to their food secure counterparts [28, 122, 124, 127, 129, 132, 143, 145]. Phillips et al. (2018) reported that food insecurity is associated with a 0.17 point lower GPA [129]. Patton-Lopez et al. (2014) found that college students reporting above a 3.0 were $60 \%$ less likely to be food insecure and Wooten et al. (2018) further stated that students reporting below a 3.0 were 2.9 times more likely to be food insecure compared to students with higher a GPA $[28,132]$. Beyond GPA, other authors have investigated food insecurity's impact on college students' academic behaviors [26, 33, 145]. McArthur et al. (2018) utilized a 4item Academic Progress Scale (APS) to measure college students perceived academic performance [26]. Authors reported that food insecure students were less likely to rate their overall academic progress as excellent or good and have a significantly lower total APS score. This poor academic performance can not only interfere with a college students progress towards degree attainment but may derail it all together. Van Woerden, Hrushchka, and Bruening (2018) followed freshman throughout their first year of college and reported that food insecure students were $28 \%$ less likely to be enrolled the following year compared to food secure students [145]. 
The health of food insecure college students may also be impacted by the dietary behavior among this population. The dietary quality of college students is suggested to be lacking in nutritional diversity, with the young adult age range exhibiting worst dietary habits compared to all other age groups [146]. Food insecurity may exacerbate these poor dietary behaviors among college students. Mirabitur et al. (2016) investigated college student fruit and vegetable intake and reported students with high food security status ate mean 4.9 daily servings while students with very low food security status ate mean 4.3 daily servings [24]. Beyond servings, McArthur et al. (2018) investigated the composition of meals being eaten by college students. Authors reported that food insecure students reported limited dietary diversity with majority of their daily energy intake coming from grains and dairy consumption [26]. Further, Bruening, van Woerden, Todd, and Laska (2018) stated that food insecure students were $33 \%$ less likely to have frequent breakfast consumption, $55 \%$ less likely to have frequent evening meal consumption and $32 \%$ less likely to have healthy eating habits on campus [120]. These poor dietary outcomes among college students may be explained by lack of knowledge and skills to prepare meals, with these deficits being more pronounced among food secure students. Knol, Robb, McKinley, and Wood (2018) conveyed that students with very low food security status had significant lower cooking self-efficacy and food preparation scores when compared to food secure counterparts [147]. However, this may also highlight the economic limitations faced by food insecure students, and thus be impacted by poor financial skills. McArthur et al. (2018) highlighted that food insecure college students often spend money on non-food items instead of purchasing food, including purchases of gasoline, car repairs, and alcohol [26], with similar findings by Cuy Castellanos and Holcomb (2018) in which students prioritized alcohol purchases [130]. Similar to cooking skills, food insecure college students are reported to have low self-efficacy regarding money management which may explain their poor purchasing habits [108]. Thus, food insecure college students may benefit from education on basic life skills, such as food preparation and money management, to develop the skills necessary to maintain a food secure lifestyle.

The college student population is suggested to develop behavioral patterns to cope with the stress of their environment [148]. Specifically, research suggests the food 
insecure students often rely on a myriad of healthy and unhealthy coping strategies. Lee et al. (2018) summarized the coping strategies food insecure students rely on into three categories: food management, income management, and social and community support [21]. Food management coping strategies included eating less frequent or smaller meals [121, 149], skipping meals all together [121, 149], buying cheaper foods [26, 109, $131,149]$, sharing food with roommates [26, 131], and increasing fluid intake to repress hunger [149]. Income management coping strategies included using credit to purchase food [115], increasing work hours [26, 109, 131, 149], delaying bill payments [131], applying for government assistance [115], and selling possessions [131, 149]. Lastly, social and community support coping strategies relied on by students included borrowing money or foods from friends or relatives [109, 131], using food pantries [115, 131], lived with others [26], and attending events on campus with free food [109, 131, 149]. Long-term reliance on unhealthy coping strategies, such as skipping meals, may impact student's health due to poor dietary intake. Further, the stress of reliance on numerous coping strategies may hinder a student's mental well-being and contribute to poor academic performance in this population.

Overall, food insecure students are subject to factors that impact their well-being. Therefore, colleges and universities are employing programs to address campus food insecurity and provide student resources to succeed [150].

\section{Aid for Food Insecure Students}

The increase in awareness and acknowledgment of campus food insecurity has come with the increase in campus-based food security programs. These programs are created with the intent to alleviate the burden on food insecure students and provide a resource to move toward a food secure environment for all student well-being. The most commonly implemented strategy is the establishment of campus food pantries [36]. Most campus food pantries are designed to provide supplemental and emergency food assistance to students. The College and University Food Bank Alliance (CUFBA) has championed the national development of college food pantries by supporting both existing and emerging campus food banks and pantries through the provision of resources on fundraising and student-run management [151]. Through their 
organization, they have built a member base of $640+$ college and university-based food banks providing support to students across the United States [151]. Developing a food pantry on campus involves partnerships on many levels, often including both administrative, student, and community buy-in [128, 152]. Long-term evaluations of food pantries on college campuses are lacking, however food pantry stakeholders have identified they meet student needs by prioritizing areas (i.e. support, partnership, awareness, etc.) specific for campus [107].

Other initiative programs to address campus food insecurity include campus gardens, farmers markets, and meal swipe programs [36]. Measurement of the success of these programs at alleviating campus food insecurity is limited. To date, authors of one study have evaluated the impact of a campus meal swipe program [150]. Novak and Johnson (2018) found that food insecurity students who received assistance with meal swipes demonstrated better academic outcomes compared to students who were waitlisted to receive swipes [150]. This findings support the use of meal swipe programs on campus and can serve as an alternative method, beyond food pantries, to provide support to students in need. Additionally, these alternative programs can increase the dietary diversity of students, as food pantries are often limited to non-perishable items and lack fresh fruits and vegetables. Manry, Mills, and Ochs (2017) presented a case study of establishing a campus garden and highlighted the contribution this garden had on the offering of the campus food pantry [153]. Therefore, food insecurity students can receive both non-perishable and perishable items to improve the nutritional quality of their diets which may prevent some of the associated physical and mental health factors.

\section{Conclusion}

This summation of literature accentuates the issues of food insecurity in the United States, but specifically among college students. Research is lacking among college students attending 4-year institutions in health disparate regions, such as the Appalachian region, where food insecurity rates are heightened. Understanding the characteristics and behaviors of food insecure students in this region will guide the implementation of food insecurity programming on campus. 


\section{Chapter III: Research Design and Statistical Analyses}




\section{Introduction}

Chapter 3 will provide a description of the research methodology used to address research questions for this investigation of food insecurity prevalence and behaviors of college students in the Appalachian and Southeastern regions of the United States. Data collection methods will be described in further detail along with associated hypothesis. Study design, data gathering, instruments and variables measured, and data analyses will be explained. As different methodologies were utilized for aim 3, each section will describe aim 1 and 2 together and aim 3 independently. This study was approved by the Institutional Review Board (IRB) at West Virginia University (1802980009).

\section{Sample and Data Collection}

Aim 1 and 2

Collaborating universities completed IRB requirements at their university. Cross sectional, online survey data collection was utilized. Surveys were distributed to students attending 10 public universities in the Appalachian and Southeastern Regions between Spring 2016 and Spring 2018. The only inclusion criterion was current enrollment at one of the participating universities. Methodologies varied at each university to fit the needs of their campus and IRB requirements. Convenience or random sampling was used at each university and recruited through emails and campus announcements. All universities distributed the survey for student completion via Qualtrics (Qualtrics, Provo, UT), except one university which used CampusLabs (CampusLabs, Buffalo, NY). Informed consent was completed online by all students as a requirement to progress on the survey platform. Incentives also varied at each university and ranged from $\$ 25-\$ 100$ gift cards. Students who elected could provide their contact to be entered into a drawing for a gift card.

Aim 3

Online survey data collection was utilized to capture feedback on the WISH4Campus toolkit. Experts from land-grant universities were chosen to provide feedback on the WISH4Campus toolkit. Experts were identified from search of each 
university's website. Name, organization, title, phone, and email of each expert was collected as available and input in an excel sheet. Identified contacts received an invitation email to participate in the evaluation. Informed consent was completed online by experts prior to beginning the survey evaluation. Once consent was obtained, the expert was provided the option to download a PDF version of the WISH4Campus Toolkit and complete the feedback survey. Participants were not paid for their feedback but could provide their email to be entered for a chance to win one of two, $\$ 200 \mathrm{gift}$ cards. Winners of the gift cards were selected through random generation in excel.

\section{Measures}

\section{Aim 1 and 2}

The full survey was developed by an Appalachian Multistate Collaborative and included previously validated tools as well as measures specific to the target population. This survey included demographic, behavioral, health, and economic independent variables. The dependent variable was food security status and was measured using the United States Department of Agriculture Adult Food Security Screener (USDA AFSS). Details of the measures used in Aim 1 and 2 of this dissertation are as follows:

United States Department of Agriculture Adult Food Security Screener: This tenitem food security screener is validated through the USDA and a common method for distinguishing between food secure and food-insecure individuals. The AFSS is a component of the USDA Household Food Security Survey Module (HFSSM) but excludes the eight questions regarding children in the household [72]. Responses are grouped into four categories based on affirmative responses into high, marginal, low, and very low food security classification as shown in Table 1. Low and very low food security categories are combined to represent food insecure respondents.

Table 1: United States Department of Agriculture (USDA) Labels to Describe the Categories of Food Security

\begin{tabular}{|l|l|l|}
\hline Category & USDA Definition & $\begin{array}{l}\text { Affirmative } \\
\text { Responses }\end{array}$ \\
\hline
\end{tabular}




\begin{tabular}{|l|l|l|}
\hline $\begin{array}{l}\text { High Food } \\
\text { Security }\end{array}$ & No reported indications of food-access problems or limitations. & 0 \\
\hline $\begin{array}{l}\text { Marginal Food } \\
\text { Security }\end{array}$ & $\begin{array}{l}\text { One or two reported indications-typically of anxiety over food } \\
\text { sufficiency or shortage of food in the house. Little or no } \\
\text { indication of changes in diets or food intake. }\end{array}$ & $1-2$ \\
\hline $\begin{array}{l}\text { Low Food } \\
\text { Security }\end{array}$ & $\begin{array}{l}\text { Reports of multiple indications of disrupted eating patterns and } \\
\text { reduced food intake. }\end{array}$ & $3-5$ \\
\hline $\begin{array}{l}\text { Very Low Food } \\
\text { Security }\end{array}$ & $\begin{array}{l}\text { Reports of multiple indications of disrupted eating patterns and } \\
\text { reduced food intake. }\end{array}$ & $6-10$ \\
\hline
\end{tabular}

Coping Strategies Scale (CSS): The CSS is a 29-item scale that examines how often students used coping strategies to obtain food in the past 12 months [26]. The coping questions encompass four topics: saving, support, food intake/access and selling. Support questions ask if students take fewer classes, use less utilities, share housing and food responsibilities with others, plan or stretch meals, use coupons, or skimp on medications or medical appointments. Support questions include if students engage in a research study/clinical trial to receive money for food, borrow money from family or friends, attend functions with free food or where you "pay when you can", obtain food from a food bank, food pantry or assistance program, visit family on weekends to bring back food to school, work one or more part/full time jobs or used a credit card to buy food. Food intake/access questions ask if students consume more than normal when food is abundant, take extra food from on-campus dining halls, eat less healthy meals to increase intake, purchase processed foods, find food in a dumpster or trash, or barter services/items for food. Selling questions ask if students have ever sold textbooks, personal possessions, blood/plasma or sperm/eggs to obtain food. Student response options are never (1), sometimes (2), or often (3) and summed for a total CSS score. Higher CSS scores indicate an increased reliance on coping strategies to obtain food. CSS questions are shown in Appendix B, question 12. 
Money Expenditure Scale (MES): The MES is an 8-item tool that measures the spending habits of college students. Specifically, the MES assesses how often in the past 12 months students spent money on other items instead of using the money to purchase food [26]. The items assessed for monetary purchases included substance purchases (i.e., alcohol, cigarettes, and recreational drugs), transportation (i.e., public transportation fees, car repairs, and gasoline), pet care, and tattoos. Student response options are never (1), sometimes (2), or often (3) to purchasing these items and are summed for a total MES score. Higher MES scores signify an increased money expenditure for items that are not food. MES questions are shown in Appendix B, question 11.

Academic Progress Scale (APS): The APS evaluates academic behaviors using 4items that capture students perceived academic performance [26]. Questions pertain to a student's class attendance, attention span, understanding of the concepts taught in class, and progression towards graduating on time. Reponses options include excellent (4), good (3), fair (2) and poor (1). Responses are summed with higher APS scores indicating a student has a better perception of their academic behaviors. Grade point average (GPA) was also self-reported by students as an indicator of academic progress but assessed separately from the APS. APS questions are shown in Appendix B, questions 24-27.

Socioeconomic Status: Variables to distinguish demographic characteristics include gender, home region (e.g., Midwest, Northeast, etc.), age, marital status, ethnicity, dependents, student status, school year, housing, car ownership, and utilization of public transportation. Health related questions include self-reported health status, having health insurance and body mass index (BMI) (calculated from self-reported height and weight). Also encompassed are two questions with a culinary focus regarding how often students cooked for themselves and how they would rate their cooking skills. Lastly, economic variables assessed if students receiving financial aid, employment status, and purchase of a meal plan. 
Aim 3

The evaluation survey was a modified version of a previous toolkit development survey [40]. Modifications were made to the survey to encompass the topics of the WISH4Campus toolkit and included both open and close ended questions. The 27item survey included six demographic questions, five questions about the expert's perception of food insecurity issues on college campuses and their knowledge of food insecurity on their own campus, and 11 questions addressed specific toolkit components including rating of the toolkit layout, content, and initiatives, barriers to using the toolkit, areas that worked well and suggested improvements.

\section{Analysis}

Aim 1 and 2

All analyses for aim 1 and 2 were performed using JMP and SAS software (JMP®, Version Pro 12.2, SAS Institute Inc., Cary, NC, Copyright @2015; SAS®, Version 9.4, SAS Institute Inc., Cary, NC, Copyright (O2002-2012). Aim 1 was to investigate the correlates and behavioral consequences of food insecurity on college students in the Appalachian region. The aim 1 hypothesis was that food insecurity rates at a school within Appalachia, West Virginia University, will be greater than national average and food insecure students will display unique behaviors compared to food secure students. Aim 2 was to expand upon aim 1 and conduct a regional investigation of college food insecurity in the Appalachian and Southeastern regions of the United States. The hypothesis for aim 2 was that student food insecurity prevalence at all universities in the regional analysis will be greater than national average and food insecure students will display unique behaviors compared to food secure students. Descriptive statistics were computed for all demographic, health, and economic variables and stratified by food security status. Pearson Chi-square analyses were used to determine bivariate associations of food secure and food-insecure students and all categorical variables. Wilcoxon analysis was used due to lack of normality for bivariate associations between food security status and continuous variables. Investigation of behavioral influences of food insecurity were tested in a forward selection logistic 
regression model, with all variables significant from bivariate analyses input in the model. Significance criterion alpha for all tests was 0.05 .

$\operatorname{Aim} 3$

Aim 3 utilized mixed methods analyses, with quantitative analyses performed in JMP (JMP®, Version Pro 12.2, SAS Institute Inc., Cary, NC, Copyright @2015). Quantitative analysis included descriptive statistics and frequency analysis. Content analysis was used to analyze qualitative data. Coding occurred in Qualtrics (Qualtrics, Provo, UT, USA) with some in vivo codes guided by the Normalization Process Theory (NPT) and the rest were based on subjective assessment of the content. Codes were reviewed multiple times and categorized into a major theme and subthemes. Each major theme also contained recommendations that were coded separately from subthemes. A second researcher reviewed all themes to make sure both reliability and validity of results occurred. If discrepancies arose both qualitative reviewers discussed the coding and collectively deciding on themes. The hypothesis was that experts $(>80 \%)$ would find the toolkit as a useful means to improving college food security.

\section{Limitations of the Study}

Utilization of a cross-sectional study design for aim 1 and 2 allowed for cost efficient and timely data collection of multiple variables to help initiate the investigation of food insecurity in the Appalachian and Southeastern Regions. However, this methodology is not without limitations. While sample sizes were sufficient for analysis, respondents may not be representative of all students within the Appalachian and Southeastern regions and should not be generalized as such. Causation is not able to be inferred, thus this research will highlight a relationship between food insecurity and other variables with no inference of cause or effect. Aim 3 is limited by data collection from experts on land-grant universities which may provide different insight than experts from community colleges, private institutions, historically black colleges and universities (HBCUs), and international institutions. Further limitations of the overall studies will be described in Chapter 7. 


\section{Chapter IV: Food Insecurity and Behavioral Characteristics for Academic Success in Young Adults Attending an Appalachian University}




\title{
ABSTRACT
}

\section{Food Insecurity and Behavioral Characteristics for Academic Success in Young Adults Attending an Appalachian University}

\author{
RL Hagedorn ${ }^{1}$, MD Olfert ${ }^{1}$
}

${ }^{1}$ West Virginia University, Davis College of Agriculture, Natural Resources and Design, Division of Animal and Nutritional Sciences, Department of Human Nutrition and Food

Background: In order to investigate the impact of food insecurity on college students in a highly health disparate region we (1) assessed the prevalence of food insecurity among young adults at a large, rural university in Appalachia, and (2) investigated the relationship between food insecurity and behavioral characteristics including academic performance, coping strategies, and money expenditure.

Methods: A cross-sectional design was used to capture a representative sample of young adults attending a large, central Appalachian university in Fall 2016. The United States Department of Agriculture (USDA) Adult Food Security Survey was used to measure food insecurity. Independent variables include money expenditure (MES), coping strategies (CSS), academic performance (APS), and demographic, health, economic and culinary variables.

Results: Participant responses $(n=692)$ showed one third $(36.6 \%)$ of respondents were food-insecure. Students with higher scores for MES and CSS had significantly higher odds of being food-insecure (odds ratio $(O R)=2.07 ; 95 \%$ confidence interval (Cl) 1.81 to 2.38 and $\mathrm{OR}=1.20 ; 95 \% \mathrm{Cl} 1.16$ to 1.23 , respectively). The odds of high APS scores (OR $=0.79 ; 95 \% \mathrm{Cl} 0.73$ to 0.86 ) were inversely related to food insecurity. Results of the logistic regression showed MES, CSS, health, and school year remained a significant predictor of food insecurity in college students.

Conclusion: These findings suggest behavioral differences in terms of coping strategies, money expenditure, and academic progress among food-insecure students and can be used to identify and target at-risk students to promote student food security and well-being. 


\section{Introduction}

Nearly thirteen percent (15.8 million households) of Americans were food-insecure at some point in 2015 [154]. The risk of food insecurity is affected by socioeconomic status [155, 156], ethnicity [157], educational attainment [158], and geographic location [16, 159]. Food insecurity has been shown to be associated with inadequate diet [47, 160$162]$, poor health [23, 158, 163], lower cognitive and academic performance [65, 148, 164-166], and higher rates of mental health and substance use disorders [163, 167-171]. Indeed, food insecurity is related to poor physical, cognitive, and emotional health in all age populations.

Maintaining optimal health and well-being during college is especially important because it is related to academic achievement and degree attainment [148]. However, until recently, little scientific work has examined food insecurity in the young adult population attending college. Previous research on college campuses shows food insecurity prevalence is higher than the national average, with a wide range of $14-59 \%$ of the student population classified as food-insecure [172]. In addition to identifying prevalence, many of these studies examined correlates of food insecurity among the young adult population, showing food insecurity as it relates to income or financial aid status [28, 115], government assistance [28, 30], employment status [117], and living or housing arrangements $[30,110]$.

The effect of food insecurity on college students' behaviors and academic achievement has been minimally investigated [23, 33, 172]. In response to the stress of college, many students develop behavioral patterns to cope with their environment [148]. Broton and Goldrick-Rab reported that students were more likely to rely on coping behaviors such as changing eating habits, borrowing money, or postponing bill payments to make ends meet [173]. However, this study reported the percent of the student population displaying coping strategies, but failed to determine whether food-insecure students displayed these coping behaviors more often [173]. In addition to coping strategies, food-insecure students are likely to have different spending behaviors. The role of food insecurity on academic progress and student-reported behaviors is largely unknown. 
As previously stated, residing in geographically rural areas can increase the risk of being food-insecure. A systematic review of food insecurity studies on college campuses included samples from an urban southwestern university [25], urban southeastern university [115], rural western university [28], and pacific island university [110] but lacked studies of colleges or universities from the Appalachian region [3]. Appalachia is recognized for being unique from the rest of the country in terms of economic, health, and academic characteristics [174]. Specifically, in regards to higher education, while Appalachia has improved in degree attainment in recent decades, the percent of adults with bachelor degrees is still $7 \%$ below the national average $[8,175]$. With the suggested impact of food insecurity on educational attainment, it is important to investigate the prevalence of food insecurity among young adults attending college within Appalachia to promote degree fulfilment.

The objectives of the present study were to (1) assess the prevalence of food insecurity among young adults attending college at a large, rural university in Appalachia, and (2) investigate the relationship between food insecurity and behavioral characteristics including academic performance, coping strategies, and money expenditure.

\section{Methods}

\section{Study Design}

This cross-sectional study examined a sample of young adults attending a large, Appalachian university in fall 2016, as part of a larger research project in conjunction with seven other universities in the Appalachian and Southeastern regions of the United States [26]. Participants were currently enrolled college students. All subjects gave their written informed consent for inclusion before they participated in the study. The study was conducted in accordance with the Declaration of Helsinki, and the protocol was approved by the Institutional Review Board at West Virginia University (170350219).

\section{Participants and Procedures}

A nonprobability sample of undergraduate and graduate students attending a large, land grant university in central Appalachia was recruited during the fall 2016 semester. All graduate and undergraduate professors teaching a fall 2016 course (across three local 
campuses, including 14 colleges and schools housed at the university) ( $n=1191)$, were emailed an online survey link to share with enrolled students. This is an estimated 22,000 undergraduate and 6000 graduate students, although a university student listserv was not available for research access to directly contact students. Students across all disciplines and academic years were eligible to complete the survey. Interested students selected the link, taking them to Qualtrics (Qualtrics, Provo, UT, USA), an anonymous, online questionnaire platform. Participants were instructed to read the informed consent and those who accepted consent were allowed to complete the survey. Students who denied the consent were thanked for their time. Students were incentivized to complete the survey by a chance to win a $\$ 100$ American Express gift card by entering their contact information following survey completion. Contact information remained separate from the results of the survey to protect participant identity. To avoid collecting data when students would more likely be provided by family support, the survey remained open from September until late November prior to when students went home for Thanksgiving break [26].

\section{Survey Design}

The 56-item survey was developed by an Appalachian Multistate Collaborative to investigate food insecurity in college students attending an Appalachian Higher Education Institutions. The survey, built and administered via Qualtrics, consisted of the United States Department of Agriculture Adult Food Security Screener (USDA AFSS), money expenditure scale (MES), coping strategies scale (CSS), academic progress scale (APS). MES, CSS, APS scale Cronbach's alpha were determined as $0.7225,0.8888,0.6945$, respectively. The remaining questions consisted of the following variable topics: demographic, economic, health, and culinary.

Dependent variable: The USDA AFSS is a ten-item validated food security screener, pulled from the USDA Household Food Security Module, and is a common method for distinguishing between food secure and food-insecure individuals. The AFSS measures behaviors and conditions regarding food purchasing and intake (i.e., In the last 12 months, did you ever eat less than you felt you should because there wasn't enough money for food?). Responses are grouped into four categories based on affirmative 
responses into high (no food access problems), marginal (anxiety over food situation), low (reduced diet quality and variety), and very low (reduced food intake and/or disrupted eating patterns) food security classification.

Independent variables: The MES is an 8-item tool that measured how often in the past 12 months that students spent money on other items instead of using the money to purchase food [26], with never, sometimes, and often answer choices. The items assessed for monetary purchases included substance purchases (i.e., alcohol, cigarettes, and recreational drugs), transportation (i.e., public transportation fees, car repairs, and gasoline), pet care, and tattoos.

The CSS development was guided by previous food insecurity literature and used in previous college settings [26, 176-178]. The 29-item scale examined how often students used coping strategies in the past 12 months with never, sometimes, and often answer choices. The coping topics included saving, support, food intake/access and selling. Saving questions asked if students took fewer classes, used less utilities, shared housing and food responsibilities with others, planned or stretched meals, used coupons, or saved on medications or medical appointments. Support questions included if students participated in a research study/clinical trial to buy food, borrowed money from family or friends, attended functions with free food or where you "pay when you can", obtained food from a food bank, food pantry or assistance program (e.g., Supplemental Nutrition Assistance Program (SNAP), Women, Infants and Children (WIC), etc.), visited family on weekends to bring back food to school, held one or more part/full time jobs or used a credit card to buy food. Questions on food intake/access asked if students ate more than normal when food was plentiful, took food home from on-campus dining hall, ate less healthy meals to eat more food, purchased processed food, obtained food from a dumpster or trash, or bartered services/items to buy food. Lastly, the selling questions enquired if students ever sold textbooks, personal possessions, blood/plasma or sperm/eggs to obtain food.

Academic behaviors were captured using the 4-item APS, on which students reported their perceived academic performance. Students completed questions regarding class attendance and attention span, understanding the concepts taught in class, and progression towards graduating on time (i.e., How would you rate your class 
attendance?). Grade point average (GPA) was also self-reported by students as an indicator of academic progress but assessed separately from the APS.

Demographic variables included gender, home region (e.g., Midwest, Northeast, etc.), age, marital status, ethnicity, dependents, student status, school year, housing, car ownership, and utilization of public transportation. Economic variables included receiving financial aid, employment status, and purchase of a meal plan. Health variables included self-reported health status, having health insurance and body mass index (BMI) (calculated from self-reported height and weight). Also included were two questions with a culinary focus regarding how often students cooked for themselves and how they would rate their cooking skills.

\section{Statistical Analysis}

Descriptive statistics were computed for all demographic, economic, health, and culinary variables as appropriate. BMI was calculated from self-reported height and weight, and categorized using the World Health Organization (WHO) BMI classification [179]. Food security status was determined for the 10 AFSS questions in accordance with the Guide to Measuring Household Food Security scoring system [72]. As protocol states, zero affirmative answers reflected high food security, 1-2 marginal food security, 3-5 low food security, and 6-10 very low food security. Prevalence of food insecurity was determined by combining those who scored in the high or marginal food secure categories (food secure) and those who scored in the low and very low food secure categories (foodinsecure).

The MES and CSS were scored on a 3-point scale with 1 point representing "never", 2 points to the "sometimes," and 3 points to the "often" responses. Total scores for MES could range from 8 to 24 points and CSS scores could range from 29 to 87 points. The 4 item APS was scored on a 4-point scale with 4 points for the "excellent," 3 for the "good," 2 for the "fair," and 1 for the "poor" responses. Therefore, scores on the APS could range from 4 to 16 points. All scales were left continuous for analysis, with higher MES scores representing more spending on items before buying food, higher CSS scores representing more reliance on coping strategies to acquire and maintain food sources, and higher APS scores representing a more positive perception of academic behaviors. 
Pearson Chi-square analyses were used to determine bivariate associations of food secure and food-insecure students with sociodemographic and behavioral variables. MES, CSS, APS, GPA and BMI were assessed as continuous variables and Wilcoxon analysis was used due to lack of normality to compare means of food-insecure and food secure students. Simple logistic regression was used to predict food security status from scores on MES, APS, and CSS scales. Forward selection multivariate logistic regression was used in a full model to predict food insecurity from the all significant or close to significant categorical and continuous variables from Chi-square and Wilcoxon analyses. Lack of fit was assessed by Hosmer and Lemeshow Goodness-of-Fit test $\left(X^{2}(8)=9,17\right.$, $p=0.3278$ ) indicating the model was adequate.

Data were analyzed using JMP and SAS software (JMP ${ }^{\circledR}$, Version Pro 12.2, SAS Institute Inc., Cary, NC, USA, 2015; SAS ${ }^{\circledR}$, Version 9.4, SAS Institute Inc., Cary, NC, USA, 2002-2012). Significance criterion alpha for all tests was 0.05 .

\section{Results}

The survey was completed by 716 undergraduate and graduate students during the fall 2016 semester. As food insecurity was the primary outcome, participants who did not supply a full response to the ten questions USDA AFSS $(n=24)$ were excluded from analysis. A final sample of 692 was used for data analysis.

Analysis of the AFSS scores showed 439 respondents (63.4\%) as food secure comprised of 236 highly food secure (34.1\%) and 203 marginally food secure (29.3\%) respondents. The remaining 253 respondents $(36.6 \%)$ were classified as food-insecure consisting of 115 with low food security (16.6\%) and 138 with very low food security (20.0\%).

Respondents were predominately white $(87.3 \%)$, single $(94.3 \%)$, females $(71.0 \%)$ with average age 21.3 years \pm 4.0 standard deviation (SD). Students were spread across all academic years with the majority being full time (97.55) with an average GPA of $3.4 \pm$ 0.45 . Most students lived off campus $(67.9 \%)$ and owned a car $(71.5 \%)$ yet many still relied on public transportation (63.4\%). Student economic situations varied with majority having one or more part-time jobs (44.6\%), receiving financial aid $(80.4 \%)$, and not having a student meal plan (67.9\%). Health status of students was predominately high with 
$85.0 \%$ reporting excellent or good health and $98.3 \%$ having health insurance. Student BMI varied from 14.9 to 52.6 (Mean $25.0 \pm 5.3$ ) and most respondents fell in the healthy (18.5-24.9) BMl range (56.7\%) followed in prevalence by the overweight (25-29.9) category $(23.2 \%)$.

Table 1: Characteristics of Respondents and Correlations with Food Security Status

\begin{tabular}{|c|c|c|c|c|c|}
\hline \multirow[t]{2}{*}{ Variable } & \multicolumn{2}{|c|}{ Food Secure } & \multicolumn{2}{|c|}{ Food-insecure } & \multirow{2}{*}{$p$-Value } \\
\hline & $n$ & $\%$ & $n$ & $\%$ & \\
\hline \multicolumn{6}{|c|}{ Total Population } \\
\hline & 438 & 63.4 & 253 & 36.6 & \\
\hline & & Gender & & & \\
\hline Male & 120 & 28.7 & 70 & 28.7 & \multirow{2}{*}{0.9957} \\
\hline Female & 298 & 71.3 & 174 & 71.3 & \\
\hline \multicolumn{6}{|c|}{ Ethnicity } \\
\hline African American & 9 & 2.3 & 10 & 4.3 & \\
\hline Asian & 15 & 3.8 & 3 & 1.3 & \\
\hline Hispanic & 11 & 2.8 & 6 & 2.6 & 0.2640 \\
\hline White & 349 & 87.3 & 203 & 87.5 & \\
\hline Other/Multiracial & 16 & 4.0 & 10 & 4.3 & \\
\hline \multicolumn{6}{|c|}{ Marital Status } \\
\hline Single & 394 & 93.8 & 233 & 95.1 & \multirow{2}{*}{0.4885} \\
\hline Married & 26 & 6.2 & 12 & 4.9 & \\
\hline \multicolumn{6}{|c|}{ Dependents } \\
\hline Has Dependents & 8 & 1.9 & 7 & 2.9 & 0.4250 \\
\hline No Dependents & 412 & 98.1 & 238 & 97.1 & \\
\hline \multicolumn{6}{|c|}{ School Year } \\
\hline Freshman & 106 & 25.6 & 48 & 19.9 & \\
\hline Sophomore & 47 & 16.6 & 40 & 11.4 & \\
\hline Junior & 66 & 15.9 & 55 & 22.8 & 0.0130 * \\
\hline Senior & 97 & 23.4 & 58 & 24.1 & \\
\hline Graduate Student & 98 & 23.7 & 40 & 16.6 & \\
\hline \multicolumn{6}{|c|}{ Home Region } \\
\hline Midwest & 34 & 8.1 & 14 & 5.7 & \\
\hline Northeast & 126 & 30.0 & 80 & 32.7 & \\
\hline Southeast & 246 & 58.6 & 148 & 60.4 & 0.3006 \\
\hline Southwest & 5 & 1.2 & 0 & 0 & \\
\hline West & 9 & 2.1 & 3 & 1.2 & \\
\hline \multicolumn{6}{|c|}{ Car Ownership } \\
\hline Yes & 286 & 71.5 & 166 & 71.6 & 0.9889 \\
\hline No & 114 & 28.5 & 66 & 28.5 & \\
\hline
\end{tabular}




\begin{tabular}{|c|c|c|c|c|c|}
\hline \multicolumn{6}{|c|}{ Use Public Transportation } \\
\hline Yes & 260 & 65.0 & 141 & 60.8 & 0.2878 \\
\hline No & 140 & 35.0 & 91 & 39.2 & \\
\hline \multicolumn{6}{|c|}{ Housing } \\
\hline On Campus & 141 & 35.3 & 62 & 26.7 & 0.0269 * \\
\hline Off Campus & 259 & 64.8 & 170 & 73.3 & \\
\hline \multicolumn{6}{|c|}{ Employment } \\
\hline Unemployed & 169 & 42.3 & 93 & 40.1 & \multirow{4}{*}{0.1509} \\
\hline Part-time Job & 172 & 43.0 & 110 & 47.4 & \\
\hline Full-time Job & 25 & 6.3 & 19 & 8.2 & \\
\hline Other & 34 & 8.5 & 10 & 4.3 & \\
\hline \multicolumn{6}{|l|}{ Financial Aid } \\
\hline Yes & 324 & 81.0 & 184 & 79.3 & 0.6062 \\
\hline No & 76 & 19.0 & 48 & 20.7 & \\
\hline \multicolumn{6}{|c|}{ Meal Plan } \\
\hline Yes & 136 & 34.0 & 67 & 28.9 & 0.1839 \\
\hline No & 264 & 66.0 & 165 & 71.1 & \\
\hline \multicolumn{6}{|c|}{ Health Status } \\
\hline Excellent & 130 & 32.5 & 38 & 16.4 & $<0.0001$ * \\
\hline Good & 236 & 59.0 & 133 & 57.3 & \\
\hline Fair & 32 & 8.0 & 54 & 23.3 & \\
\hline Poor & 2 & 0.5 & 7 & 3.0 & \\
\hline \multicolumn{6}{|c|}{ Health Insurance } \\
\hline Yes & 395 & 98.8 & 226 & 97.4 & 0.2157 \\
\hline No & 5 & 1.25 & 6 & 2.6 & \\
\hline \multicolumn{6}{|c|}{ BMI Category } \\
\hline Underweight & 16 & 3.9 & 11 & 4.6 & $0.0601+$ \\
\hline Normal & 243 & 58.7 & 128 & 53.3 & \\
\hline Overweight & 101 & 24.4 & 51 & 21.3 & \\
\hline Obese & 54 & 13.0 & 50 & 20.8 & \\
\hline \multicolumn{6}{|c|}{ Cook for Self } \\
\hline Often & 192 & 48.0 & 96 & 41.4 & 0.1804 \\
\hline Sometimes & 150 & 37.5 & 104 & 44.8 & \\
\hline Never & 58 & 14.5 & 32 & 13.8 & \\
\hline \multicolumn{6}{|c|}{ Cooking Skills } \\
\hline Excellent & 105 & 26.3 & 47 & 20.3 & 0.3710 \\
\hline Good & 190 & 47.5 & 121 & 52.2 & \\
\hline Fair & 85 & 21.3 & 50 & 21.6 & \\
\hline \multirow[t]{2}{*}{ Poor } & 20 & 5.0 & 14 & 6.0 & \\
\hline & Mean & SD & Mean & SD & \\
\hline BMI & 24.72 & 0.24 & 25.57 & 0.39 & 0.2638 \\
\hline Age & 21.43 & 0.21 & 21.06 & 0.23 & 0.8116 \\
\hline
\end{tabular}




$\begin{array}{cccccc}\text { GPA } & 3.51 & 0.02 & 3.33 & 0.03 & <0.0001 \text { * } \\ \text { MES Score } & 10.58 & 0.06 & 12.33 & 0.14 & <0.0001 \text { * } \\ \text { CSS Score } & 36.72 & 0.32 & 46.61 & 0.50 & <0.0001^{*} \\ \text { APS Score } & 13.28 & 0.09 & 12.39 & 0.13 & <0.0001^{*}\end{array}$

Demographic data represented in frequency and percentages. Pearson Chi-square frequency and Wilcoxon analyses were performed. * $p<0.05,+p<0.07$. SD, standard deviation; BMI, body mass index; GPA, grade point average; MES, money expenditure scale; CSS, coping strategies scale; APS, academic progress scale.

Sample characteristics by food security status are presented in Table 1. Investigation of categorical sociodemographic variables with food security showed significant associations between food security status and academic year $(p=0.0130)$, self-reported health status $(p<0.0001)$, and housing $(p=0.0269)$. Specifically, food insecurity was associated with academic year and found to be at the highest prevalence during the sophomore $(46.0 \%)$ and junior (45.8\%) years with the lowest prevalence in graduate students (29.4\%). Students who lived off campus displayed higher prevalence of food insecurity (36.9\%) compared to those who lived on campus (30.5\%). Self-reported health status showed a higher proportion of food-insecure students who reported fair or poor health represented in Figure 1.

Figure 1. Percent of Health Status Category by Food Security Status among Students

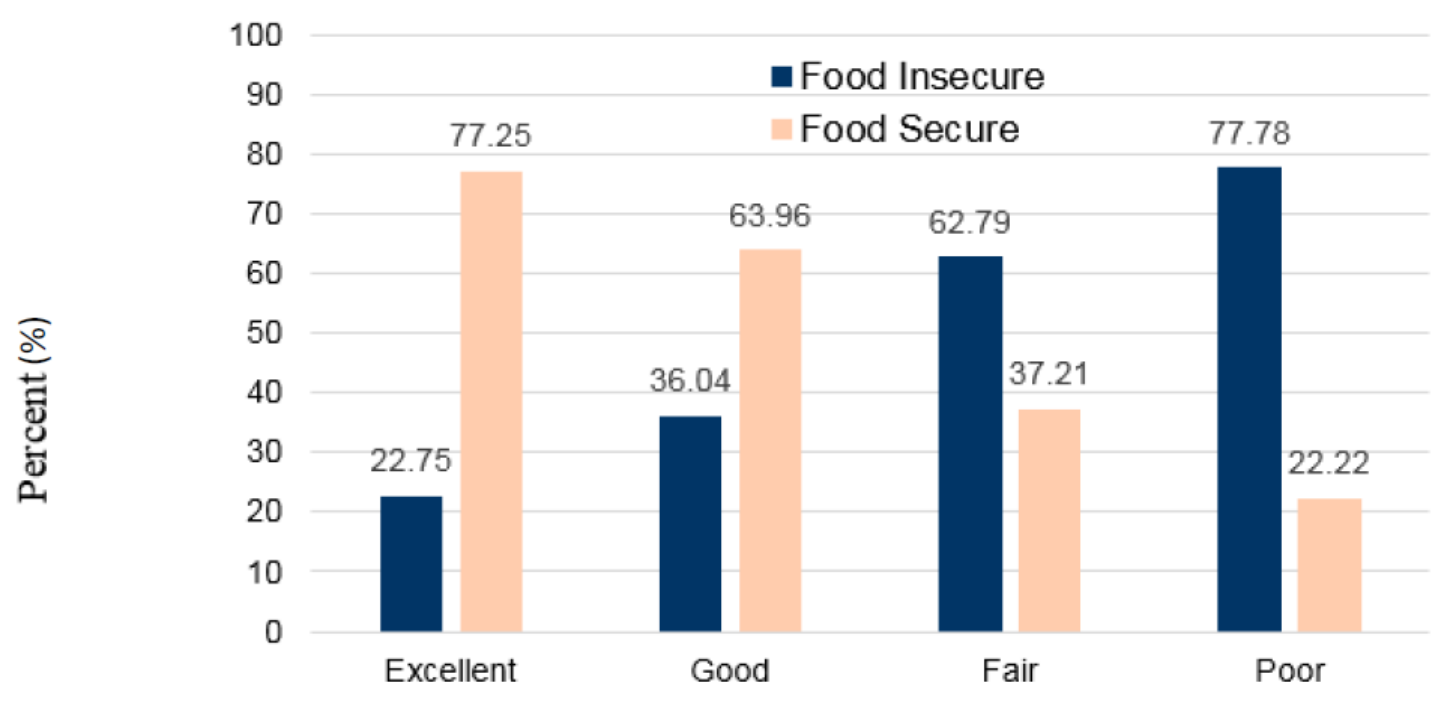

Health Status 
Association of health status and food security group showed a higher proportion of food-insecure students reported poor or fair health while food secure students reported good or excellent health. Chi-square $(p<0.0001)$.

Mean BMI was not significantly different between food secure and food-insecure students $(p=0.2636)$, however, BMI classification showed association that trended toward significance $(p=0.0601)$, with higher prevalence of obese classification in the food-insecure population than in the food secure population. Food insecurity status also showed significant differences in GPA as average GPA of food-insecure students was $3.33 \pm 0.03$ and average GPA of food secure students was $3.51 \pm 0.02(p<0.0001)$.

Significant relationships were found between food security status and MES, CSS, and APS scores ( $p<0.0001$ for all). Students who reported spending money on other items before purchasing food, as represented by high MES scores (odds ratio $(O R)=2.07 ; 95 \%$ $\mathrm{Cl}$ 1.81-2.38) and displayed more coping strategies for food had significantly higher odds of being food-insecure $(\mathrm{OR}=2.07 ; 95 \% \mathrm{Cl} 1.81-2.38$ and $\mathrm{OR}=1.20 ; 95 \% \mathrm{Cl} 1.16-1.23$, respectively). The odds of high academic progress scores ( $\mathrm{OR}=0.79 ; 95 \% \mathrm{Cl} 0.73-0.86)$ were inversely related to food insecurity.

All variables significant in simple analyses (MES, CSS, GPA, APS, school year, housing and health) and close to significant (BMI category) were entered in a full logistic regression model. Forward selection was used to identify the most important variables predictive of food insecurity. MES (OR $=1.44 ; 95 \% \mathrm{Cl} 1.24-1.67)$, CSS (OR $=1.17 ; 95 \%$ Cl 1.13-1.23), school year (specifically freshman vs. graduate student, $\mathrm{OR}=2.85 ; 95 \%$ $\mathrm{Cl} 1.36-5.97)$ and health $(\mathrm{OR}=2.88 ; 95 \% \mathrm{Cl} 1.54-5.41)$ remained significant predictors of food insecurity. MES and CSS were the best predictors of food insecurity based on $p$ values of Wald Chi-Square (data not shown) [180]. Results are shown in Table 2.

Table 2. Logistic Regression Model Predicting Food Insecurity in Students

\begin{tabular}{ccc}
\hline Variable & $\begin{array}{c}\text { Odds } \\
\text { Ratio }\end{array}$ & 95\% Confidence Interval \\
\hline MES Score & 1.44 & $1.24-1.67$ \\
CSS Score & 1.17 & $1.13-1.22$ \\
School Year & & \\
Freshman & 2.85 & $1.36-5.97$ \\
\hline
\end{tabular}




$\begin{array}{lll}\text { Sophomore } & 2.23 & 0.99-5.07 \\ \quad \text { Junior } & 1.94 & 0.95-3.96 \\ \quad \text { Senior } & 1.75 & 0.88-3.47 \\ \quad \text { Health } & & \\ \begin{array}{l}\text { Excellent/Good vs. } \\ \quad \text { Fair/Poor } \\ \text { GPA }\end{array} & 2.88 & 1.54-5.41 \\ & 0.65 & 0.40-1.06\end{array}$

Selection criteria for the model entry was $p<0.07$. Variables from simple analyses were entered into a forward selection multiple logistic regression model. MES, money expenditure scale; CSS, coping strategies scale; school year and health remained significant predictors of food security status. GPA, grade point average was not a significant predictor.

\section{Discussion}

To our knowledge, this study is the first to investigate the prevalence of food insecurity at a central Appalachian university and the second within the region all together. Along with McArthur et al. [26], this study provides a representation of food insecurity correlates in young adults attending a large Appalachian university and the relationships between food security and behavior (money expenditure, coping strategies and academic progress). Over one third of students (36.6\%) were food-insecure, with higher prevalence of food insecurity occurring in sophomore and junior year students, those who live off campus, and those reporting poor health. Food-insecure students displayed behaviors that differed from food secure students including spending more money on other items, engaging in more coping strategies to find food, and having lower academic success in the classroom.

The prevalence of food insecurity found in this study is consistent with previous studies that have determined food insecurity rates among college students are higher than the national average $[3,154]$. Studies show food insecurity rates ranging from $14 \%$ to $59 \%$ at universities with varying demographic locations and sample characteristics [3]. Within the Appalachian region, McArthur et al. [26], found a higher prevalence of food insecurity at $46.2 \%$ of student population, suggesting the increased need within the region.

Associations between food security and insecurity with covariates is consistent with some previous findings. The health of food-insecure students has been previously reported as being fair or poor when compared to food secure students, comparable with our results $[26-28,30]$. This could be attributed to the role access to food and dietary 
quality play on mental and physical heath [156, 162, 163, 168, 170]. Additionally, our study found that academic year of the student influenced food insecurity, with increased food-insecure populations occurring following the freshman year, similar to previous research [26, 181, 182]. Housing status has been conflicted in previous literature on influence on food insecurity, with some studies finding it plays a significant role, and others showing no differences in food security status by housing status [28, 110, 124]. This study found that housing, specifically living off campus, influenced the prevalence of food insecurity. The influence of academic year and housing are especially important as avenues for food insecurity interventions in at-risk populations. Additionally, both housing and academic year were more common in McArthur et al. [26], making them potential variables of interest throughout the Appalachian region.

Beyond correlates, this study investigated the money expenditure and coping behaviors used by university attending young adults. Students who spent more money on items such as substances or rent instead of food (higher MES score) were at higher odds of being food-insecure. There are possible explanations for this finding. First, many college students are new to financial independence and lack the skills necessary to manage money efficiently. This in turn could lead to deprioritizing food and, ultimately, to developing food insecurity. More specifically, with the limited income of many college students, it is possible that food and financial management skills can aid in the prevention of food insecurity [115]. Secondly, the increase in the cost of university tuition and decrease in subsidies for students may play a role in the spending habits of students and consequently lead to food insecurity. In this study, food-insecure students commonly displayed behavioral coping strategies to make ends meet and obtain food. This is consistent with previous studies showing college students often cut back on activities, changed eating habits, borrowed money, and even forwent purchasing school supplies as coping strategies in order to afford food [173]. The impact of coping on student success is equivocal with some, but not all, studies finding a relationship between use of coping strategies and academic success [183, 184]. Similar to our results, one study found reliance on coping strategies in college students as a predictor of academic achievement [148]. 
In the present study, academic achievement was assessed by the APS score which enumerates how the student rated their own overall progress in school including graduating on time, class attendance, attention span in class, and understanding of concepts taught in class. Food-insecure students displayed greater odds of receiving lower APS scores and lower GPA, representing poorer academic success. Food insecurity has been associated with increased behavioral problems and emotional burdens that can impact a student's success in academia [164]. In particular in the college population, food-insecure students are less likely to attend and perform well in class and more likely to withdraw from a course all together [33, 185]. Other studies confirm this association through GPA and have found that students with a GPA above 3.1 were 60\% less likely to be food-insecure [28] with another reporting food-insecure students having a mean GPA of 3.1 vs. 3.4 in food secure students [32].

\section{Limitations}

This cross-sectional study has limitations that must be noted. First, the use of a nonprobability sample from a single geographical, predominately Caucasian public university prevents generalizability to university populations such as universities outside the Appalachian region, community colleges, or private institutions, and those with ethnic diversity. Although respondents were disproportionally white, this is representative of demographics in the Appalachian region compared to other regions in the United States and can be interpreted as such [186]. Additionally, the cross-sectional design and nonprobability sample cannot set establishment of causation. Next, the self-report of measures may limit the validity of results and the inclusion of freshman may provide inconstancy within literature. McArthur et al. [26] excluded freshman from their sample due to the AFSS question referencing the previous 12 months. This has occurred within literature but is not consistent across studies within college students, therefore our sample included freshman based on the studies such as Bruening et al. [3]. Lastly, as a listserv for students was unavailable it is unknown how many students were exposed to the study and depict an accurate response rate. The response received is approximately $2.5 \%$ of 
the total student body, however the demographic characteristics collected are consistent with reports from the university on student body characteristics.

\section{Conclusion}

This study sheds light on the prevalence of food insecurity among young adults attending a large university in central Appalachia. Further, the study reveals the impact food insecurity can have on students' behaviors with increased money expenditure and coping strategies and decreased academic progress in food-insecure students. The behaviors of young adult college students are essential for success and degree retention, with numerous students leaving college without successful degree completion, causing a financial burden to both the university and the student [185]. Providing for the basic needs of students and fostering positive behaviors would promote student success and are important avenues for addressing food insecurity on college campuses. University administrators and public health experts can benefit from this information through targeted interventions for promoting academic success. 


\section{Chapter V: Food Insecurity Impacts Behavior of College Students at 10 Higher Education Institutions in the Appalachian and Southeastern Regions}




\section{ABSTRACT}

\section{Money Expenditure, Coping and Academic Behaviors Among Food Insecure College Students at 10 Higher Education Institutes in the Appalachian and Southeastern Regions}

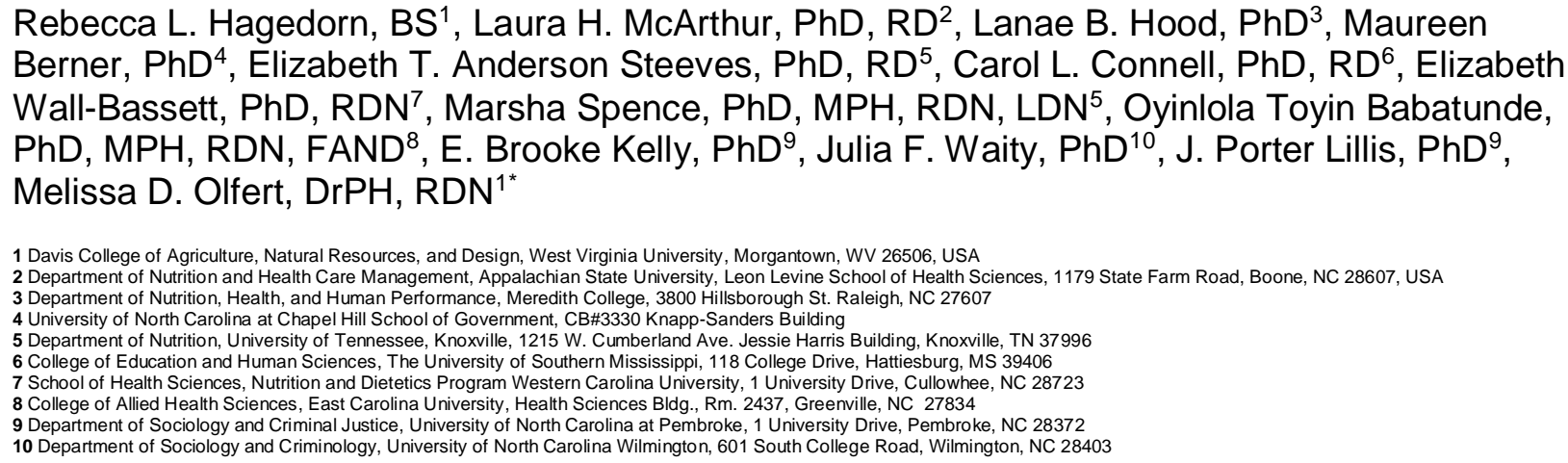

1 Davis College of Agriculture, Natural Resources, and Design, West Virginia University, Morgantown, WV 26506, USA

2 Department of Nutrition and Health Care Management, Appalachian State University, Leon Levine School of Health Sciences, 1179 State Farm Road, Boone, NC 28607 , USA

3 Department of Nutrition, Health, and Human Performance, Meredith College, 3800 Hillsborough St. Raleigh, NC 27607

4 University of North Carolina at Chapel Hill School of Government, CB\#3330 Knapp-Sanders Building

5 Department of Nutrition, University of Tennessee, Knoxville, 1215 W. Cumberland Ave. Jessie Harris Building, Knoxville, TN 37996

6 College of Education and Human Sciences, The University of Southern Mississippi, 118 College Drive, Hattiesburg, MS 39406

7 School of Health Sciences, Nutrition and Dietetics Program Western Carolina University, 1 University Drive, Cullowhee, NC 28723

8 College of Allied Health Sciences, East Carolina University, Health Sciences Bldg., Rm. 2437, Greenville, NC 27834

9 Department of Sociology and Criminal Justice, University of North Carolina at Pembroke, 1 University Drive, Pembroke, NC 28372

10 Department of Sociology and Criminology, University of North Carolina Wilmington, 601 South College Road, Wilmington, NC 28403

Background: A number of studies have measured college student food insecurity prevalence higher than the national average, however, no multi-campus regional study among students at 4-year institutions has occurred.

Objective: The objectives were to determine the prevalence of food insecurity among college students in the Appalachian and Southeastern regions and determine the association between food insecurity status and money expenditures, coping strategies, and academic performance among a regional sample of college students.

Methods: This regional, cross-sectional, online survey study included 13,642 college students at 10 public universities. Food insecurity status was measured using the United States Department of Agriculture Adult Food Security Survey (USDA AFSS). The outcomes were associations between food insecurity and behaviors using the Money Expenditure Scale (MES), Coping Strategy Scale (CSS) and Academic Progress Scale (APS). Forward selection logistic regression model was used with all variables significant from individual Pearson Chi-square and Wilcoxon analyses. Significance criterion alpha for all tests was 0.05 .

Results: Prevalence of food insecurity at the universities ranged from $22.4-51.8 \%$ with an average prevalence of $30.5 \%$ for the full sample. From the forward selection logistic regression model, MES (OR $=1.47 ; 95 \% \mathrm{Cl} 1.40-1.55)$, CSS (OR $=1.19 ; 95 \% \mathrm{Cl} 1.18-$ 1.21 ), and APS (OR $=0.95 ; 95 \% \mathrm{Cl} 0.91-0.99$ ) behaviors remained significant predictors of food insecurity. Grade point average (GPA), academic year, health, race/ethnicity, financial aid, cooking frequency, and health insurance also remained significant predictors of food security status.

Conclusions: Food insecurity prevalence was higher than the national average. Food insecure college students were more likely to display high money expenditures and coping behaviors, and poor academic performance.

Keywords: college students, food insecurity, money spending, coping strategies, academic performance 


\section{Introduction}

Food insecurity is defined as the inability to secure consistent access to a sufficient quantity of affordable, nutritious food to sustain a healthy lifestyle. Nationally, $11.8 \%$ of households were food insecure in 2017, equating to 40 million Americans living in food insecure conditions [2]. The prevalence of food insecurity has been associated with factors including poor socioeconomic status [155], presence of children in the household [2,164], and minority ethnicity [187]. A large body of work has shown the negative impacts food insecurity can have on both youth and adults alike. Food insecurity has been shown to be linked with lower academic performance and increased behavioral issues at school $[26,144,148,165,166]$, higher rates of physical and mental health disorders [60,120,167, 169, 188-192], higher rates of stigma experienced by individuals [193, 194], and poor diet quality [26, 47, 120, 160, 195, 196].

In recent years it has been identified that a population largely affected by food insecurity is college students $[3,21]$ with rates of food insecurity on college campuses being identified as high as $59 \%[3,21,22]$. Many studies have examined correlates of college food insecurity and find a number of the aforementioned health and behavioral effects of food insecurity also present in the college population, including risk of physical and mental illness $[21,29,120,144]$ and poor diet quality $[21,26,120]$. These detriments of food insecurity can be especially harmful to college students who experience high stress, adjustment, and pressure to succeed [197, 198]. These circumstances can lead to the development of negative behaviors among food insecure college students, such as poor spending behaviors, unhealthy ways of coping, and poor academic performance.

To date, these behaviors have only been investigated in a few smaller studies on a single campus $[26,144]$. Most college food insecurity studies are based on individual universities with few large-scale food insecurity studies completed across multiple states and regions [36, 185, 199]. Research thus far, however, generally fails to capture students from 4-year institutions, and instead focuses primarily on community colleges $[185,199]$. While community colleges are of equal importance, a majority of students in the United States are enrolled in 4-year institutions [200]. The demographics and lifestyles of these 4-year students often differ from those who are enrolled at 
community colleges [201, 202], making it important to investigate food insecurity among multiple 4-year institutions as well. For this reason, the relationship between food insecurity and expenditure behavioral choices, coping mechanisms and the academic performance of college students needs to be examined at a larger scale.

Lastly, regions of the United States including the Appalachian and Southern regions [2] are disproportionately affected by food insecurity and have higher rates of health disparities [4, 5]. Variables including environmental, cultural, social, and economic factors differ from region to region, and significantly influence how and when people eat [203]. Geographic variability is lacking in the college food insecurity literature, especially for regions that are high risk for food insecurity. It is apparent that food insecurity can have detrimental effects on the physical and mental health of college students [3,21], but the magnitude of these effects has not been largely studied within the Appalachian and Southeastern regions of the United States [26, 144].

The present study has the following aims: 1) determine the prevalence of food insecurity among college students in the Appalachian and Southeastern regions of the United States and 2) investigate relationship between food insecurity status and money expenditures, coping strategies, and academic performance among a regional sample of college students. These aims will help to understand if college student food insecurity is high within this geographic region and justify if there is a need for state and federal policies and programs aimed at facilitating an adequate diet for this population.

\section{Methods}

Study Design

This study used a cross sectional design to capture food insecurity among young adults attending 10 public universities in the Appalachian and Southeastern Regions between Spring 2016 and Spring 2018. For the purposes of this article, participating universities have been de-identified and will be referenced as University 1-10. At all universities, participants were currently enrolled college students. A convenience sample of undergraduate and graduate students were recruited from each university. Universities 1, 2, 5, and 6 recruited via student listserv with all enrolled students receiving the survey link. Universities 3 and 7 recruited through campus wide 
announcements, with university 3 also utilizing flyers around campus. University 4 recruited through professors, with all active professors being emailed and asked to share the survey with students. All universities distributed the survey for student completion via Qualtrics (Qualtrics, Provo, UT), except one university which used CampusLabs (CampusLabs, Buffalo, NY). Both platforms are anonymous, online questionnaire programs. Students were required to complete informed consent online prior to survey initiation. Students who denied the consent were thanked for their time and exited from the link. Student incentive value varied at universities, but all included a random chance for incentive after survey completion. Incentive value ranged from $\$ 25$ $\$ 100$ gift cards that could be used universally (i.e. American Express); two universities only provided the incentives strictly for the campus dining halls; one university provided Amazon gift cards. Recruitment and incentive methods are available in Table 1. This study was approved by the Institutional Review Board at each university.

Table 1: Methodologies used for Student Recruitment at 10 Universities 


\begin{tabular}{|c|c|c|c|c|}
\hline University & Enrollment & Recruitment & Incentive & Response Rate \\
\hline $\begin{array}{l}\text { University } \\
1\end{array}$ & 10,805 & $\begin{array}{l}\text { Email directly to all } \\
\text { students }\end{array}$ & $\mathrm{N} / \mathrm{A}$ & $12.7 \%$ \\
\hline $\begin{array}{l}\text { University } \\
2\end{array}$ & 28,321 & $\begin{array}{l}\text { Email directly to all } \\
\text { students via listserv with } \\
\text { reminders }\end{array}$ & $\begin{array}{l}\text { Chance to win one of } \\
\text { eight } \$ 100 \text { gift cards }\end{array}$ & $12.5 \%$ \\
\hline $\begin{array}{l}\text { University } \\
3\end{array}$ & 13,331 & $\begin{array}{l}\text { Flyers around campus, } \\
\text { announced in campus } \\
\text { email }\end{array}$ & $\begin{array}{l}\text { Chance to win one of } \\
\text { five } \$ 25 \text { campus dining } \\
\text { gift cards }\end{array}$ & $\begin{array}{l}\text { Unknown due to } \\
\text { recruitment } \\
\text { methods }\end{array}$ \\
\hline $\begin{array}{l}\text { University } \\
4\end{array}$ & 31,514 & $\begin{array}{l}\text { Email to all professors to } \\
\text { pass on to students }\end{array}$ & $\begin{array}{l}\text { Chance to win a } \$ 100 \\
\text { gift card }\end{array}$ & $\begin{array}{l}\text { Unknown due to } \\
\text { recruitment } \\
\text { methods }\end{array}$ \\
\hline $\begin{array}{l}\text { University } \\
5\end{array}$ & 17,932 & Email to random students & $\begin{array}{l}\text { Chance to win one of } \\
\text { two } \$ 100 \text { gift cards }\end{array}$ & $20.3 \%$ \\
\hline $\begin{array}{l}\text { University } \\
6\end{array}$ & 29,469 & $\begin{array}{l}\text { Email directly to all } \\
\text { students via listserv with } \\
\text { reminders }\end{array}$ & $\begin{array}{l}\text { Chance to win a } \$ 100 \\
\text { gift card }\end{array}$ & $18.8 \%$ \\
\hline $\begin{array}{l}\text { University } \\
7\end{array}$ & 21,127 & $\begin{array}{l}\text { Announced in campus } \\
\text { email and flyers around } \\
\text { campus }\end{array}$ & $\begin{array}{l}\text { Chance to win a } \$ 50 \\
\text { gift card }\end{array}$ & $\begin{array}{l}\text { Unknown due to } \\
\text { recruitment } \\
\text { methods }\end{array}$ \\
\hline $\begin{array}{l}\text { University } \\
8\end{array}$ & 7,137 & $\begin{array}{l}\text { Email directly to all } \\
\text { students }\end{array}$ & $\begin{array}{l}\text { Chance to win one of } \\
\text { four } \$ 25 \text { Amazon gift } \\
\text { cards }\end{array}$ & $9.4 \%$ \\
\hline
\end{tabular}




\begin{tabular}{|c|c|c|c|c|}
\hline $\begin{array}{l}\text { University } \\
9\end{array}$ & 28,962 & Email to random students & $\begin{array}{l}\text { Chance to win a } \$ 50 \\
\text { gift card }\end{array}$ & $12.3 \%$ \\
\hline $\begin{array}{l}\text { University } \\
10\end{array}$ & 16,886 & Email to random students & $\begin{array}{l}\text { Chance to win one of } \\
\text { five } \$ 25 \text { campus dining } \\
\text { gift cards }\end{array}$ & $14.9 \%$ \\
\hline
\end{tabular}

\section{Measures}

All universities were involved in the development of a 73-item survey to investigate the prevalence and correlates of food insecurity among college students, as well as associated behavioral characteristics. All variables were self-reported, and the survey took approximately 20-30 minutes to complete.

Food Insecurity: Student food insecurity status was measured using the validated 10-item United States Department of Agriculture Adult Food Security Survey (USDA AFSS) [204]. Students responded to questions regarding their ability to afford and maintain a source of food with questions such as "The food that I bought just didn't last, and I didn't have money to get more", "I couldn't afford to eat balanced meals", and "In the last 12 months, did you ever not eat for a whole day because there wasn't enough money for food". Food insecurity status was determined by the USDA's protocol [72] where zero affirmative answers reflected high food security, 1-2 = marginal food security, 3-5 = low food security, and 6-10 = very low food security. Those who scored in the high or marginal food secure categories were combined and considered food secure and those who scored in the low and very low food secure categories were combined and considered food insecure.

Behavioral Scales: Three behavioral measures were used: an 8-item money expenditure scale (MES), 29-item coping strategies scale (CSS) and a 4-item academic progress scale (APS). The MES measured spending behaviors of students and has been used in previous college food insecurity research [26, 144]. This scale assessed how often in the past 12 months students spent money on other items rather than spending the money on food, specifically assessing the monetary purchases of items including substance purchases (i.e., alcohol, cigarettes, and recreational drugs), transportation (i.e., public transportation fees, car repairs, and gasoline), pet care, and 
tattoos. Student answer choices were never, sometimes, and often. Responses were scored on a 3-point scale with 1 point representing "never", 2 points = "sometimes," and 3 points = "often" responses. Total scores for MES could range from 8 to 24 points. Higher MES scores represent students spending more money on other items rather than using the money to buy food.

The CSS has also been used in previous college food insecurity research [26] and was developed with guidance from the food insecurity literature [176-178]. The CSS measured how often students used coping strategies and included strategies that addressed food intake/access, saving, support, and selling. Food intake/access questions asked if students ate in excess when food was plentiful, took food home from on-campus dining, ate less healthy options and purchased processed food, obtained food from a dumpster or trash, or bartered services/items for food. The saving topic included questions regarding if students took fewer classes, used less utilities, shared responsibilities such as housing or meals with others, stretched meals, used coupons and planned meals, or spent less on medications and medical appointments. Support questions included if students participated in a research study/clinical trial for extra money for food, borrowed money or visited family for food, attended functions with free food or where you "pay when you can", obtained food from a food bank, food pantry or assistance program (e.g., Supplemental Nutrition Assistance Program (SNAP), Women, Infants and Children (WIC), etc.), or held one or more part/full time jobs or used a credit card to buy food. Lastly, the selling topic included questions to inquire about if students ever sold items, including textbooks, personal possessions, blood/plasma or sperm/eggs, to obtain food. Similar to the MES, the CSS answer choices were never, sometimes, and often. Responses were scored on a 3-point scale with 1 point representing "never", 2 points = "sometimes," and 3 points = "often" responses. CSS scores could range from 29 to 87 points with higher scores indicating use of more coping strategies and more frequent use of these behaviors

The APS measured students perceived academic behaviors regarding class attendance and attention span, comprehension of class concepts, and progression towards graduating on time [26]. APS answer choices were excellent, good, fair, and poor and were scored on a 4-point scale with 4 points assigned for the "excellent," 3 = "good," 
2 = "fair," and $1=$ "poor" responses. Therefore, scores on the APS could range from 4 to 16 points, with higher scores representing students who displayed better academic performance behaviors. Grade point average (GPA) was also captured for an additional measure of academic performance.

Sociodemographic and Health Characteristics: The remaining variables captured student demographics, economic and health status, and culinary skills. Demographics included gender (male/female), age, marital status (married/not married), race (white/minority), dependents (has dependents/does not have dependents), student status (part time/full time), academic year (freshman, sophomore, junior, senior, graduate), housing (on campus/off campus), international student (yes/no), car ownership (has car/does not have car), and utilization of public transportation (uses public transportation/does not use public transportation). Economic variables included financial aid receipt (receives financial aid/does not receive financial aid), employment status (employed/unemployed), and meal plan (has a meal plan/does not have a meal plan). Income was also assessed but was excluded from analysis due to the high variability in student response. Health variables included self-reported health status (excellent or good/fair or poor), health insurance (has health insurance/does not have health insurance) and body mass index (BMI). BMI was calculated from self-reported height and weight as kilograms per meter squared. Two remaining questions with a culinary focus asked students how often they cooked for themselves (sometimes/often/never) and how they would rate their cooking skills (excellent or good/fair or poor).

\section{Statistical Analyses}

Descriptive statistics were computed for all demographic, economic, health, support and dietary variables as appropriate. As aforementioned, food insecurity status was determined in accordance with the Guide to Measuring Household Food Security scoring system [72]. Pearson Chi-square frequency analyses were used to determine associations between each variable and university. Pearson Chi-square frequency analyses were also used to determine bivariate associations between food secure and 
food insecure students with all variables to assess which variables to include in the full model. MES, CSS, APS, age, GPA and BMI were assessed as continuous variables and Wilcoxon analyses were used due to lack of normality. All variables that showed significant association between food security status were used in the full regional model. A forward selection multivariate logistic regression was used in a full model to predict food insecurity. Forward selection was used to identify the most important variables predictive of food insecurity. Data were analyzed using JMP and SAS software (JMP®, Version Pro 12.2, SAS Institute Inc., Cary, NC, Copyright (2015; SAS®, Version 9.4, SAS Institute Inc., Cary, NC, Copyright @2002-2012). Significance criterion alpha for all tests was 0.05 .

\section{Results}

\section{Student Demographics}

The survey was completed by 14,293 students across all 10 universities. Data from all schools were combined and cleaned by two researchers at one university for consistency. Due to food insecurity being the primary outcome, all responses that did not have a complete response on the USDA AFSS ( $n=651$ ) were excluded from analysis. A final sample of 13,642 was used for data analysis of aim 1. Sample characteristics by university are presented in Table 2 . 
University 8

$$
n(\%)
$$

$n(\%)$

$n(\%)$

$n(\%)$

University

University 10

\section{Food Security Status}

Food Secure

Food Insecure

Gender

Male

Female

Race

White

Minority

Marital Status

Married

Not Married

\section{Dependents}

Yes

No

\section{Academic Year}

Freshman

Sophomore

Junior

Senior

\begin{tabular}{|c|c|c|c|c|c|c|c|c|c|}
\hline $212(61.5 \%)$ & $3138(70.3 \%)$ & $27(48.2 \%)$ & $439(63.4 \%)$ & $588(53.8 \%)$ & $4086(77.3 \%)$ & $360(63.3 \%)$ & $127(52.7 \%)$ & $269(65.0 \%)$ & $271(53.4 \%)$ \\
\hline$\%$ & $1325(29.7 \%)$ & $29(51.8 \%)$ & $253(36.6 \%)$ & $505(46.2 \%)$ & $1176(22.4 \%)$ & $209(36.7 \%)$ & $114(47.3 \%)$ & $145(35.0 \%)$ & $236(46.6 \%)$ \\
\hline
\end{tabular}

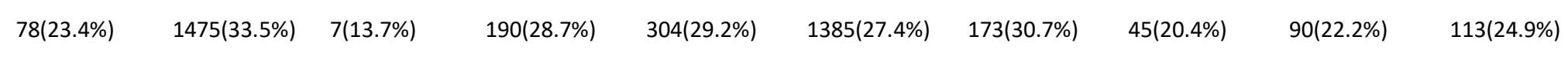

$255(76.6 \%)$

$2925(66.5 \%) \quad 44(86.3 \%)$

$472(86.3 \%) \quad 739(70.8 \%)$

$3675(72.6 \%) \quad 391(69.3 \%)$

$175(79.6 \%)$

$315(77.8 \%)$

$340(75.1 \%)$

$276(84.2 \%) \quad 3551(81.7 \%) \quad 39(76.5 \%)$

$552(87.3 \%) \quad 925(88.4 \%)$

$3459(68.8 \%) \quad 421(74.9 \%)$

$93(42.3 \%)$

$268(66.3 \%)$

$357(80.4 \%)$

$52(15.9 \%)$

$798(18.3 \%) \quad 12(23.5 \% \quad 80(12.7 \%)$

$121(11.6 \%)$

$1570(31.2 \%) \quad 141(25.1 \%)$

$127(57.7 \%)$

$136(33.7 \%) \quad 87(19.6 \%)$

$75(22.5 \%) \quad 469(10.6 \%) \quad 8(15.7 \%)$

$38(5.7 \%)$

$51(4.8 \%)$

$610(12.0 \%) \quad 57(10.0 \%)$

$28(12.8 \%)$

$35(8.6 \%)$

$38(8.4 \%)$

$258(77.5 \%) \quad 3964(89.4 \%) \quad 43(84.3 \%)$

$627(94.3 \%)$

1002(95.2\%)

4488(88.0\%) 511(90.0\%)

191(87.2\%)

372(91.4\%)

$413(91.6 \%)$

$40(12.0 \%)$

201(4.5\%) $\quad 7(13.7 \%)$

$15(2.3 \%)$

20(1.9\%)

$220(4.3 \%) \quad 26(4.6 \%)$

23(10.4\%)

23(5.7\%)

17(3.7\%)

293(88\%)

$4232(95.5 \%) \quad 44(86.3 \%)$

650(97.7\%)

1035(98.1\%) 4881(95.7\%) 540(95.4\%)

197(89.6\%)

$384(94.3 \%)$

437(96.3\%)

$<0.0001$

$\begin{array}{lccccccccc}8(2.4 \%) & 1089(24.9 \%) & 9(17.7 \%) & 154(23.5 \%) & 18(1.7 \%) & 841(16.6 \%) & 117(20.7 \%) & 42(19.2 \%) & 86(21.5 \%) & 140(21.3 \%) \\ 74(22.7 \%) & 689(15.7 \%) & 8(15.7 \%) & 87(13.3 \%) & 297(28.3 \%) & 650(12.9 \%) & 113(20.1 \%) & 38(17.3 \%) & 82(20.5 \%) & 70(15.6 \%) \\ 80(24.5 \%) & 743(17.0 \%) & 10(19.6 \%) & 121(18.5 \%) & 270(25.7 \%) & 757(15.0 \%) & 121(21.5 \%) & 55(25.1 \%) & 88(22.0 \%) & 91(20.3 \%) \\ 82(25.2 \%) & 684(15.7 \%) & 6(11.7 \%) & 155(23.7 \%) & 313(29.8 \%) & 753(14.9 \%) & 96(17.0 \%) & 65(29.7 \%) & 127(31.8 \%) & 97(21.6 \%)\end{array}$

$<0.0001$

$<0.0001$

$<0.0001$

$<0.0001$

$<0.0001$ 
Graduate Student

International Student

Yes

No

\section{Student Status}

Part Time

Full Time

Employment

Unemployed

Employed

\section{Housing}

On Campus

Off Campus

\section{Car Ownership}

Yes

No

Use of Public

\section{Transportation}

Yes

No
$82(25.2 \%) \quad 1162(26.6 \%) \quad 18(35.3 \%$

138(21.1\%)

$2069(40.7 \%)$

$117(20.7 \%)$

19(8.7\%)

$17(4.2 \%)$

$50(11.2 \%)$

$1(0.3 \%) \quad 246(5.6 \%) \quad 2(3.9 \%)$

$35(5.3 \%) \quad 8(0.8 \%)$

$302(5.9 \%) \quad 23(4.1 \%)$

$1(0.4 \%)$

$5(1.2 \%)$

$329(99.7 \%)$

4151(94.4\%) $\quad 49(94.7 \%)$

$621(94.7 \%)$

1045(99.2\%)

4785(94.1\%) $\quad$ 540(95.9\%)

$219(99.6 \%)$

$402(98.8 \%$

435(97.1\%)

$47(14.4 \%) \quad 311(7.1 \%) \quad 5(9.8 \%)$

$46(4.4 \%)$

$266(5.2 \%)$

$38(6.7 \%)$

$18(8.3 \%)$

$36(8.0 \%)$

$280(85.6 \%) \quad 4055(92.9 \%) \quad 46(90.2 \%)$

$615(97.5 \%)$

1005(95.6\%)

$527(93.3 \%)$

$200(91.7 \%)$

$383(94.3 \%)$

$412(92.0 \%)$

$<0.0001$

$97(29.6 \%) \quad 1770(40.6 \%) \quad 13(25.5 \%)$

$277(43.8 \%)$

$386(36.9 \%)$

2005(39.6\%)

$264(46.5 \%)$

$88(40.0 \%)$

$168(41.5 \%)$

175(39.2\%)

$231(70.4 \%) \quad 2585(59.4 \%) \quad 38(74.5 \%)$

$355(56.2 \%)$

$660(63.1 \%)$

$3055(60.4 \%) \quad 304(53.5 \%)$

$132(60.0 \%)$

237(58.5\%)

$271(60.8 \%)$

$<0.0001$

$109(33.2 \%) \quad 1482(34.0 \%) \quad 19(37.2 \%)$

$203(32.1 \%) \quad 253(24.2 \%)$

$1837(36.2 \%) \quad 179(31.5 \%)$

102(47.2\%)

$213(47.8 \%)$

$219(66.8 \%)$

$2876(66.0 \%) \quad 32(62.8 \%)$

429(67.9\%) 794(75.8\%)

$3232(63.8 \%) \quad 389(68.5 \%)$

$114(52.8 \%)$

$286(70.3 \%)$

$233(52.2 \%)$

$<0.0001$

$297(90.6 \%) \quad 3645(83.7 \%) \quad 48(94.1 \%)$

$452(71.5 \%)$

$877(83.8 \%)$

$3293(65.0 \%) \quad 501(88.5 \%)$

$163(75.5 \%)$

$323(79.6 \%)$

$358(80.8 \%)$

$180(28.5 \%) \quad 170(16.2 \%)$

$1772(35.0 \%) \quad 65(11.5 \%)$

$53(24.5 \%)$

$83(20.4 \%)$

$85(19.2 \%)$

$<0.0001$

\begin{tabular}{|c|c|c|c|c|c|c|c|c|c|}
\hline $34(10.4 \%)$ & $1287(29.6 \%)$ & $0(0.0 \%)$ & $401(63.4 \%)$ & $664(63.5 \%)$ & $3695(73.0 \%)$ & $136(24.1 \%)$ & $6(2.8 \%)$ & $205(50.5 \%)$ & $89(20.1 \%)$ \\
\hline $294(89.6 \%)$ & $3068(70.4 \%)$ & $51(100.0 \%)$ & $231(36.6 \%)$ & $383(36.5 \%)$ & $1367(27.0 \%)$ & $429(75.9 \%)$ & $208(97.2 \%)$ & $201(49.5 \%)$ & $354(79.9 \%)$ \\
\hline
\end{tabular}




\section{Financial Aid}

$<0.0001$

Yes

223(68.0\%)

$3128(73.2 \%) \quad 47(92.2 \%)$

$508(80.4 \%)$

674(64.5\%)

$3266(64.5 \%)$

$422(64.4 \%)$

$164(76.6 \%)$

$280(69.1 \%)$

295(67.3\%)

$1144(26.8 \%) \quad 4(7.8 \%)$

124(19.6\%)

$371(35.5 \%)$

$1797(35.5 \%) \quad 145(25.6 \%)$

50(23.4\%)

125(30.9\%)

$143(32.7 \%)$ 
Food insecurity prevalence at the universities ranged from 22.4 to $51.8 \%$ with an average food insecurity prevalence of $30.5 \%$ for the full sample. Individual university food insecurity rates are as follows: University $1: 38.6 \%$, University $2: 29.7 \%$, University 3: $51.8 \%$, University 4: $36.6 \%$, University 5: $46.2 \%$, University 6: $22.3 \%$, University 7 : 36.7\%, University 8: 47.3\%, University 9: $35.0 \%$, University 10: 46.6\%. More specific food insecurity status detail is provided in Table 3.

Table 3: Food Security Status Categorization for Students at 10 Universities

\begin{tabular}{|c|c|c|c|c|}
\hline University (n) & $\begin{array}{l}\text { High Food } \\
\text { Security } \\
n(\%)\end{array}$ & $\begin{array}{c}\text { Marginal Food } \\
\text { Security } \\
n(\%)\end{array}$ & $\begin{array}{c}\text { Low Food } \\
\text { Security } \\
n(\%)\end{array}$ & $\begin{array}{c}\text { Very Low Food } \\
\text { Security } \\
n(\%)\end{array}$ \\
\hline $\begin{array}{c}\text { University } 1 \\
\text { (345) }\end{array}$ & $145(42.0)$ & $67(19.4)$ & $62(18.0)$ & $71(20.6)$ \\
\hline $\begin{array}{c}\text { University } 2 \\
(4463)\end{array}$ & $2132(47.8)$ & $1006(22.5)$ & $626(12.0)$ & $699(15.7)$ \\
\hline $\begin{array}{c}\text { University } 3 \\
\text { (56) }\end{array}$ & $16(28.6)$ & $11(19.6)$ & $16(28.6)$ & $13(23.2)$ \\
\hline $\begin{array}{c}\text { University } 4 \\
(692)\end{array}$ & $236(34.1)$ & 209 (29.3) & 115 (16.6) & 138 (19.9) \\
\hline $\begin{array}{c}\text { University } 5 \\
(1093)\end{array}$ & $337(30.8)$ & $251(30.0)$ & $240(22.0)$ & 265 (24.2) \\
\hline $\begin{array}{c}\text { University } 6 \\
(5262)\end{array}$ & 2939 (55.9) & $1147(21.8)$ & $663(12.6)$ & $513(9.7)$ \\
\hline $\begin{array}{c}\text { University } 7 \\
(569)\end{array}$ & $202(35.5)$ & $158(27.8)$ & 107 (18.8) & $102(17.9)$ \\
\hline $\begin{array}{c}\text { University } 8 \\
\text { (241) }\end{array}$ & $72(29.9)$ & $55(22.8)$ & $76(15.8)$ & $76(31.5)$ \\
\hline $\begin{array}{c}\text { University } 9 \\
\text { (414) }\end{array}$ & $153(37.0)$ & $116(28.0)$ & $66(15.9)$ & $79(19.1)$ \\
\hline $\begin{array}{c}\text { University } 10 \\
(507)\end{array}$ & $176(34.7)$ & $95(18.7)$ & $111(21.9)$ & $125(24.7)$ \\
\hline
\end{tabular}

Regional Analysis 
For full regional analysis, University $2(n=4,463)$ omitted CSS questions from their survey and was consequently excluded in the full model. Additionally, responses from each of the universities that were missing data from one of the behavioral scales $(n=853)$, were excll Table 4: Characteristic of Respondents for Regional Analysis and 2, the investigation of foom Correlations with Food Security Status

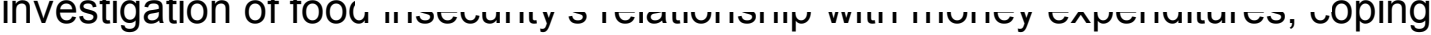
strategies, and academic performance. Relationship between all variables and food security status is presented in Table 4.

\begin{tabular}{|c|c|c|c|c|c|}
\hline \multirow[t]{2}{*}{ Variable } & \multicolumn{2}{|c|}{ Food Secure } & \multicolumn{2}{|c|}{ Food-insecure } & \multirow{2}{*}{$p$-Value } \\
\hline & $n$ & $\%$ & $n$ & $\%$ & \\
\hline \multicolumn{6}{|c|}{ Total Population } \\
\hline & 6379 & 69.5 & 2800 & 30.5 & \\
\hline \multicolumn{6}{|c|}{ Gender } \\
\hline Male & 1641 & 18.7 & 744 & 8.4 & \multirow{2}{*}{0.2434} \\
\hline Female & 4490 & 51.1 & 1916 & 21.8 & \\
\hline \multicolumn{6}{|c|}{ Ethnicity } \\
\hline White & 4573 & 52.5 & 1817 & 20.8 & \multirow{2}{*}{$<0.0001$} \\
\hline Minority & 1496 & 17.2 & 830 & 9.5 & \\
\hline \multicolumn{6}{|c|}{ Student Status } \\
\hline Part Time & 370 & 4.2 & 125 & 1.5 & \multirow{2}{*}{0.0118} \\
\hline Full Time & 5748 & 65.4 & 2540 & 28.9 & \\
\hline \multicolumn{6}{|c|}{ Marital Status } \\
\hline Not Married & 5393 & 61.0 & 2512 & 28.4 & \multirow{2}{*}{$<0.0001$} \\
\hline Married & 764 & 8.6 & 176 & 2.0 & \\
\hline \multicolumn{6}{|c|}{ Dependents } \\
\hline Has Dependents & 266 & 3.0 & 125 & 1.4 & \multirow[t]{2}{*}{0.5000} \\
\hline No Dependents & 5895 & 66.6 & 2566 & 29.0 & \\
\hline \multicolumn{6}{|c|}{ School Year } \\
\hline Freshman & 1072 & 12.2 & 343 & 3.9 & \multirow{5}{*}{$<0.0001$} \\
\hline Sophomore & 891 & 10.2 & 528 & 6.0 & \\
\hline Junior & 977 & 11.2 & 616 & 7.0 & \\
\hline Senior & 1054 & 12.0 & 640 & 7.3 & \\
\hline Graduate Student & 2107 & 24.0 & 544 & 6.2 & \\
\hline \multicolumn{6}{|c|}{ International Student } \\
\hline Yes & 282 & 3.2 & 108 & 1.2 & \multirow{2}{*}{0.2600} \\
\hline No & 5855 & 66.4 & 2570 & 29.2 & \\
\hline \multicolumn{6}{|c|}{ Car Ownership } \\
\hline Yes & 4415 & 50.4 & 1897 & 21.7 & 0.2611 \\
\hline
\end{tabular}




\begin{tabular}{|c|c|c|c|c|c|}
\hline No & 1678 & 19.2 & 764 & 8.7 & \\
\hline \multicolumn{6}{|c|}{ Use Public Transportation } \\
\hline Yes & 3638 & 41.6 & 1592 & 18.2 & \multirow[t]{2}{*}{0.8523} \\
\hline No & 2453 & 28.1 & 1064 & 40.1 & \\
\hline \multicolumn{6}{|c|}{ Housing } \\
\hline On Campus & 2114 & 24.1 & 3987 & 45.5 & \multirow[t]{2}{*}{0.9802} \\
\hline Off Campus & 922 & 10.5 & 1741 & 19.9 & \\
\hline \multicolumn{6}{|c|}{ Employment Status } \\
\hline Unemployed & 2535 & 29.0 & 938 & 10.7 & \multirow{2}{*}{$<0.0001$} \\
\hline Employed & 3559 & 40.6 & 1724 & 19.7 & \\
\hline \multicolumn{6}{|c|}{ Financial Aid } \\
\hline Yes & 3883 & 44.4 & 1996 & 22.8 & \multirow[t]{2}{*}{$<0.0001$} \\
\hline No & 2205 & 25.2 & 659 & 7.6 & \\
\hline \multicolumn{6}{|c|}{ Meal Plan } \\
\hline Yes & 1985 & 22.7 & 887 & 10.1 & \multirow[t]{2}{*}{0.4518} \\
\hline No & 4111 & 47.0 & 1770 & 20.2 & \\
\hline \multicolumn{6}{|c|}{ Health Status } \\
\hline Excellent/Good & 5551 & 63.4 & 2028 & 23.2 & \multirow[t]{2}{*}{$<0.0001$} \\
\hline Fair/Poor & 546 & 6.2 & 629 & 7.2 & \\
\hline \multicolumn{6}{|c|}{ Health Insurance } \\
\hline Yes & 6018 & 68.8 & 78 & 0.9 & \multirow[t]{2}{*}{$<0.0001$} \\
\hline No & 2554 & 29.2 & 101 & 1.1 & \\
\hline \multicolumn{6}{|c|}{ Cooking Frequency } \\
\hline Often & 2883 & 33.1 & 1164 & 13.4 & 0.0009 \\
\hline Sometimes & 2393 & 27.4 & 1156 & 13.3 & \\
\hline Never & 792 & 9.1 & 324 & 3.7 & \\
\hline \multicolumn{6}{|c|}{ Cooking Skills } \\
\hline Excellent/Good & 4217 & 48.6 & 1860 & 21.4 & 0.4473 \\
\hline \multirow[t]{2}{*}{ Fair/Poor } & 1829 & 21.1 & 776 & 8.9 & \\
\hline & Mean & SD & Mean & SD & \\
\hline BMI & 23.89 & 0.06 & 24.69 & 0.10 & $<0.0001$ \\
\hline Age & 22.9 & 0.07 & 22.0 & 0.11 & $<0.0001$ \\
\hline MES Score & 8.55 & 0.02 & 10.10 & 0.03 & $<0.0001$ \\
\hline CSS Score & 37.69 & 0.09 & 47.57 & 0.13 & $<0.0001$ \\
\hline APS Score & 13.39 & 0.02 & 12.41 & 0.03 & $<0.0001$ \\
\hline GPA & 3.49 & 0.42 & 3.29 & 0.53 & $<0.0001$ \\
\hline
\end{tabular}

Demographic data represented in frequency and percentages. Pearson Chi-square frequency and Wilcoxon analyses were performed. SD (standard deviation), BMI (body mass index), MES (money expenditure scale) CSS (coping strategies scale), APS (academic progress scale)

Significant associations were shown for ethnicity, student status, marital status, academic year, employment, financial aid, health status, health insurance, BMI, cooking frequency, age, MES, CSS, APS, and GPA. Therefore, these variables were included in 
the full, forward selection logistic regression model. When using the forward selection logistic regression, observations that had a missing value for any variable were automatically excluded from analysis resulting in a final sample of 5,578 . Results are shown in Table 5.

For the forward selection logistic regression model, the reference were white graduate students with excellent/good health who receives financial aid, has health insurance and cooks often. Results showed MES (OR $=1.47 ; 95 \% \mathrm{Cl} 1.40-1.55)$, CSS $(\mathrm{OR}=1.19 ; 95 \% \mathrm{Cl} 1.18-1.21)$, and $\mathrm{APS}(\mathrm{OR}=0.95 ; 95 \% \mathrm{Cl} 0.91-0.99)$ behaviors remained significant predictors of food insecurity, as well as GPA $(O R=0.70 ; 95 \% \mathrm{Cl}$ 0.58-0.84). Academic year, health status, ethnicity, financial aid, cooking frequency, and health insurance also remained significant predictors of food security status. Specifically, sophomore $(\mathrm{OR}=1.71 ; 95 \% \mathrm{Cl} 1.33-2.20)$ and junior $(\mathrm{OR}=1.36 ; 95 \% \mathrm{Cl}$ 1.07-1.72) academic years showed heightened risk for food insecurity. Further, ethnic minority $(\mathrm{OR}=1.35 ; 95 \% \mathrm{Cl} 1.14-1.60)$ students who reported fair/poor health $(\mathrm{OR}=$ $1.35 ; 95 \% \mathrm{Cl} 1.10-1.66)$, received financial aid $(\mathrm{OR}=1.33 ; 95 \% \mathrm{Cl} 1.13-1.56)$, and cooked sometimes $(\mathrm{OR}=1.28 ; 95 \% \mathrm{Cl} 1.08-1.50)$ or never $(\mathrm{OR}=1.65 ; 95 \% \mathrm{Cl} 1.27$ 2.14) had increased risk for food insecurity.

Table 5. Logistic Regression Model Predicting Food Insecurity in Regional Sample of Students

\begin{tabular}{ccc}
\hline Variable & Odds Ratio & 95\% Confidence Interval \\
\hline MES Score & 1.47 & $1.40-1.55$ \\
CSS Score & 1.19 & $1.18-1.21$ \\
APS Score & 0.95 & $0.91-0.99$ \\
GPA & 0.70 & $0.58-0.84$ \\
Academic Year & & \\
Freshman & 1.30 & $0.96-1.76$ \\
Sophomore & 1.71 & $1.33-2.20$ \\
Junior & 1.36 & $1.07-1.76$ \\
Senior & 1.19 & $0.94-1.51$ \\
Fair/Poor Health & 1.35 & $1.10-1.66$ \\
Minority Ethnicity & 1.35 & $1.14-1.60$ \\
Receives Financial Aid & 1.33 & $1.13-1.56$ \\
Cooking Frequency & & \\
Sometimes & 1.28 & $1.08-1.50$ \\
Never & 1.65 & $0.32-0.86$ \\
\hline Has Health Insurance & 0.52 &
\end{tabular}


Selection criteria for the model entry was $p<0.05$. Variables from simple analyses were entered into a forward

selection multiple logistic regression model. The reference categories were white graduate students with excellent/good health who receives financial aid, has health insurance and cooks often.

Students who had health insurance $(\mathrm{OR}=0.52 ; 95 \% \mathrm{Cl} 0.32-0.86)$ showed a decreased risk of being food insecure. BMI, student status, employment, age and marital status were removed from the model because they were not significant predictors. MES and CSS were the best predictors of food insecurity based on Wald Chi-Square $p$-values (data not shown) [43]

\section{Discussion}

To date, this study represents the largest study of food insecurity among college students attending 4-year institutions. Specifically, this study highlights the high prevalence of food insecurity among college students within the Appalachian and Southeastern regions of the United States. The study average of $30.5 \%$ students identifying as food insecure, which is above that of the national food insecurity average [2], is consistent with what has been demonstrated in the college food insecurity literature $[3,21,22]$. This continues to suggest that college students are an at-risk population for food insecurity, and therefore, calls for policies and programs to prevent the detrimental effects of food insecurity among this population. Additionally, the prevalence of food insecurity among the 10 universities within the Appalachian and Southeastern regions are similar to data presented at other universities across the nation, suggesting that the geographical differences shown with household food insecurity might not be present among college students but may indicate that the disparity is among the college student population in general.

Certain determinants of food insecurity identified among this sample population are similar to previous studies. Specifically, ethnic minority students, those who receive financial aid, report their health as fair or poor, and report cooking less frequently have been previously identified as at a higher risk for food insecurity [26-28, 110, 115, 124]. This calls attention to the type of students who might need additional resources to maintain food secure while attending college and can identify a target population for intervention. Additionally, within this study, student food insecurity risk was greatest 
during the undergraduate years, specifically sophomore and junior years. Predication of food insecurity was at the peak for sophomore students, suggesting that students may require additional resources as they end their freshman year to prevent the increased occurrence of food insecurity. This finding agrees with McArthur et al. and Wooten et al. that undergraduate students are at increased risk, although these authors identified the junior and senior academic years as highest predictors of student food insecurity [26, 132]. It is further suggested that food insecurity prevalence increases following the freshman year [26, 181, 182], making it important that students transitioning out of their freshman year are equipped with the knowledge and skills to maintain a food secure lifestyle when possible. However, in a more recent study of only freshman, McArthur et al. found that food insecurity was almost three times higher when the students lived on campus compared to when they lived with their families [127]. Therefore, it could be suggested that it is warranted to equip all students transitioning into college and independence, including all academic years, with the skills to ward off food insecurity. Additionally, some factors that have been previously identified as having association with food insecurity among college students, such as off-campus housing [26, 110, 124], were not identified as significant in this large scale student assessment despite being found as important predictors within the Appalachian region previously [26]. Overall, campuses should seek to understand their campus specific food insecurity correlates, such as the ones identified here, for helping universities pinpoint students that may be at increased risk for food insecurity and developing appropriate programs to assist them.

The behavioral impact of food insecurity among college students in this study are also consistent with previous literature [26, 30, 34, 35, 173]. First, in this study, food secure students displayed better academic behaviors and higher GPA's, suggesting that having a secure source of food can be beneficial to overall college success. This is consistent with previous literature, as food insecure college students are less likely to show positive academic performance including attending class and maintaining a high GPA [26, 33, 185]. As acquiring a college degree is dependent upon academic progress, barriers to high academic performance should be limited. Thus, ensuring college students have a secure source of food is essential for universities to help 
prevent poor student outcomes in the classroom, and may potentially promote student retention rates[33, 148].

Further, this study found that food insecure college students were more likely to display an increased number of coping strategies to receive food and spend their money on other items rather than buying food. This may indicate that many college students lack the financial skills necessary to utilize their limited means in a manner that protects against food insecurity [180]. An important time to ensure that students have the skills needed could be as they progress from their freshman year since it was found that they are at greater risk. Incorporating budgeting, cooking, and other life skills into freshman orientation courses could assist students in gaining the skills to manage more efficiently and nutritionally. The need for these skills have also been acknowledged by students themselves, and thus, from a community-based approach, could enhance current campus curricula $[26,109]$.

Due to the unfavorable effects of food insecurity, it is essential that universities employ programming that can aid students in need, while also advocating for policy change that can improve social justice for college students [22]. Many colleges and universities are beginning to implement initiatives on campus that can provide emergency relief to students [36], including food pantries [123, 128], campus gardens and farmers markers [153], and food recovery programs [205] that can provide food for hungry students. These programs can help to alleviate some of the short-term symptoms of hunger and ensure that students can avoid going without a meal, to possibly improve academic performance of affected students. However, even with available programs, students often do not utilize resources [36, 123]. University personnel should aim to alleviate the stigma of receiving benefits and promote the use of resources for all students [123].

Lastly, there is a need to delve deeper into the issue and promote policy change that prevents college students from becoming food insecure or relieves the burden from those who are currently food insecure[132]. Targeting campus, state and national policy change to address longer-term student needs is essential. Suggested advocacy includes expanding college students' Supplemental Nutrition Assistance Program (SNAP) eligibility [22, 36, 199], making college more affordable [22] and reform of 
campus dining programs for low-income students [22]. Directing efforts toward policy change can help to shift the college environment towards one that is just for students from all backgrounds and create a food secure campus that fosters students' academic success and well-being.

\section{Limitations}

This study is limited by the cross-sectional study design which used a nonprobability sample of college students and therefore causation cannot be determined. Additionally, results only represent students at 10 public universities in the Appalachian and Southeastern regions and may not be generalizable to other regions or private institutions. Further, there was large variability in the response rate from each university and thus university representation is disproportionate. Next, the survey measures were all self-report and some self-response bias may have occurred. The survey measures, such as the USDA AFFS, have also not been validated within a college population. Therefore, it is unclear if college students respond to this questionnaire in the same manner as previous populations and calls for a need for validated tools to use among college students. Additionally, income was excluded from analysis due to the high variability in student response and therefore limits the understanding of students' socioeconomic status. It is recommended that moving forward, researchers ensure studies capture the food insecurity risk factors identified by the Government Accountability Office in their 2018 report to congress[141].

\section{Conclusions}

Food insecurity prevalence among college students in the Appalachian and Southeastern regions is found to be higher than the national household food insecurity average. These food insecure students are at risk for poor spending behaviors and resort to a variety of coping behaviors and have diminished academic performance. It is warranted for administrators of higher education institutes to evaluate the impact of food insecurity on students to help provide resources to ensure student success. 


\section{Chapter VI: Development and Evaluation of a Higher Education Food Security Toolkit to Provide Ideas of Initiatives for Student Wellbeing}




\title{
ABSTRACT
}

\section{Development and Evaluation of a Higher Education Food Security Toolkit to Provide Ideas of Initiatives for Student Wellbeing: WISH4Campus}

\author{
Rebecca L. Hagedorn, BS ${ }^{1}$, Alex L. Pampalone ${ }^{1}$, Lanae B. Hood, PhD², Catherine A. Yura, \\ $\mathrm{EdD}^{3}$, Deana F. Morrow, PhD, LICSW, ACSW ${ }^{4}$, Melissa D. Olfert, DrPH, RDN ${ }^{1}$
}

${ }^{1}$ Davis College of Agriculture, Natural Resources, and Design, West Virginia University, Morgantown, WV 26506, USA

${ }^{2}$ Department of Nutrition, Health, and Human Performance, Meredith College, 3800 Hillsborough St. Raleigh, NC 27607

${ }^{3}$ Department of Psychology and Carruth Center for Psychological and Psychiatric Services, West Virginia University, Morgantown,

West Virginia, USA

${ }^{4}$ School of Social Work, West Virginia University, Morgantown, West Virginia USA

Background: Many universities are starting initiatives on campus to support food insecure students in receiving nutritious food. However, there is no comprehensive resource of these initiatives to help guide universities in starting a program on campus. The objective of this study is to describe the development and evaluation of a toolkit that can assist higher education institutions in promoting a campus environment, providing adequate resources for food insecure students.

Methods: The toolkit development was guided by the basis of the Normalization Process Theory (NPT) to evaluate factors that could facilitate or inhibit initiative success on campus. A review of literature was undertaken by two independent reviewers to gather all peer reviewed and grey literature on food insecurity programs currently available on college campuses in the United States. Findings were compiled into a toolkit that contained six initiative chapters: food pantries, campus gardens, farmers' markets, dining and recovery programs, mobile applications, and policy initiatives. The toolkit was evaluated by experts from land-grant universities who work with food insecurity issues $(n=126)$. Experts completed a 27-question survey to determine demographics, perceptions of food insecurity and evaluation of specific toolkit components. Descriptive statistics and frequency analyses were performed on quantitative data and content analysis was used to analyze qualitative data.

Results: Thirty experts (23.8\% response rate) completed the evaluation survey. Evaluation feedback covered four main topics: layout, overall content, initiatives, and application. Eight themes emerged from the coding and categorization of responses. They were visual appeal, organization, value, provoking, comprehensive, barriers, collaboration, and efficiency. Corrections and recommendations were provided for each topic.

Conclusion: The themes derived from expert feedback encompassed the initial objective of the toolkit. This toolkit serves as a comprehensive resource that can be utilized by student leaders, clubs or organizations, campus stakeholders or administrators to begin a food security initiative on campus to promote student wellbeing.

Keywords: college students, food insecurity, initiatives, campus, toolkit 


\section{Introduction}

Food insecurity, which can be defined as the limited access and availability to nutritious food, has become an acknowledged issue among college students in recent years. Alarmingly, studies examining college students show an elevated rate of food insecurity compared to the national average, with one systematic review showing rates in peer-reviewed studies ranging from $14-59 \%$ of the student population as food insecure [3], and a more recent review showing food insecurity rates between 9-89.6\% among college students in developed countries [21]. Being burdened with food insecurity while in college has been found to provoke consequences on college student's well-being including risk for poor diet quality, physical and mental health status, and academic performance [21]. Therefore, it is essential that resources be in place to help students avoid being in a food insecure situation.

Although college students are experiencing food insecurity at rates that surpass the national average, many are unable to access adequate resources that aid the general population in sustaining a food secure lifestyle [185]. In particular, college students are often unable to access the Supplemental Nutrition Assistance Program (SNAP), which is a valuable resource to food insecure populations [206]. Students are only able to receive SNAP benefits if they meet certain state-mandated requirements which exclude the majority of college students from SNAP benefits [207]. The Government Accountability Office (GAO) has recommended that state SNAP agencies share information to help eligible students [141] and some advocacy groups have directed their efforts toward policy change to create food secure campus environments for students [22]. However, development and implementation of policy change takes time and thus there is a need for college campuses to provide alternative resources to college students to improve student wellbeing in the realm of living assistance.

Some college campuses provide support through food pantries, campus gardens, meal programs, assistance or ambassador programs, mobile applications, and policy change [36]. These programs aim to alleviate the burden on food insecure students and provide immediate relief to promote student well-being. However, while many college campuses are pioneering initiatives to promote a food secure campus, many of these developed programs and processes are not published for other 
campuses to replicate. To date, only four published manuscripts discuss college food pantries $[107,128,152,153]$, and only one fully describes the process of developing a food pantry on campus [128]. Publications on meal swipe programs and campus gardens are even more limited $[150,153]$. Consequently, university personnel looking to initiate a food security program on campus have few published resources to guide the process. Therefore, providing college campuses a tangible guide in the form of a toolkit could be a viable solution for increasing the food security initiatives on college campuses nationwide and working to alleviate the high rates of food insecurity among students.

Toolkits are one means of dissemination and implementation (D\&l) research that are used to facilitate behavioral and environmental change [208]. Toolkits allow researchers to expand the dissemination of feasible interventions beyond traditional methods of presentations and manuscripts and overcome D\&I communication barriers by translating research materials in user-friendly terms and formats [209, 210]. Toolkits offer flexibility during the D\&I process and are a cheap alternative to research-driven implementation by providing resources (implementation guidelines, validated measures, strategies for change, training, etc.) directly to those will be driving the targeted change. Hence, toolkits can allow more of a self-directed approach which allows for more program sustainability and continued impact. A systematic review on toolkits in clinical care championed toolkits as having potential promise to facilitate change and improve health outcomes [208]. This was further expanded by a review of toolkits for public health and healthcare change, with toolkits noted as an effective means for knowledge transfer in implementation [211]. However, authors of both reviews state similar limitations in the understanding of toolkit effectiveness due to the lack of theoretical implementation and systematic evaluations. Therefore, there is a need to develop and implement toolkits using validated theoretical frameworks and monitor and evaluate the implementation process.

To date, toolkits to empower college administrators to start a food security initiative on campus are lacking. WISH4Campus - Wellbeing Increased by Security from Hunger for Campus - is a college food security initiative striving to empower college campuses to develop, implement and sustain food security programming for 
student wellbeing. The WISH4Campus toolkit is a compilation of previous food security initiatives that have been started on college campuses to aid other universities in starting programming on their campus. The objective of this manuscript is to describe the development and evaluation of a toolkit, using a theoretical backing, that can assist higher education institutions in promoting a campus environment that provides adequate resources for food insecure students.

\section{Methods}

This study was conducted in accordance with the Declaration of Helsinki, and the protocol was approved by the Institutional Review Board at West Virginia University (1802980009).

\section{Theoretical Backing}

The toolkit was built on the basis of the Normalization Process Theory (NPT), a theory that can aid in understanding the social processes that occur that can promote or inhibit implementation of new programming $[37,38]$. The NPT focuses on "the social organization of the work (implementation), of making practices routine elements of everyday life (embedding) and of sustaining embedded practiced in their social contexts (integration)" [37].

The four main constructs aim at understanding what is the program, who does the work, how does the work get done and how is the program understood. These constructs are coherence, cognitive participation, collective action, and reflective monitoring and are described in more detail below.

1) Coherence: To ensure successful program implementation, this construct is made up of the factors that contribute to the community, making sense of the intervention/program purpose. For those implementing the initiative, this construct encompasses the understanding of the work that will occur during implementation.

2) Cognitive Participation: This construct highlights the human resources necessary for implementing a new program and the factors that promote or inhibit 
involvement in the program. This includes the "who" of program implementation and how to sustain the engagement of people for continued impact.

3) Collective Action: In order to promote successful implementation, the program must become part of everyday practices. This construct evaluates how the proposed initiative fits within the current operations of the community in terms of structure, functionality and overall objectives, as well as the capacity to take on implementation.

4) Reflective Monitoring: To ensure program sustainability, this construct aims to understand the appraisal of the implemented program by evaluating how understood the program is in the community. For those implementing the initiative, this construct evaluates how embedded the new program has become in the community and any modifications that must take place to ensure long term program success.

This theory guided the writing of the toolkit to highlight factors that could promote or inhibit college campuses from making sustainable initiatives on their campus, as done previously in toolkit development [40]. Therefore, the toolkit was intended to encompass the NPT constructs to promote the normalization of the interventions in the toolkit. This process has been used in previous toolkit development for health care technologies, with positive reception from implementers [40].

\section{Toolkit Development}

A review of the literature was undertaken by two independent reviewers (R.L.H and A.L.P), with the aim of gathering all peer-reviewed and grey literature on college food security initiatives. The search engines PubMed and CINAHL were used to search for peer-reviewed literature. Google Scholar and Google were utilized to capture any overlooked or grey literature. Inclusion criteria for this search were that all articles must be available in English and include the college student population. Search mesh terms include: "Food insecurity or security AND college or university AND food pantry"; "Food insecurity or security AND college or university AND garden; "Food insecurity or security AND college or university AND meal program"; "Food insecurity or security AND college 
or university AND support or ambassador"; "Food insecurity or security AND college or university AND initiative or program". Additional searches were completed for topics that were brought to light from the systematic search. Excel spreadsheets and EndNote (Clarivate Analytics, Philadelphia, PA) were used to extract and assess articles and webpages. Each article was assessed for what kind of food security initiative it was (food pantry, campus garden, etc.), where the food security initiative was completed (University name, state, region, etc.), outcomes from the initiative if available, and any resources to guide replication of the food security initiative. All information was compiled into an excel spreadsheet to guide the writing of the toolkit.

From the systematic search, 6 topics were included in the toolkit. This included food pantries, campus gardens, farmers' markets, dining and recovery programs, mobile applications, and policy change. Each initiative topic had its own chapter within the toolkit that provides an introduction to the initiative, insight on campuses have are currently running a program, recommendations to start and maintain this type of initiative on the campus based on NPT constructs, and resources to help start a program. Additional literature recommendations were also included in each topic chapter. The toolkit also included an overall introduction to food insecurity among college students, methods to measure food insecurity and justify need on campus, details of food security initiatives on college campuses, and a take-home message at the end. The toolkit was written by the two reviewers who completed the systematic search and was sent to a graphic designer to improve aesthetic appeal prior to evaluation. Prior to being evaluated by experts, the toolkit underwent an internal review with a team of 6 graduate students and postdoctoral fellows to evaluate the content for grammatical errors. Revisions were made for errors prior to sending for external review.

The completed toolkit consisted of 41 pages that included 10 chapters: Introduction, Measuring Food Insecurity, Campus Initiative Description, Food Pantries, Campus Gardens, Farmers Markets, Dining and Recovery Programs, Mobile Applications, Policy Change, and Conclusion. The six initiative topic chapters all included an introduction to the topic, a glimpse at peer reviewed (if available) and grey literature that highlights campuses that are operating an initiative for students, recommendations aimed to help implementers navigate the execution process, 
available resources on how to start a program on campus, and additional literature if applicable.

\section{Evaluator Recruitment}

Experts at land-grant universities were chosen to provide feedback on the WISH4Campus toolkit. The term expert is used loosely as one who works food insecurity issues. Land-grant institutions were specifically targeted for their commitment to community engagement and enhancement [212]. To identify experts at land-grant universities, each university's website was accessed. If a search bar was available, the terms of food security and food insecurity were entered. Results were assessed for an individual who was working on the issue of food insecurity. If no search bar was available or resulted in no findings, the university site was searched for faculty or staff including, but not limited to, a professor in community nutrition (or related field) or coordinator of a student wellness program that was involved in food insecurity issues. If none were available, the research office or related contact was emailed requesting an appropriate contact for this study. Name, organization, title, phone, and email of each expert were collected as available and input in an excel sheet.

A contact from all 106 land-grant universities was identified, with some universities having more than one contact. A total of 126 contacts were identified from the website search and received an invitation email to participate in the evaluation. The email described the purpose of the WISH4Campus study, their role in participating as expert review, the estimated time the review survey will require, the questions to be asked, and incentive to be offered as required by Institutional Review Board (IRB) protocol. Participants were not paid for their feedback but were provided the opportunity to be entered for a chance to win one of two, $\$ 200$ gift cards. Those who were interested could access the Qualtrics survey link that was attached to the email. Once experts clicked on the link, an online consent was available. Experts were instructed to read the informed consent and those who accepted consent were allowed to continue with the survey. Experts who denied the consent were thanked for their time and exited from the survey. Once consent was obtained, the expert was provided the 
option to download a PDF version of the WISH4Campus Toolkit and complete the feedback survey.

Two reminder emails were sent via Qualtrics to contacts that had not yet started the evaluation survey. Survey data collection was open from the beginning of December 2018 to the end of January 2019.

\section{Evaluation Survey}

The evaluation survey was created based on a previous toolkit development survey using NPT constructs [40] with modifications for this topic and including both open and close-ended questions. The survey was 27 questions, with three additional questions to gauge experts' interest in future collaboration. With each question, experts were provided with space to elaborate or provide additional feedback for improvement. Survey questions included six demographic questions followed by five questions about the expert's perception of food insecurity issues on college campuses and their knowledge of food insecurity on their own campus. The remaining questions addressed specific toolkit components including a rating of the toolkit layout, overall content, and initiatives, application of the toolkit, areas that worked well and suggested improvements. The feedback survey is available in Appendix C.

\section{Analysis}

Quantitative data were analyzed in JMP (JMP®), Version Pro 12.2, SAS Institute Inc., Cary, NC, Copyright (@2015). Quantitative analysis included descriptive statistics and frequency analysis. Thematic analysis was used to analyze qualitative data. Coding occurred in Qualtrics (Qualtrics, Provo, UT, USA) with some in vivo codes guided by the Normalization Process Theory (NPT) and the rest based on subjective assessment of the content. Codes were reviewed multiple times and categorized into a topic and theme. Each topic also contained recommendations that were coded separately from themes. A second researcher reviewed all themes to make sure both reliability and validity of results occurred. If discrepancies arose both qualitative reviewers discussed the coding and collectively deciding on themes. 


\section{Results}

\section{Expert Evaluator Characteristics}

The evaluation survey was completed by 30 experts ( $23.8 \%$ response rate) from 23 states primarily not in the Appalachian region (82.4\%). Experts were predominately female $(85.3 \%)$ aged $41( \pm 13.5 \mathrm{SD})$ years with $11.5( \pm 9.8 \mathrm{SD})$ years' experience.

Expert's feedback was received from higher education faculty including professors and researchers $(50 \%)$, higher education staff including food pantry directors and directors of student affairs and engagement (26.5\%), campus dietitians (14.7\%) and graduate students (8.8\%). Almost all experts (97.1\%) believed food insecurity is an issue on college campuses and were involved in improving food security on their campus (91.2\%). Experts (94.1\%) stated their campuses have resources for food insecure students currently, however, only half of the experts stated their campus measures the prevalence of food insecurity among students.

\section{Toolkit Evaluation}

The thematic analysis highlighted 4 topics which included eight themes as shown in Table 1. The first topic consisted of evaluation comments related to the layout. The layout was rated $7.8 \pm 1.7$ out of 10 by experts. The layout topic included two themes: visual appeal and organization. Experts found the toolkit to have an appealing layout that was described as "nice and colorful" with a "mixture of photos and text". The order of the materials throughout the toolkit was described as logical. Overall, experts expressed that the toolkit was "easy to follow" with "headings that direct you to information relevant to your needs". Despite the toolkit being mentioned as "long", the layout was suggested to be an "easy read" that is not "overly academic" and "clearly written".

The second topic, overall content, highlighted the usefulness of the content that was included in the toolkit but not specific to the initiatives. The overall content was rated $7.8 \pm 2.2$ out of 10 . The theme value emerged under the topic of content. Experts expressed that the toolkit was a "helpful resource" that compiles a lot of information into "one convenient document" The links to additional resources and programs were spoken highly of by experts and considered a "feature that worked well". One expert 
described the content as "guidance for new-comers that gives background information, shares tools to create their own food security assessments and recommend actions that can be taken on campus and throughout the community".

The third topic was initiatives and was rated $7.4 \pm 2.3$ out of 10 . This topic focuses specifically on the types of initiatives within the toolkit and how useful the initiative sections were for those wanting to implement a program on campus. Two themes surfaced from the analysis: provoking and comprehensive. Experts stated the toolkit covered a "wide variety of programs" across "diverse universities" which was expressed to be beneficial because "not all campus settings and resources are the same". One expert noted that the toolkit "contained wonderful examples that could be modified" while another stated that toolkit "provides multiple strategies to suit different needs". The toolkit was also noted as a resource that was "motivating but not overwhelming" and thus can aid universities that are beginning to provide food insecurity resources on campus. The toolkit was mentioned to be a "great primer for schools who are interested in starting one of these initiatives" and offers insight on "what other schools are doing as best practices".

The last topic regarded the application of using the toolkit. Experts (90\%) found this to be a useful approach to helping campuses improve student food security, $50 \%$ of experts thought there would be barriers to implementing the toolkit. Three themes were developed regarding the application. These were efficiency, collaboration, and barriers. Experts described the toolkit as a resource that will make it easier for university personnel to start the discussion on campus. For example, one expert expressed "putting all the information under one roof - making access easy for colleges - makes it easier for initiatives to happen". Another agreed that the toolkit "saves time for those who are interested who likely do not have time to conduct this much research and find resources to implement these programs". Responses highlighted that the toolkit can be used to create collaborations between students, administrators, and community stakeholders which may be necessary for initiative implementation. One expert stated they would "share this toolkit with the administrators" at their university and another stated it can justify to administrators "what has been done other places [universities]". The need for a "champion" on the campus and in the community to make successful 
partnerships was mentioned, but experts highlighted campus stuff (e.g. student service office, financial services) can provide "unrelenting support" and are often looking to "improve the initiatives on campus" However, experts also highlight that there are barriers to the application of the toolkit. One expert stated that "not everyone believes food insecurity is an issue" and thus program justification may be a challenge on campus. Further, staffing and funding issues may be roadblocks to ensuring program success on campus. Experts mentioned these initiatives require "student contribution" and it's a challenge for students to "see the outcome of their voluntary contribution of time and money".

Table 1: Thematic Analysis of Evaluator Feedback with Related Quotes

$\begin{array}{lll}\text { TOPIC THEMES } & \text { RELATED QUOTES }\end{array}$

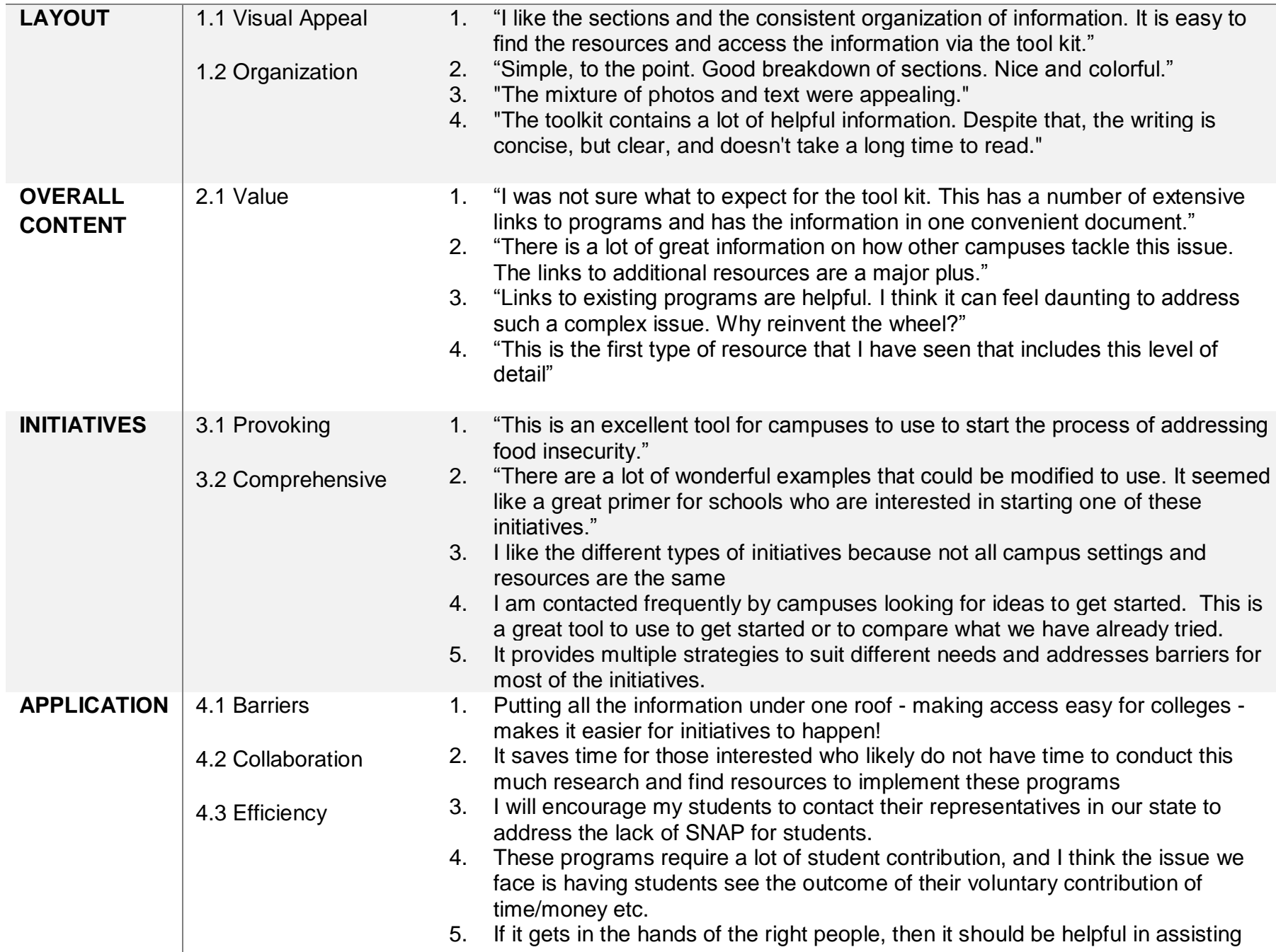


Recommendations were also coded for each of the topics, as shown in Table 2. Layout recommendations included visual changes. The most common visual change was regarding the font color, which was a shade of grey. Experts found the "color contrast difficult to read" with the "very light writing". Other visual changes including adding more graphics throughout the toolkit and revising the hyperlinks. One expert suggested having a hyperlink in the "the table of contents to go straight to the sections".

Content recommendations included grammatical errors, additional sections, and more research. Experts pointed out a few minor grammatical errors throughout the toolkit that require revisions. Many experts suggested the addition of content within the toolkit. This included discussions on the determinants of food insecurity to include discussion on "low income, first-generation college students. Another expert suggested their campus was already utilizing "a great packet on food safety for food pantries" and thought food safety should be included in the toolkit. Lastly, experts stressed the need to strengthen the research section of the toolkit. This section highlights how to justify need on campus by measuring food insecurity prevalence on campus. One expert suggested adding a link to the Hope Center which offers a "research guide with detailed information", with another suggesting campuses "sign onto the Hope survey, and they can get their own school's data from that".

The initiatives section recommendations included additional initiatives, more upstream, and outcomes. Additional initiatives included a larger section on SNAP and a mobile application that was not included (Free Food Alert app from John Hopkins). Further, a few experts requested increased diversity in the universities highlighted in each section to help universities "find campuses with similar demographic and geographic qualities". The type of initiatives was also questioned, with some experts requesting for more of a focus on upstream solutions (i.e. at the root of the problem) instead of highlighting the downstream emergency programs (i.e. treating the symptoms). One expert stated that "Food insecurity is a complex issue and a symptom of other unmet needs, such as finances" and therefore called for more focus to be put on upstream solutions. Another agreed and stated the initiatives were " good for campuses currently doing nothing, but we should try to think more upstream". Suggestions of upstream improvements included expanding the policy section to 
highlight more campuses and policy initiatives including financial literacy training, financial aid reform, cost reduction, and free school meals expansion to colleges. Lastly, experts wanted to see more outcomes from each of the initiatives. One expert highlighted that "providing some outcomes on the different approaches would be to show if the initiatives are proven to be successful." Another expert suggested that the toolkit needs to highlight more on "Engaging students that are closely affected by the issue" and gauge "student feedback on the initiatives" to assess outcomes.

Recommendations regarding the toolkit application comprised a need for evaluation and steps for implementation. Experts mentioned that the toolkit did not fully encompass how to evaluate the initiatives and "some suggestions for evaluation methods would be helpful." One expert mentioned that overall the toolkit "needs data collection strategies after implementation or program creation." Additionally, experts wanted to see more step by step of the implementation process. Specifically, one expert stated that "creating a step-by-step guide for implementing one of the initiatives would be helpful to understand which stakeholders to contact, how to recruit student help, etc.", thus calling for more detail of the implementation process.

Table 2: Recommendations for Topics within the WISH4Campus Toolkit and Related Quotes

TOPIC

\begin{tabular}{|l|l|}
\hline LAYOUT & 1.1 Visual Changes \\
& \\
\hline $\begin{array}{l}\text { OVERALL } \\
\text { CONTENT }\end{array}$ & 2.1 Grammatical Errors \\
& 2.2 More Research \\
\hline
\end{tabular}

2.3 Additional Sections

INITIATIVES

3.1 Additional Initiative

3.2 More Upstream

\section{RELATED QUOTES}

1. "Wish there was an option to hyperlink the table of contents to go straight to the sections "Simple, to the point."

2. "I like the layout, I just find the color contrast difficult to read. Accessibility standards are at least a 4:1 contrast ratio"

3. "Too hard to read - very light writing."

4. "I think that it would be good to have all the links that are included in the reading, listed again at the end under a quick reference guide."

5. " "I think it could be graphically more interesting."

1. "I noticed some minor grammar errors"

2. "The toolkit could use better research resources and more information about comprehensive support services for students with food and housing insecurity and other issues."

3. "The research section is sparse, although it is the beginning step for many food security initiatives. The Hope Center (formerly the Wisconsin HOPE Lab), offers a research guide with detailed information."

4. "Great information, but there was nothing specific to colleges that may serve more food insecure students by percentage because they are serving many low income, first-generation college students."

5. "Food safety should be included. Our State food bank has a great packet on food safety for food pantries, and this should be a \#1 consideration for anyone thinking of opening a pantry. We even utilize the ServSafe guidelines."

1. "SNAP should get a much bigger section, including the opportunity for campuses to join the SNAP outreach grants that many extension offices oversee."

2. "Enhancing the policy section to focus on local and state policy that could have major impacts for students in need. Again, there aren't a lot of clear examples, but some campuses are working on thinking more upstream. Food insecurity is 
3.3 Outcomes

a complex issue and a symptom of other unmet needs, such as finances. Encouraging schools to include those departments in their conversations, thinking about how to make college more affordable, provide more income for students, etc. Engaging students that are closely affected by the issue."

3. "Good initiatives, consider a pro-con of each"

APPLICATION

4.1 Steps for Implementation

4.2 Evaluation
1. Needs data collection strategies after implementation or program creation.

2. If you could provide some more tips on reducing stigma for students in need.

3. I think a section on evaluating the initiatives would be helpful. Some suggestions for evaluation methods etc.

\section{Discussion}

This study described the development and evaluation of the WISH4Campus toolkit. To our knowledge, this is the first toolkit that provides a comprehensive resource of the initiatives that university personnel are utilizing to address food insecurity on college campuses. Evaluation of the toolkit highlight experts' perceptions of the layout, content, initiatives, and application components of the toolkit and provides recommendations for improvement moving forward. The sample population, all from land-grant universities, expressed generally favorable views of the WISH4Campus toolkit. The themes derived from thematic analysis align with the objective of creating a resource that can assist higher education institutions in providing adequate resources for food insecure students.

Experts also provided a critique of the toolkit and recommendations were formed for each topic area. Some recommendations were minor and included changing font color to increase readability and fixing grammatical errors. Other recommendations were more content, initiative, and application specific. Content recommendations included more research and information on the determinants of food insecurity. One specific recommendation was to incorporate the Hope Center research guide and advocate for universities to sign up for the \#RealCollege Survey lead by the Hope Center [213]. Partnering with the Hope Center would allow universities to sign on for a national data college and eliminate the need for campus personnel to develop their own survey. For those with limited time and resources, this can be a valuable option.

Contradictory, other recommendations stress the need for campus-specific questions with student stakeholders. Gaining student input can provide insight on student desires and promote campus environment and policies to improve student success by addressing student identified needs [214]. Qualitative studies with students 
have identified areas in which universities can increase their dedication to making the campus a more food secure environment [109, 123, 149]. These recommendations include addressing inadequate financial aid programs, unaffordable cost of living on campus, inflexibility of meal plans, unrealistic food costs on campus, and opportunities to learn life skills [109]. Further, food pantries with discreet locations, reduction of campus food waste, and meal vouchers have also been identified by food insecure students as a means to help students in need $[123,149]$. Thus, university personnel should look to students as stakeholders and incorporate student directed needs into campus programs to improve student outcomes.

The aforementioned student identified programs for food insecure students support the promotion of emergency food programs within this toolkit. However, some policy-driven solutions and social justice issues have been brought to light by students and align with some expert recommendations that the toolkit should incorporate more upstream solutions. The use of both upstream and downstream solutions have been promoted [22] and provide for a holistic approach to food insecurity on college campuses. As national efforts and policy change will take time to develop, ensuring student needs are met in the interim is essential to promoting student success. However, both upstream and downstream approaches are limited by the lack of peer-reviewed literature on their efficiency at increasing student food security [22] and thus, future research should aim to include measure the impact programming has on student outcomes.

The toolkit was developed with the backing of the NPT to help authors incorporate recommendations to make the initiatives more likely to succeed in being implemented on a college campus. Based on responses in the qualitative investigation, it can be inferred that the toolkit encompasses the constructs of coherence and cognitive participation. Experts were able to grasp the intention of the toolkit and understand the information on the different initiatives. Further, experts suggested the toolkit wasn't "overly academic" meaning the toolkit could be easily understood by populations with different levels of education and increasing the coherence of the toolkit materials. The cognitive participation construct was also achieved in the toolkit with experts identifying the potential champions on campus to carry out the implementation of initiatives. For example, experts stated the toolkit can be "used by students to create 
these initiatives" and "the student services people are always looking to improve their initiatives" as avenues in which the toolkit may be implemented. However, staffing was also mentioned as a barrier and inclusion of a staffing section within the toolkit may strengthen the cognitive participation construct.

The NPT constructs collective action and reflective monitoring were encompassed in the expert recommendations and thus could be amplified with the toolkit. Experts recommended adding a "step-by-step guide" to implementation which would improve upon the collective action construct within the toolkit by detailing how the initiative can be made part of the current campus operations. Additionally, experts call for suggestions on how to evaluate the program after implementation which aligns with the reflective monitoring construct. By utilizing expert recommendations, collective action and reflective monitoring constructs can be added into the toolkit and thus encompass all constructs of the NPT. However, both guide of implementation and evaluation suggestions within the toolkit are limited due to the lacking peer-reviewed research on campus food security initiatives $[107,128,152,153]$. Therefore, as stated above, future research should aim to describe and evaluate the implementation process and outcomes to provide a reference guide to other campuses.

The WISH4Campus toolkit has a number of strengths. First, undertaking a systematic review of peer-reviewed and grey literature allowed for the toolkit to contain a comprehensive synthesis of the topic. Further, using a theoretical backing for the development of the toolkit helped guide the writing of the content to highlight necessary components to improve the implementation and success of food insecurity initiatives on campus [40, 215]. Additionally, the qualitative evaluation from experts in the field provided insight from the target population and allowed for constructive criticism and recommendations that will strengthen the toolkit for use. However, limitations are also present. Despite the positive evaluation feedback, the toolkit has never been implemented. Therefore, the feasibility of using the toolkit as a guide for colleges beginning the implementation process is unknown. Future research should aim to evaluate the toolkit as it is used by campus personnel. Further, the initiatives within the toolkit have not been heavily evaluated as well and many initiatives came from grey literature. It is beneficial for campus initiatives to be evaluated and reported in peer- 
reviewed literature to help fill the literature gap on this topic. Lastly, the toolkit was only evaluated by experts on land-grant universities. While these experts were from diverse universities throughout the United States, representing 23 states, their perceptions may not be generalized to other university personnel. As community colleges, private institutions, historically black colleges and universities (HBCUs) are often home to different student populations, gaining insight from experts on these campuses may improve the diversity of expert response.

\section{Conclusion}

The WISH4Campus toolkit has the potential to serve as a comprehensive resource that can be utilized by student leaders, clubs or organizations, campus stakeholders or administrators to begin a food security initiative on campus to promote student well-being. As stated by one expert, the toolkit is a "great tool to use to get started or to compare what we have already tried." As food insecurity among college students is a known public health issue $[3,141]$, this novel toolkit may aid university personnel in implementing programs to promote student well-being through a more food secure environment. 
Chapter VII: Discussion and Conclusion 


\section{Discussion}

Chapter 7 provides a summarization of the findings within this dissertation and explores relationships with previous literature. Additionally, this chapter postulates furture research to improve upon the work of this dissertation and expand the understanding of college food insecurity. The research in this dissertation aimed to investigate the prevalance and impact of food insecurity among college students in the Appalchan and Southeastern regions. The findings of this dissertation are valuable and fill the void of research among college students in these at risk regions. Further, this dissertation introduced a novel food insecurity toolkit that can help to address the needs of food insecure college students throughout the United States.

In chapters 4 and 5 of this dissertation, it was hypothesized that college students within the Applachian and Southeastern regions would demonstrate rates of food insecurity higher than the national average. Indeed, average food insecurity rates of college students at West Virginia University and nine other universities throughout the Appalchian and Southeastern were above the $11.8 \%$ national average. Specifically in our population, food insecurity prevalance ranged from $22.4 \%$ to $51.8 \%$ with an average food insecurity prevalence of $30.5 \%$. This aligns with previous college food insecurity research, falling in range with recent systematic review estimates [3, 21, 22]. To date, this is first regional investigation of food insecurity and the largest scale investigation of students attending 4-year institutions. The heightened rate of food insecurity reported in this dissertation adds continued justification that food insecurity is a public health issue among the college population.

Research in chapters 4 and 5 also addressed the hypothesis that food insecure students would display unique characteristics compared to their food secure counterparts. Findings suggest the food insecure students display worse money spending behaviors, rely on more coping strategies to obtain food, and display poorer classroom performance. These findings are consistent with previous research. In regard to academic performance, previous literature supports the notion that food insecure students are subject to lower success in the classroom. A majority of research investigates food insecurity's impact on academics through GPA, with food insecure students commonly reporting lower GPA's compared to their food secure counterparts 
$[28,122,124,127,129,132,143,145]$. Other research has investigated specific academic behaviors including class attendance, attention span, comprehension of class materials, and progress towards graduation with food insecure students again showing worse academic performance compared to food secure students [26, 33, 145]. The research in this dissertation investigated both GPA and other academic behaviors and agrees with previous research that food insecure students are left with detrimental effects on their scholastic performance. Impaired academic performance can lead to delayed degree attainment or student dropout all together. Student dropout is a financial burden to both student and university and thus it is advantageous for universities to employ resources to ensure student academic success [145]. College degree attainment is a determinant in a student's future health and financial well-being and could potentially aid in preventing food insecurity in adulthood $[68,216]$.

With respect to spending behaviors, food insecure students have been reported to have increased money expenditure on items other than food [26]. College is often a young adults first glimpse at independence, including autonomy in financial management. Students frequently enter college with limited knowledge of managing their finances and courses aimed at improving a student's personal financial literacy are often limited [217, 218]. At times, students are forced to prioritize spending money on academic related expenses, such as textbooks and tuition [26, 130]. However, Cuy Castellos and Holcomb (2018) reported that students often prioritize spending on alcohol purchases as well [130]. In both instances, the purchasing of academic related or extra-curricular (i.e. alcohol, entertainment, etc.) items increased a student's likelihood of being food insecure $[26,130]$. These reports align with the findings of this dissertation, as food insecure students were more likely to have higher money expenditure scores, indicating they were purchasing other items prior to food. The lack of knowledge on how to properly budget funds between academic, essential, and extracurricular purchases, put students at risk for food insecure situations. In fact, food insecure students report not being confident at their ability to manage finances [108]. Further, students have identified that the university environment lacks opportunity to learn life skills and indicated incorporating financial literature training may be a potential way to help food insecure students [109]. Therefore, universities could aim to improve 
college student's financial literacy skills as a means to help prevent students becoming food insecure.

The college student population reported in this dissertation also displayed coping strategies similar to previous research. Due the financial constraints mentioned above, as well as the mental and physical requirements of succeeding in college, students often develop behavioral patterns to cope with their environment [148, 173]. Specially for food insecure students, coping strategies may be developed as a means to obtain food. Similar to McArthur et al. (2018) [26], food insecure students in this dissertation reported a higher number of coping strategies to secure a source of food. The coping strategies used by food insecure college students vary and include some healthy (e.g. couponing, making a budget, etc.) and unhealthy (stealing food, avoiding bill payment, etc.) coping strategies [26, 109, 115, 121, 149]. Students utilizing healthy coping strategies may be beneficial as a mean to receive food but may also aid in avoiding other detrimental outcomes of food insecurity, including poor academic achievement. The impact of coping on student success varies [183, 184], but reliance on healthy coping strategies in college students may be protective against poor academic outcomes [148]. Therefore, educating students on healthy coping options, specifically on healthy strategies to obtain food, may be beneficial in promoting student well-being and academic success.

Other strategies for promoting well-being of food insecure students were discussed in chapter 6 of this dissertation as part of the WISH4Campus toolkit. Expert's who reviewed the toolkit considered it to be a helpful tool to engage campuses looking to start a program to support food insecure students. Experts identified the level of importance for both upstream (i.e. policy and systems change) and downstream (i.e. emergency food programs) solutions in holistically promoting student well-being. Both upstream and downstream solutions should be encouraged to ensure that students have access to adequate resources as policy change at the university, state, and national levels are being developed and implemented [22]. This apporach is supported by previous research. Student stakeholders have championed the use of food pantries, campus gardens, and other campus-based aid programs but also acknowledged the need for change to the colliegete system including financial aid reform and nutrition and 
financial education [109, 123, 149]. Viewing college students as partners allows for unviversities to employ community based particiaptory research (CBPR) and invest in intitiaves that address campus specific need and provide student driven programming.

\section{Limitations}

The research within this dissertation was able to answer the proposed research questions but still has limitations. This research in chapters 4 and 5 is limited by the cross-sectional study design. Use of cross-sectional data eliminates the ability to investigate causation and thus this dissertation is limited to highlighting the correlation between food insecurity and associated variables. Moreover, the identified associations with food insecurity only represent students at 10 universities in the Appalachian and Southeastern regions and therefore may not be generalizable to other regions, private institutions, or community colleges. However, use of this methodology in the Appalachian and Southeastern region allowed for cost-effective and time efficiency data collection that is the largest regional collection in 4-year institutions to date.

The survey measures used within this dissertation may be a potential limitation. All data in chapters 4 and 5 were self-reported and some self-response bias may have occurred. Specifically, as incentives were offered for survey completion, students in need of money may have been more likely to complete the survey for a chance at monetary reward. Further, the USDA AFFS has also not been validated within a college population. Therefore, it is unclear if college students respond to this questionnaire in the same manner as previous populations and calls for a need for validated tools to use among college students. As shown in Appendix D, college students answer more affirmatively to different questions than adults in the clinical care setting. Thus, as no qualitative data is available on college student's perceptions and interpretation of the survey is available, the validity of the survey tools is unknown.

Research in chapter 6 is limited by lack of peer-reviewed literature available to develop the toolkit. Therefore, the initiatives within the toolkit lack evaluation as methods of food insecure alleviation on campus. Additionally, those who evaluated the toolkit only came from land-grant universities and thus lack evaluation by experts at 
community colleges, private institutions, and other diverse universities which may provide different assessment of the toolkit.

\section{Future Research}

Future research can overcome the identified limitations of this dissertation. First and foremost, it is essential that researchers understand the validity of the USDA food security screeners when used among the college population. The USDA survey tools are the most commonly used in college food insecurity research, however, no research to date has aimed to understand the accuracy of these tools. Therefore, the prevalence rates identified within the literature may be skewed and calls for future research to address this limitation. A validation study, as performed with food security screeners in other populations using Rasch methods [73, 219, 220], is a key first step to assessing the validity of the USDA screener tools. Secondly, qualitative data should also be acquired through the completion of cognitive interviews with college students. This will allow for research to understand college students' perceptions of food insecurity and the survey questions to ensure clarity of questions aimed at the college population.

Once a sound survey tool is identified for the college population, the food insecurity screener should be added to national and local college assessments. Including food insecurity screening questions to existing national collegiate surveys will help gauge a more accurate representation of the prevalence of college food insecurity. The American College Health Assessment (ACHA), sponsored by the National College Health Association (NCHA), captures national and local data on the health habits and behaviors of college students [20]. This preexisting survey could incorporate food insecurity questions, along with determinants recommended by the GAO [141], to investigate food insecurity at a larger scale.

Additionally, more longitudinal research is needed to monitor food insecurity throughout the college years. To date, only two longitudinal studies are available in the college population. The first followed freshman throughout their first year to investigate how food security status fluctuates and predictive factors [120]. The second tracked students across two years of college to examine pathways in which food insecurity may impact academic performance [221]. Although both studies provide an initial glimpse on 
the progression of food insecurity across time in college students and some potential mechanisms for the detriments caused by food insecurity, more work is needed. Longitudinal studies that follow students from the start of college throughout their years until degree attainment are needed to track food insecurity in the college population over time. This research should aim to understand what factors are contributing to or protecting from student food insecurity and continue to investigate the mechanisms in which food insecurity is hindering student success.

Lastly, intervention research is needed to understand the effectiveness of proposed solutions to food insecurity on college campuses. The WISH4Campus toolkit, described in this dissertation, is one potential starting point. Implementation of the toolkit could allow for universities to choose a food insecurity initiative to implement on campus with instruction to monitor and evaluate program impact. Evaluation research is an integral part of understanding the sustainability and impact food insecurity initiatives may have on improving the food environment for students [214]. Additionally, evidence is needed on the impact of local, state, and nationally policy change to justify expanding support for college students [22]. Therefore, future research should aim to provide evidence of the impact both upstream and downstream initiatives can have on improving the food security status of college students.

\section{Conclusion}

Food is a basic need and a fundamental right that should be met for all including college students. Food insecurity is roadblock that can hinder many facets of college student well-being. The growing amount of research on the occurance of food insecurity on college campus calls for need to recognize college food insecurity as a public health priority. University officals have an obligation to promote student success and should provide adequate resources to improve student well-being. Further, local, state and federal governments can heed advice from the GAO and implement policy change to improve the food security of college students through affordable education and equitable access to food assistence programs [141]. Promoting food security among the college population can foster the physical, mental, and economic prosperity of emerging adults for years to come. 
References 


\section{References:}

1. Maslow A, Lewis KJ: Maslow's hierarchy of needs. Salenger Incorporated 1987, 14:987.

2. Alisha Coleman-Jensen MPR, Christian A. Gregory, and Anita Singh. 2018. Household Food Security in the United States in 2017, ERR-256, U.S. Department of Agriculture, Economic Research Service.

3. Bruening M, Argo K, Payne-Sturges D, Laska MN: The Struggle Is Real: A Systematic Review of Food Insecurity on Postsecondary Education Campuses. Journal of the Academy of Nutrition and Dietetics 2017.

4. Commission AR: Health Disparities in Appalachia. Appalachian Regional Commission: Washington, DC, USA 2017.

5. Baciu A, Negussie Y, Geller A, Weinstein JN, National Academies of Sciences E, Medicine: The State of Health Disparities in the United States. 2017.

6. Myers CA, Slack T, Martin CK, Broyles ST, Heymsfield SB: Regional disparities in obesity prevalence in the $U$ nited $S$ tates: A spatial regime analysis. Obesity 2015, 23:481-487.

7. Voeks JH, McClure LA, Go RC, Prineas RJ, Cushman M, Kissela BM, Roseman JM: Regional differences in diabetes as a possible contributor to the geographic disparity in stroke mortality: the REasons for Geographic And Racial Differences in Stroke Study. Stroke 2008, 39:1675-1680.

8. The Appalachian Region - Appalachian Regional Commission [https://www.arc.gov/appalachian_region/TheAppalachianRegion.asp]

9. SouthEastern Division of the Association of American Geographers [http://sedaag.org]

10. Adult Obesity Prevalence Maps [https://www.cdc.gov/obesity/data/prevalence-maps.html]

11. Center for Disease Control and Prevention: CDC identifies diabetes belt. CDC 2011. [https://www.cdc.gov/diabetes/pdfs/data/diabetesbelt.pdf]

12. United States Cancer Statistics [https://gis.cdc.gov/Cancer/USCS/DataViz.html]

13. Heart Disease Mortality by State [https://www.cdc.gov/nchs/pressroom/sosmap/heart_disease_mortality/heart_disease.htm]

14. United States Department of Health and Human Service. Health, United States, 2017: With special feature on mortality. Hyattsville, MD. 2018.

15. Appalachian Regional Commission: Economic assessment of Appalachia: an Appalachian regional development initiative report. Washington, DC2010.

16. America F: Rural Hunger Facts. Feeding America 2017.

17. Food Insecurity in the United States [http://map.feedingamerica.org]

18. Food insecurity - it's real and it's a problem in the High Country [https://today.appstate.edu/2017/11/01/insecurity]

19. Data Reports [https://www.arc.gov/research/DataReports.asp]

20. National College Health Assessment [https://www.acha.org/ncha]

21. Lee SD, Hanbazaza M, Ball GD, Farmer A, Maximova K, Willows ND: Food insecurity among postsecondary students in developed countries: A narrative review. British Food Journal 2018.

22. Nazmi A, Martinez S, Byrd A, Robinson D, Bianco S, Maguire J, Crutchfield RM, Condron K, Ritchie L: A systematic review of food insecurity among US students in higher education. Journal of Hunger \& Environmental Nutrition 2018:1-16.

23. Farahbakhsh J, Hanbazaza M, Ball GD, Farmer AP, Maximova K, Willows ND: Food insecure student clients of a university-based food bank have compromised health, dietary intake and academic quality. Nutrition \& dietetics 2017, 74:67-73. 
24. Mirabitur E, Peterson KE, Rathz C, Matlen S, Kasper N: Predictors of college-student food security and fruit and vegetable intake differ by housing type. Journal of American College Health 2016, 64:555-564.

25. Bruening M, Brennhofer S, van Woerden I, Todd M, Laska M: Factors Related to the High Rates of Food Insecurity among Diverse, Urban College Freshmen. Journal of the Academy of Nutrition and Dietetics 2016.

26. McArthur LH, Ball L, Danek AC, Holbert D: A High Prevalence of Food Insecurity Among University Students in Appalachia Reflects a Need for Educational Interventions and Policy Advocacy. Journal of nutrition education and behavior 2018, 1;50(6):564-572.

27. Knol LL, Robb CA, McKinley EM, Wood M: Food Insecurity, Self-rated Health, and Obesity among College Students. American Journal of Health Education 2017, 48:248-255.

28. Patton-Lopez MM, Lopez-Cevallos DF, Cancel-Tirado DI, Vazquez L: Prevalence and correlates of food insecurity among students attending a midsize rural university in Oregon. Journal of nutrition education and behavior 2014, 46:209-214.

29. Payne-Sturges DC, Tjaden A, Caldeira KM, Vincent KB, Arria AM: Student hunger on campus: food insecurity among college students and implications for academic institutions. American Journal of Health Promotion 2018, 32:349-354.

30. Hughes R, Serebryanikova I, Donaldson K, Leveritt M: Student food insecurity: The skeleton in the university closet. Nutrition \& dietetics 2011, 68:27-32.

31. Maroto ME: Food Insecurity among Community College Students: Prevalence and Relationship to GPA, Energy, and Concentration. ProQuest LLC 2013.

32. Martinez S, Brown E, Ritchie L: What Factors Increase Risk for Food Insecurity Among College Students? Journal of Nutrition Education and Behavior 2016, 48:S4.

33. Silva MR, Kleinert WL, Sheppard AV, Cantrell KA, Freeman-Coppadge DJ, Tsoy E, Roberts T, Pearrow M: The Relationship Between Food Security, Housing Stability, and School Performance Among College Students in an Urban University. Journal of College Student Retention: Research, Theory \& Practice 2015

34. Farahbakhsh J, Ball GDC, Farmer AP, Maximova K, Hanbazaza M, Willows ND: How do Student Clients of a University-based Food Bank Cope with Food Insecurity? Canadian Journal of Dietetic Practice and Research 2015, 76:200-203.

35. Hanbazaza M, Ball GD, Farmer AP, Maximova K, Farahbakhsh J, Willows ND: A Comparison of Characteristics and Food Insecurity Coping Strategies between International and Domestic Postsecondary Students Using a Food Bank Located on a University Campus. Canadian Journal of Dietetic Practice and Research 2017, 78:208-211.

36. Dubick J, Mathews B, Cady C: Hunger on campus: The challenge of food insecurity for college students. College and University Food Bank Alliance [http://studentsagainsthunger org/wpcontent/uploads/2016/10/Hunger_On_Campus pdf 2016.]

37. May C, Finch $\mathrm{T}$ : Implementing, embedding, and integrating practices: an outline of normalization process theory. Sociology 2009, 43:535-554.

38. May CR, Mair F, Finch T, MacFarlane A, Dowrick C, Treweek S, Rapley T, Ballini L, Ong BN, Rogers A: Development of a theory of implementation and integration: Normalization Process Theory. Implementation Science 2009, 4:29.

39. Ong BN, Morden A, Brooks L, Porcheret M, Edwards JJ, Sanders T, Jinks C, Dziedzic K: Changing policy and practice: making sense of national guidelines for osteoarthritis. Social Science \& Medicine 2014, 106:101-109.

40. Murray E, May C, Mair F: Development and formative evaluation of the e-Health Implementation Toolkit (e-HIT). BMC medical informatics and decision making 2010, 10:61. 
41. Peters Jr RJ, Ford K, Meshack A, Johnson RJ, Hill M, Peters RJ: The Relationship Between Perceived Psychological Distress, Behavioral Indicators and African-American Female College Student Food Insecurity. American Journal of Health Studies 2013, 28.

42. Maslow A, Lewis K: Maslow's hierarchy of needs. Salenger Incorporated 1987:14.

43. Gross $\mathrm{R}$, Schoeneberger $\mathrm{H}$, Pfeifer $\mathrm{H}$, Preuss $\mathrm{H}-\mathrm{J}$ : The four dimensions of food and nutrition security: definitions and concepts. SCN News 2000, 20:20-25.

44. Leroy JL, Ruel M, Frongillo EA, Harris J, Ballard TJ: Measuring the food access dimension of food security: A critical review and mapping of indicators. Food and nutrition bulletin 2015, 36:167195.

45. Webb P, Coates J, Frongillo EA, Rogers BL, Swindale A, Bilinsky P: Measuring household food insecurity: why it's so important and yet so difficult to do. The Journal of nutrition 2006, 136:1404S-1408S.

46. Holben DH, Marshall MB: Position of the Academy of Nutrition and Dietetics: food insecurity in the United States. Journal of the Academy of Nutrition and Dietetics 2017, 117:1991-2002.

47. Robaina KA, Martin KS: Food insecurity, poor diet quality, and obesity among food pantry participants in Hartford, CT. Journal of nutrition education and behavior 2013, 45:159-164.

48. Hanson KL, Connor LM: Food insecurity and dietary quality in US adults and children: a systematic review-. The American journal of clinical nutrition 2014, 100:684-692.

49. Bhattacharya J, Currie J, Haider S: Poverty, food insecurity, and nutritional outcomes in children and adults. Journal of health economics 2004, 23:839-862.

50. Kaiser LL, Lamp CL, Johns MC, Sutherlin JM, Harwood JO, Melgar-Quinonez HR: Food security and nutritional outcomes of preschool-age Mexican-American children. Journal of the American Dietetic Association 2002, 102:924-929.

51. Eicher-Miller HA, Mason AC, Weaver CM, McCabe GP, Boushey CJ: Food Insecurity Is Associated with Diet and Bone Mass Disparities in Early Adolescent Males but Not Females in the United States-3. The Journal of nutrition 2011, 141:1738-1745.

52. Eicher-Miller HA, Mason AC, Weaver CM, McCabe GP, Boushey CJ: Food insecurity is associated with iron deficiency anemia in US adolescents. The American journal of clinical nutrition 2009, 90:1358-1371.

53. Rose $D$, Oliveira V: Nutrient intakes of individuals from food-insufficient households in the United States. American Journal of Public Health 1997, 87:1956-1961.

54. Montoya MF, Hite AW, Rohrbeck P, Bawa B, Akinwolemiwa OO, Benson AM, Hollen ML, Ortiz CAR: Quality of diet related to food insecurity and food stamps use among older people. Ageing Research 2011, 2:3.

55. Basiotis PP, Lino M: Food insufficiency and prevalence of overweight among adult women. Family Economics and Nutrition Review 2003, 15:55.

56. Dixon LB, Winkleby MA, Radimer KL: Dietary intakes and serum nutrients differ between adults from food-insufficient and food-sufficient families: Third National Health and Nutrition Examination Survey, 1988-1994. The Journal of nutrition 2001, 131:1232-1246.

57. Kendall A, Olson CM, Frongillo Jr EA: Relationship of hunger and food insecurity to food availability and consumption. Journal of the American Dietetic Association 1996, 96:1019-1024.

58. Gundersen C, Ziliak JP: Food insecurity and health outcomes. Health Affairs 2015, 34:18301839.

59. McIntyre L, Williams JV, Lavorato DH, Patten S: Depression and suicide ideation in late adolescence and early adulthood are an outcome of child hunger. Journal of affective disorders 2013, 150:123-129. 
60. Melchior M, Caspi A, Howard LM, Ambler AP, Bolton H, Mountain N, Moffitt TE: Mental health context of food insecurity: a representative cohort of families with young children. Pediatrics 2009, 124:e564-e572.

61. Melchior M, Chastang J-F, Falissard B, Galéra C, Tremblay RE, Côté SM, Boivin M: Food insecurity and children's mental health: a prospective birth cohort study. PloS one 2012, 7:e52615.

62. Whitaker RC, Phillips SM, Orzol SM: Food insecurity and the risks of depression and anxiety in mothers and behavior problems in their preschool-aged children. Pediatrics 2006, 118:e859e868.

63. Huang J, Matta Oshima KM, Kim Y: Does food insecurity affect parental characteristics and child behavior? Testing mediation effects. Social Service Review 2010, 84:381-401.

64. Howard LL: Does food insecurity at home affect non-cognitive performance at school? A longitudinal analysis of elementary student classroom behavior. Economics of Education Review 2011, 30:157-176.

65. Shankar P, Chung R, Frank DA: Association of food insecurity with children's behavioral, emotional, and academic outcomes: a systematic review. Journal of Developmental \& Behavioral Pediatrics 2017, 38:135-150.

66. Tarasuk V, Mitchell A, McLaren L, McIntyre L: Chronic physical and mental health conditions among adults may increase vulnerability to household food insecurity. The Journal of nutrition 2013:jn. 113.178483.

67. Weaver L, Fasel CB: A Systematic Review of the Literature on the Relationships between Chronic Diseases and Food Insecurity. Food and Nutrition Sciences 2018, 9:519.

68. Beaulieu S: Current and Prospective Scope of Hunger and Food Security in America: A Review of Current Research. In A Report for the US President and Congress Prepared Under Contract No: AG-3198-C-14-0004 in Response to Section2014: 113-176.

69. Peterkin BB, Rizek RL, Tippett KS: Nationwide food consumption survey, 1987. Nutrition Today 1988, 23:18-27.

70. Wunderlich G, Norwood J: Food Insecurity and Hunger in the United States: An Assessment of the Measure. 2006. National Research Countil of the National Academies: Washington, DC.

71. Jones AD, Ngure FM, Pelto G, Young SL: What are we assessing when we measure food security? A compendium and review of current metrics. Advances in Nutrition 2013, 4:481-505.

72. Bickel G, Nord M, Price C, Hamilton W, Cook J: Guide to measuring household food security. Revised; 2000.

73. Connell CL, Nord M, Lofton KL, Yadrick K: Food security of older children can be assessed using a standardized survey instrument. The Journal of Nutrition 2004, 134:2566-2572.

74. Harrison GG, Stormer A, Herman DR, Winham DM: Development of a Spanish-language version of the US household food security survey module. The Journal of nutrition 2003, 133:11921197.

75. Marques ES, Reichenheim ME, de Moraes CL, Antunes MM, Salles-Costa R: Household food insecurity: a systematic review of the measuring instruments used in epidemiological studies. Public health nutrition 2015, 18:877-892.

76. Ashby S, Kleve S, McKechnie R, Palermo C: Measurement of the dimensions of food insecurity in developed countries: a systematic literature review. Public health nutrition 2016, 19:28872896.

77. Gollub EA, Weddle DO: Improvements in nutritional intake and quality of life among frail homebound older adults receiving home-delivered breakfast and lunch. Journal of the American Dietetic Association 2004, 104:1227-1235. 
78. Kuyper EM, Espinosa-Hall G, Lamp CL, Martin AC, Metz DL, Smith D, Townsend MS, Kaiser LL: Development of a tool to assess past food insecurity of immigrant La tino mothers. Journal of Nutrition Education and Behavior 2006, 38:378-382.

79. Kuyper EM, Smith D, Kaiser LL: Does food insecurity influence child feeding practices? Journal of Hunger \& Environmental Nutrition 2009, 4:147-157.

80. Sharkey JR, Nalty C, Johnson CM, Dean WR: Children's very low food security is associated with increased dietary intakes in energy, fat, and added sugar among Mexican-origin children (6-11 y) in Texas border Colonias. BMC pediatrics 2012, 12:16.

81. Jimenez-Cruz A, Bacardi-Gascon M, Spindler A: Obesity and hunger among Mexican-Indian migrant children on the US-Mexico border. International Journal of Obesity 2003, 27:740.

82. Hager ER, Quigg AM, Black MM, Coleman SM, Heeren T, Rose-Jacobs R, Cook JT, de Cuba SAE, Casey $\mathrm{PH}$, Chilton M: Development and validity of a 2-item screen to identify families at risk for food insecurity. Pediatrics 2010, 126:e26-e32.

83. Swindle TM, Whiteside-Mansell L, McKelvey L: Food insecurity: validation of a two-item screen using convergent risks. Journal of Child and Family Studies 2013, 22:932-941.

84. Girard A, Sercia P: Immigration and food insecurity: social and nutritional issues for recent immigrants in Montreal, Canada. International Journal of Migration, Health and Social Care 2013, 9:32-45.

85. Weiser SD, Bangsberg DR, Kegeles S, Ragland K, Kushel MB, Frongillo EA: Food insecurity among homeless and marginally housed individuals living with HIV/AIDS in San Francisco. AIDS and Behavior 2009, 13:841-848.

86. Weiser SD, Hatcher A, Frongillo EA, Guzman D, Riley ED, Bangsberg DR, Kushel MB: Food insecurity is associated with greater acute care utilization among HIV-infected homeless and marginally housed individuals in San Francisco. Journal of general internal medicine 2013, 28:91-98.

87. Weiser SD, Yuan C, Guzman D, Frongillo EA, Riley ED, Bangsberg DR, Kushel MB: Food insecurity and HIV clinical outcomes in a longitudinal study of urban homeless and marginally housed HIV-infected individuals. AIDS 2013, 27:2953.

88. Townsend MS, Kaiser LL, Allen LH, Joy AB, Murphy SP: Selecting items for a food behavior checklist for a limited-resource audience. Journal of Nutrition Education and Behavior 2003, 35:69-82.

89. Bartfeld J, Dunifon R, Nord M, Carlson S: What factors account for state-to-state differences in food security? : United States Department of Agriculture, Economic Research Service; 2006.

90. Gundersen C, Ziliak JP: Food Insecurity Research in the United States: Where We Have Been and Where We Need to Go. Applied Economic Perspectives and Policy 2018, 40:119-135.

91. Pheley AM, Holben DH, Graham AS, Simpson C: Food security and perceptions of health status: a preliminary study in rural Appalachia. The Journal of Rural Health 2002, 18:447-453.

92. Holben DH, McClincy MC, Holcomb Jr JP, Dean KL, Walker CE: Food security status of households in Appalachian Ohio with children in Head Start. Journal of the American Dietetic Association 2004, 104:238-241.

93. Holben DH, Pheley AM: Peer reviewed: diabetes risk and obesity in food-insecure households in rural Appalachian Ohio. Preventing chronic disease 2006, 3.

94. Rhone A, Ploeg M, Dicken C, Williams R, Breneman V: Low-income and Low-supermarket-access Census Tracts, 2010-2015. United States Department of Agriculture, Economic Research Service; 2017.

95. Morton LW, Bitto EA, Oakland MJ, Sand M: Solving the problems of lowa food deserts: Food insecurity and civic structure. Rural Sociology 2005, 70:94-112. 
96. Morton LW, Blanchard TC: Starved for access: life in rural America's food deserts. Rural Realities 2007, 1:1-10.

97. Bartfeld JS, Ryu J-H, Wang L: Local characteristics are linked to food insecurity among households with elementary school children. Journal of Hunger \& Environmental Nutrition 2010, 5:471-483.

98. United States Department of Agriculture: Access to affordable and nutritious food: measuring and understanding food deserts and their consequences. Report to Congress Washington, DC; 2009

99. Hege A, Ball L, Christiana RW, Wallace C, Hubbard C, Truesdale D, Hege J, Fleming H: Social Determinants of Health and the Effects on Quality of Life and Well-being in 2 Rural Appalachia Communities: The Community Members' Perspective and Implications for Health Disparities. Family \& community health 2018, 41:244-254.

100. National Student Clearninghouse Research Center: Total Enrollment Estimates Spring 2018. [https://nscresearchcenter.org/currenttermenrollmentestimate-spring2018/]

101. Snyder T, de Brey C, Dillow S: Digest of Education Statistics 2017. National Center for Education Statistics2019.

102. Deil-Amen R: The "traditional" college student: A smaller and smaller minority and its implications for diversity and access institutions. In Mapping Broad-Access Higher Education Conference at Stanford University 2011

103. Ma J, Baum S, Pender M, Bell DW: Trends in College Pricing, 2015. Trends in Higher Education Series. College Board 2015.

104. Mitchell M, Leachman M, Masterson K: Funding down, tuition up: State cuts to higher education threaten quality and affordability at public colleges. Center on Budget and Policy Priorities 2016.

105. Mitchell M, Palacios V, Leachman M: States are still funding higher education below prerecession levels. Journal of Collective Bargaining in the Academy 2015:71.

106. Tuition and Fees over Time [https://trends.collegeboard.org/college-pricing/figurestables/tuition-fees-room-board-over-time]

107. Reppond HA, Thomas-Brown K, Sampson NR, Price CE: Addressing Food Insecurity in College: Mapping a Shared Conceptual Framework for Campus Pantries in Michigan. Analyses of Social Issues and Public Policy 2018, 18:378-399.

108. Forman M, Mangini L, Dong Y, Hernandez L, Fingerman K: Food Insecurity and Hunger: Quiet Public Health Problems on Campus. J Nutr Food Sci 2018, 8:2.

109. Glik D, Martinez S: College students identify university support for basic needs and life skills as key ingredient in addressing food insecurity on campus. California Agriculture 2017, 71:130138.

110. Chaparro MP, Zaghloul SS, Holck P, Dobbs J: Food insecurity prevalence among college students at the University of Hawai'i at Mānoa. Public health nutrition 2009, 12:2097-2103.

111. Food Insecurity in the US: Key Statistics \& Graphics [https://www.ers.usda.gov/topics/foodnutrition-assistance/food-security-in-the-us/key-statistics-graphics/\#trends]

112. Nord M: Household Food Security in the US (2006). DIANE publishing; 2008.

113. Kassier S, Veldman F: Food security status and academic performance of students on financial aid: The case of University of KwaZulu-Natal. Alternation 2013, 9:248-264.

114. Van den Berg L, Raubenheimer J: Food insecurity among students at the University of the Free State, South Africa. South African Journal of Clinical Nutrition 2015, 28:160-169.

115. Gaines A, Robb CA, Knol LL, Sickler S: Examining the role of financial factors, resources and skills in predicting food security status among college students. International Journal of Consumer Studies 2014, 38:374-384. 
116. Evans N, Lasen M, Tsey K: A systematic review of rural development research: Characteristics, design quality and engagement with sustainability. Springer; 2015.

117. Freudenberg N, Manzo L, Jones H, Kwan A, Tsui E, Gagnon M: Food insecurity at CUNY: Results from a survey of CUNY undergraduate students. Campaign for a Healthy CUNY, New York, NY 2011.

118. Meza A, Altman E, Martinez S, Leung CW: "It'sa Feeling That One Is Not Worth Food": A Qualitative Study Exploring the Psychosocial Experience and Academic Consequences of Food Insecurity Among College Students. Journal of the Academy of Nutrition and Dietetics 2018.

119. Poll KL, Holben $\mathrm{DH}$, Valliant $\mathrm{M}$, Joung $\mathrm{H}-\mathrm{W}$ : Food insecurity is associated with disordered eating behaviors in NCAA division 1 male collegiate athletes. Journal of American College Health 2018:1-5.

120. Bruening M, van Woerden I, Todd M, Laska MN: Hungry to learn: the prevalence and effects of food insecurity on health behaviors and outcomes over time among a diverse sample of university freshmen. International Journal of Behavioral Nutrition and Physical Activity 2018, 15:9.

121. Hanna L: Evaluation of food insecurity among college students. American International Journal of Contemporary Research 2014, 4:46-49.

122. Martinez SM, Frongillo EA, Leung C, Ritchie L: No food for thought: Food insecurity is related to poor mental health and lower academic performance among students in California's public university system. Journal of health psychology 2018

123. El Zein A, Mathews A, House L, Shelnutt K: Why Are Hungry College Students Not Seeking Help? Predictors of and Barriers to Using an On-Campus Food Pantry. Nutrients 2018, 10:1163.

124. Morris LM, Smith S, Davis J, Null DB: The prevalence of food security and insecurity among Illinois university students. Journal of nutrition education and behavior 2016, 48:376-382. e371.

125. Silva MR, Kleinert WL, Sheppard AV, Cantrell KA, Freeman-Coppadge DJ, Tsoy E, Roberts T, Pearrow M: The relationship between food security, housing stability, and school performance among college students in an urban university. Journal of College Student Retention: Research, Theory \& Practice 2017, 19:284-299.

126. Davidson A, Morrell J: Food insecurity prevalence among university students in New Hampshire. Journal of Hunger \& Environmental Nutrition 2018:1-10.

127. McArthur LH, Fasczewski KS, Wartinger E, Miller J: Freshmen at a University in Appalachia Experience a Higher Rate of Campus than Family Food Insecurity. Journal of community health 2018:1-8.

128. Twill SE, Bergdahl J, Fensler R: Partnering to build a pantry: A university campus responds to student food insecurity. Journal of Poverty 2016, 20:340-358.

129. Phillips E, McDaniel A, Croft A: Food Insecurity and Academic Disruption Among College Students. Journal of Student Affairs Research and Practice 2018:1-20.

130. Cuy Castellanos D, Holcomb J: Food insecurity, financial priority, and nutrition literacy of university students at a mid-size private university. Journal of American College Health 2018:15.

131. Miles R, McBeath B, Brockett S, Sorenson P: Prevalence and Predictors of Social Work Student Food Insecurity. Journal of Social Work Education 2017, 53:651-663.

132. Wooten R, Spence M, Colby S, Steeves EA: Assessing food insecurity prevalence and associated factors among college students enrolled in a university in the Southeast USA. Public Health Nutrition 2018:1-8.

133. Biediger-Friedman L, Sanchez B, He M, Guan J, Yin Z: Food Purchasing Behaviors and Food Insecurity among College Students at The University of Texas at San Antonio. Journal of Food Security 2016, 4:52-57. 
134. Calvez K, Miller C, Thomas L, Vazquez D, Walenta J: The university as a site of food insecurity: Evaluating the foodscape of Texas A\&M University's main campus. The Southwestern Geographer 2016, 19:1-14.

135. Broton KM, Goldrick-Rab S: Going without: An exploration of food and housing insecurity among undergraduates. Educational Researcher 2018, 47:121-133.

136. Broton K, Weaver K, Mai M: Hunger in Higher Education: Experiences and Correlates of Food Insecurity among Wisconsin Undergraduates from Low-Income Families. Social Sciences 2018, 7:179.

137. Wattick R, Hagedorn R, Olfert M: Relationship between Diet and Mental Health in a Young Adult Appalachian College Population. Nutrients 2018, 10:957.

138. Wintz R, Chriest N: Food insecurity within the University student population A survey at the University of Alaska Anchorage. 2016.

139. MacDonald A: Food insecurity and educational attainment at the University of Arkansas. 2016.

140. Shapiro E, Leighton R: Food for Thought: A look at food insecurity at the University of Minnesota. 2018.

141. Office USGA: Food Insecurity Better Information Could Help Eligible College Students Access Federal Food Assistance Benefits. Washington, DC2018.

142. Knol LL, Robb CA, McKinley EM, Wood M: Food Insecurity Is Related to Financial Aid Debt Among College Students. Journal of Family \& Consumer Sciences 2018, 110:35-41.

143. Martinez SM, Webb K, Frongillo EA, Ritchie LD: Food insecurity in California's public university system: What are the risk factors? Journal of Hunger \& Environmental Nutrition 2018, 13:1-18.

144. Hagedorn RL, Olfert MD: Food Insecurity and Behavioral Characteristics for Academic Success in Young Adults Attending an Appalachian University. Nutrients 2018, 10:361.

145. van Woerden I, Hruschka D, Bruening M: Food insecurity negatively impacts academic performance. Journal of Public Affairs 2018:e1864.

146. Pelletier JE, Laska MN: Campus food and beverage purchases are associated with indicators of diet quality in college students living off campus. American Journal of Health Promotion 2013, 28:80-87.

147. Knol LL, Robb CA, McKinley EM, Wood M: Very Low Food Security Status is Related to Lower Cooking Self-Efficacy and Less Frequent Food Preparation Behaviors Among College Students. Journal of nutrition education and behavior 2018.

148. DeBerard MS, Spielmans GI, Julka DL: Predictors of academic achievement and retention among college freshmen: A longitudinal study. College student journal 2004, 38:66-81.

149. Henry L: Understanding Food Insecurity Among College Students: Experience, motivation, and local solutions. Annals of Anthropological Practice 2017, 41:6-19.

150. Novak H, Johnson JJ: Students Against Hunger: An Approach to Food Insecurity at a Large Public Land Grant University. Journal of Student Affairs, 26:99.

151. College and University Food Bank Alliance [https://cufba.org]

152. Buch K, Langley S, Johnson T, Coleman N: A University-Community Partnership to Combat Food Insecurity among College Students. Partnerships: A Journal of Service-Learning and Civic Engagement 2016, 7:16-26.

153. Manry J, Mills S, Ochs D: Combatting Food Insecurity on a College Campus. International Journal for Innovation Education and Research 2017, 5:67-74.

154. Coleman-Jensen A, Rabbitt MP, Gregory C, Singh A: Household Food Security in the United States in 2015. Economic Research Service Report 2016.

155. Cook JT, Frank DA: Food security, poverty, and human development in the United States. Annals of the New York Academy of Sciences 2008, 1136:193-209. 
156. Bocquier A, Vieux F, Lioret S, Dubuisson C, Caillavet F, Darmon N: Socio-economic characteristics, living conditions and diet quality are associated with food insecurity in France. Public health nutrition 2015, 18:2952-2961.

157. Coleman-Jensen A, Gregory C, Singh A: Household food security in the United States in 2013. 2014.

158. Seligman HK, Laraia BA, Kushel MB: Food insecurity is associated with chronic disease among low-income NHANES participants. The Journal of nutrition 2010, 140:304-310.

159. Haldemen L: A comparison of food insecurity levels and weight status among rural-and urbanresiding Latinos/Hispanics in North Carolina. Food Assistance and Nutrition Programs: RIDGE Prospects 2006.

160. Champagne CM, Casey PH, Connell CL, Stuff JE, Gossett JM, Harsha DW, McCabe-Sellers B, Robbins JM, Simpson PM, Weber JL: Poverty and food intake in rural America: diet quality is lower in food insecure adults in the Mississippi Delta. Journal of the American Dietetic Association 2007, 107:1886-1894.

161. Rose D, Bodor JN: Household food insecurity and overweight status in young school children: results from the Early Childhood Longitudinal Study. Pediatrics 2006, 117:464-473.

162. Mello JA, Gans KM, Risica PM, Kirtania U, Strolla LO, Fournier L: How is food insecurity associated with dietary behaviors? An analysis with low-income, ethnically diverse participants in a nutrition intervention study. J Am Diet Assoc 2010, 110:1906-1911.

163. Tarasuk VS: Household food insecurity with hunger is associated with women's food intakes, health and household circumstances. The Journal of nutrition 2001, 131:2670-2676.

164. Alaimo K, Olson CM, Frongillo EA: Food insufficiency and American school-aged children's cognitive, academic, and psychosocial development. Pediatrics 2001, 108:44-53.

165. Jyoti DF, Frongillo EA, Jones SJ: Food insecurity affects school children's academic performance, weight gain, and social skills. The Journal of nutrition 2005, 135:2831-2839.

166. Perez-Escamilla R, Pinheiro de Toledo Vianna R: Food insecurity and the behavioral and intellectual development of children: a review of the evidence. Journal of Applied Research on Children: Informing Policy for Children at Risk 2012, 3:9.

167. McLaughlin KA, Green JG, Alegría M, Costello EJ, Gruber MJ, Sampson NA, Kessler RC: Food insecurity and mental disorders in a national sample of US adolescents. Journal of the American Academy of Child \& Adolescent Psychiatry 2012, 51:1293-1303.

168. Weaver $\amalg$, Hadley $C$ : Moving beyond hunger and nutrition: a systematic review of the evidence linking food insecurity and mental health in developing countries. Ecology of food and nutrition 2009, 48:263-284.

169. Weinreb L, Wehler C, Perloff J, Scott R, Hosmer D, Sagor L, Gundersen C: Hunger: its impact on children's health and mental health. Pediatrics 2002, 110:e41-e41.

170. Davison KM, Gondara L, Kaplan BJ: Food Insecurity, Poor Diet Quality, and Suboptimal Intakes of Folate and Iron Are Independently Associated with Perceived Mental Health in Canadian Adults. Nutrients 2017, 9.

171. Davison KM, Holloway C, Gondara L, Hatcher AS: Independent associations and effect modification between lifetime substance use and recent mood disorder diagnosis with household food insecurity. PLoS One 2018, 13:e0191072.

172. Cady CL: Food insecurity as a student issue. Journal of College and Character 2014, 15:265-272.

173. Broton K, Goldrick-Rab S: The dark side of college (un) affordability: Food and housing insecurity in higher education. Change: The Magazine of Higher Learning 2016, 48:16-25.

174. Couto RA: Appalachian health and well-being. University Press of Kentucky; 2012.

175. Shaw TC, DeYoung AJ, Rademacher EW: Educational attainment in Appalachia: Growing with the nation, but challenges remain. Journal of Appalachian Studies 2004, 10:307-329. 
176. Kempson K, Keenan DP, Sadani PS, Adler A: Maintaining food sufficiency: Coping strategies identified by limited-resource individuals versus nutrition educators. Journal of Nutrition Education and Behavior 2003, 35:179-188.

177. Pinard C, Smith TM, Calloway EE, Fricke HE, Bertmann FM, Yaroch AL: Auxiliary measures to assess factors related to food insecurity: Preliminary testing and baseline characteristics of newly designed hunger-coping scales. Preventive medicine reports 2016, 4:289-295.

178. Maxwell DG: Measuring food insecurity: the frequency and severity of "coping strategies". Food policy 1996, 21:291-303.

179. World Health Organization: Obesity: preventing and managing the global epidemic. World Health Organization; 2000.

180. Thompson D: Ranking predictors in logistic regression. Paper D10-2009 [http://www mwsug org/proceedings/2009/stats/MWSUG-2009-D10 pdf]

181. Hughes R: Food insecurity amongst university students. Nutridate 2012, 23:2.

182. Martinez S: Student Food Access and Security Study. Global Food Initiative; 2016.

183. Ryland EB, Riordan RJ, Brack G: Selected characteristics of high-risk students and their enrollment persistence. Journal of College Student Development 1994.

184. Brown N, Cross E: Coping resources and family environment for female engineering students. College Student Journal 1997, 31:282-288.

185. Goldrick-Rab S, Richardson J, Hernandez A: Hungry and homeless in college: Results from a national study of basic needs insecurity in higher education. Madison: Wisconsin Hope Lab and the Association of Community College Trustees; 2017.

186. Pollard K, Jacobsen LA: The Appalachian region in 2010: A census data overview chartbook. [http://wwwarcgov/research/researchreportdetailsasp] 2011.

187. Myers AM, Painter MA: Food insecurity in the United States of America: an examination of race/ethnicity and nativity. Food Security 2017, 9:1419-1432.

188. Leung CW, Epel ES, Willett WC, Rimm EB, Laraia BA: Household Food Insecurity Is Positively Associated with Depression among Low-Income Supplemental Nutrition Assistance Program Participants and Income-Eligible Nonparticipants1-3. The Journal of nutrition 2014, 145:622627.

189. Siefert K, Heflin CM, Corcoran ME, Williams DR: Food insufficiency and physical and mental health in a longitudinal survey of welfare recipients. Journal of health and social behavior 2004, 45:171-186.

190. Martin M, Maddocks E, Chen Y, Gilman S, Colman I: Food insecurity and mental illness: disproportionate impacts in the context of perceived stress and social isolation. Public health 2016, 132:86-91.

191. Pryor L, Lioret S, Van Der Waerden J, Fombonne É, Falissard B, Melchior M: Food insecurity and mental health problems among a community sample of young adults. Social psychiatry and psychiatric epidemiology 2016, 51:1073-1081.

192. Gundersen C, Ziliak JP: Food Insecurity And Health Outcomes. Health Aff 2015, 34:1830-1839.

193. Purdam K, Garratt EA, Esmail A: Hungry? Food insecurity, social stigma and embarrassment in the UK. Sociology 2016, 50:1072-1088.

194. David E: Food Insecurity in America. 2017.

195. Leung CW, Epel ES, Ritchie LD, Crawford PB, Laraia BA: Food insecurity is inversely associated with diet quality of lower-income adults. Journal of the Academy of Nutrition and Dietetics 2014, 114:1943-1953. e1942.

196. Nnakwe NE: Dietary Patterns and Prevalence of Food Insecurity Among Low-Income Families Participating in Community Food Assistance Programs in a Midwest Town. Family and Consumer Sciences Research Journal 2008, 36:229-242. 
197. Kerr S, Johnson VK, Gans SE, Krumrine J: Predicting adjustment during the transition to college: Alexithymia, perceived stress, and psychological symptoms. Journal of College Student Development 2004, 45:593-611.

198. Pancer SM, Hunsberger B, Pratt MW, Alisat S: Cognitive complexity of expectations and adjustment to university in the first year. Journal of Adolescent Research 2000, 15:38-57.

199. Goldrick-Rab S, Broton K, Eisenberg D: Hungry to learn: Addressing food \& housing insecurity among undergraduates. Wisconsin Hope Lab 2015:1-25.

200. Ginder SA, Kelly-Reid JE, Mann FB: Enrollment and Employees in Postsecondary Institutions, Fall 2016; and Financial Statistics and Academic Libraries, Fiscal Year 2016: First Look (Provisional Data). NCES 2018-002. National Center for Education Statistics 2017.

201. Horn L, Nevill S, Griffith J: Profile of Undergraduates in US Postsecondary Education Institutions, 2003-04: With a Special Analysis of Community College Students. Statistical Analysis Report. NCES 2006-184. National Center for Education Statistics 2006.

202. Tierney WG: Organizational socialization in higher education. The Journal of Higher Education 1997, 68:1-16.

203. Friel S, Ford L: Systems, food security and human health. Food security 2015, 7:437-451.

204. Food security in the U.S.: measurement [http://www.ers.usda.gov/topics/food-nutritionassistance/food-security-in-the-us/measurement.aspx,]

205. Committee FR: Comprehensive Resource for Food Recovery Programs. In Conference for Food Protection2016.

206. United States Department of Agriculture, Food and Nutrition Service [https://www.fns.usda.gov/snap/supplemental-nutrition-assistance-program-education-snaped

207. Facts About SNAP, Food and Nutrition Service [https://www.fns.usda.gov/snap/facts-aboutsnap]

208. Yamada J, Shorkey A, Barwick M, Widger K, Stevens BJ: The effectiveness of toolkits as knowledge translation strategies for integrating evidence into clinical care: a systematic review. BMJ open 2015, 5:e006808.

209. Waddell C: So much research evidence, so little dissemination and uptake: mixing the useful with the pleasing. Evidence-Based Mental Health 2001, 4:3-5.

210. Bellamy JL, Bledsoe SE, Traube DE: The current state of evidence-based practice in social work: A review of the literature and qualitative analysis of expert interviews. Journal of EvidenceBased Social Work 2006, 3:23-48.

211. Barac R, Stein S, Bruce B, Barwick M: Scoping review of toolkits as a knowledge translation strategy in health. BMC medical informatics and decision making 2014, 14:121.

212. Kellogg Commission on the Future of State and Land-Grant Universities Returning to our roots: The engaged institution. National Association of State Universities and Land-Grant Colleges, Office of Public Affairs; 1999.

213. \#RealCollege Survey [https://realcollege.org/realcollege-survey/]

214. Paola J, DeBate R: Employing Evaluation Research to Inform Campus Food Pantry Policy. Health Behavior and Policy Review 2018, 5:83-94.

215. Group ICEtBR: Designing theoretically-informed implementation interventions. Implementation Science 2006, 1:4.

216. Adler NE, Newman K: Socioeconomic disparities in health: pathways and policies. Health affairs 2002, 21:60-76.

217. Cude B, Lawrence F, Lyons A, Metzger K, LeJeune E, Marks L, Machtmes K: College students and financial literacy: What they know and what we need to learn. Proceedings of the Eastern Family Economics and Resource Management Association 2006, 102:106-109. 
218. Lusardi A, Mitchell OS, Curto V: Financial literacy among the young. Journal of consumer affairs 2010, 44:358-380.

219. Melgar-Quinonez H, Nord M, Perez-Escamilla R, Segall-Correa A: Psychometric properties of a modified US-household food security survey module in Campinas, Brazil. European Journal of Clinical Nutrition 2008, 62:665.

220. Derrickson JP, Fisher AG, Anderson JE: The core food security module scale measure is valid and reliable when used with Asians and Pacific Islanders. The Journal of nutrition 2000, 130:2666-2674.

221. Raskind IG, Haardörfer R, Berg CJ: Food insecurity, psychosocial health and academic performance among college and university students in Georgia, USA. Public health nutrition 2019, 22:476-485.

222. Decker D, Flynn M: Food Insecurity and Chronic Disease: Addressing Food Access as a Healthcare Issue. Rhode Island Medical Journal 2018, 101.

223. Xiao H, Carney DM, Youn SJ, Janis RA, Castonguay LG, Hayes JA, Locke BD: Are we in crisis? National mental health and treatment trends in college counseling centers. Psychological services 2017, 14:407.

224. Hager ER, Quigg AM, Black MM, Coleman SM, Heeren T, Rose-Jacobs R, Cook JT, Ettinger de Cuba SA, Casey PH, Chilton M, et al: Development and validity of a 2-item screen to identify families at risk for food insecurity. Pediatrics 2010, 126:e26-32.

225. Medina C, Umoren J, Yao P, Ozier A: Food Insecurity, BMI, Depression, and Eating Behaviors in College Students. Journal of the Academy of Nutrition and Dietetics 2018, 118:A79.

226. Nelson TF, Gortmaker SL, Subramanian S, Cheung L, Wechsler H: Disparities in overweight and obesity among US college students. American journal of health behavior 2007, 31:363-373.

227. Wolfe WS, Frongillo EA, Valois P: Understanding the experience of food insecurity by elders suggests ways to improve its measurement. The Journal of nutrition 2003, 133:2762-2769. 
Appendix 


\section{Appendix A: Institutional Review Board Approval}

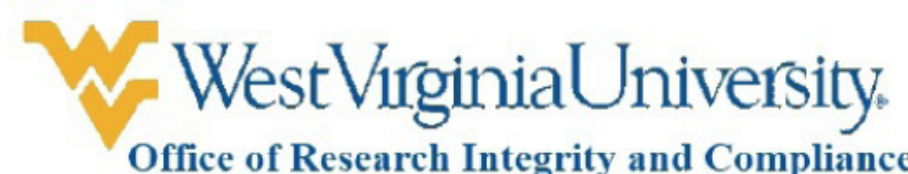

Office of Research Integrity and Compliance

886 Chestnut Ridge Road Morgantown, WV 26506

Approval of Human Research Protocol

$11 / 08 / 2018$

To: Melissa Olfert

From: WVU Office of Research Integrity \& Compliance

Protocol Type: Expedited

Approval Date: 11/08/2018

Submission Type: Initial

Expiration Date: 11/07/2019

Funding: N/A

WVU Protocol \#: 1802980009

Protocol Title: WISH4Campus - Hunger Prevention

The West Virginia University Institutional Review Board has reviewed and granted your request for approval of Expedited protocol 1802980009, in accordance with the Federal regulations 45 CFR 46, 21

CFR 50, and 21 CFR 56 (when applicable). Additional details concerning the review are below:

- Category 7. Research on individual or group characteristics or behavior (including, but not limited to, research on perception, cognition, motivation, identity, language, communication, cultural beliefs or practices, and social behavior) or research employing survey, interview, oral history, focus group, program evaluation, human factors evaluation, or quality assurance methodologies. [NOTE: Some research in this category may be exempt from the DHHS regulations for the protection of human subjects. See Exempt Categories and 45 CFR 46.101(b)(2) and (b)(3). This listing refers only to research that is not exempt.]

The following documents were reviewed and approved for use as part of this submission. Only the documents listed below may be used in the research. Please access and print the files in the Notes \& Attachments section of your approved protocol.

- WISH4Campus Toolkit Consent .pdf

- WISH4Campus Toolkit Survey.pdf

- WISH4CampusToolkit_Email_recruitment.pdf

Protocol \#: 1802980009

FWA: 00005078

IORG: 0000194
Phone: 304-293-7073

Fax: 304-293-3098

Email: IRB@mail.wvu.edu 
- WISH4Campus Toolkit_Sample.pdf

\section{WVU IRB approval of protocol 1802980009 will expire on 11/07/2019.}

If any study related activities are to continue beyond the expiration date, a renewal application should be submitted no later than four (4) weeks prior to the expiration date. It is your responsibility to submit your protocol for continuing review.

Once you begin your human subjects research, the following regulations apply:

1. Unanticipated or serious adverse events and/or side effects encountered in this research study must be reported to the IRB within five (5) days using the Notify IRB action in the electronic protocol.

2. Any modifications to the study protocol or informed consent form must be reviewed and approved by the IRB prior to implementation. These modifications should be submitted as an amendment.

3. You may not use a modified informed consent form until it has been reviewed and approved by the WVU IRB. Only consent forms with the WVU+ke watermark may be used to obtain informed consent from participants.

The Office of Research Integrity and Compliance will be glad to provide assistance to you throughout the research process. Please feel free to contact us by phone, at 304.293 .7073 or by email at $\underline{\mathrm{IRB} @ \text { mail.wvu.edu. }}$

Sincerely,

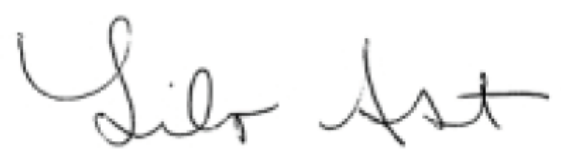

Lile Ast

IRB Administrator 


\section{Appendix B: Aim 1 and 2 Survey}

\section{Food Insecurity Questionnaire}

Greetings! You are invited to take part in a research study about your usual access to food. This study is being conducted by Dr. Melissa Olfert in the Department of Human Nutrition and Foods at West Virginia University. If you agree to participate, we will ask for approximately 10 minutes of your time to complete a self-administered, questionnaire that you are asked to complete in a private setting. Your participation in this study is strictly voluntary, and you are free to stop answering questions at any time. We do not anticipate that you will experience any inconvenience from completing this questionnaire other than the time it takes to answer the questions. Please understand that no compensation or academic credit is being offered for your participation; however, you may enter your email address to enter a drawing for a $\$ 100$ Gift Card by clicking a new link on the last page of the survey. Your participation would be very valuable to us since the answers you provide will help us to design activities about how to enhance student access to nutritious food. We assure you that the answers you give will not be connected to your email address and that only group answers, not individual answers, will be reported in the article that we write about this research. Thank you for considering this invitation. If you have any questions about this study, please contact Dr. Melissa Olfert at 304-293-1918 or e-mail melissa.olfert@mail.wvu.edu.

Questions regarding the protection of human subjects may be addressed to the IRB Administrator, Research Protections, West Virginia University.

1. Select the school you currently attend.

Appalachian State University

East Carolina University (2)

Mississippi State University (3)

University of North Carolina at Greensboro (4)

University of Southern Mississippi (5)

West Virginia University (6)

\section{Select the answer choice that BEST applies to you. All questions concern your access to food within the past 12 months.}

2. Which statement best describes the food available to you in the past 12 months? Check your answer.

Enough of the kinds of food I want to eat (1)

Enough, but not always the kinds of food I want to eat (2) 
Sometimes not enough to eat

Often not enough to eat (4)

3. In the last 12 months, I worried whether my food would run out before I got money to buy more.

Often (2)

Sometimes (1)

Never (0)

4. The food I bought just didn't last, and I didn't have money to get more.

Often (2)

Sometimes (1)

Never (0)

5. I couldn't afford to eat balanced meals.

Often (2)

Sometimes (1)

Never (0)

6. In the last 12 months, did you ever cut the size of your meals or skip meals because there wasn't enough money for food?

Yes (1)

No $(0)$

6a. How often did this happen? Please choose the answer choice that BEST applies to you.

Almost every month

Some months, but not every month

In only one or two months (0) 
7. In the last 12 months, did you ever eat less than you thought you should because there wasn't enough money for food?
Yes (1)
No $(0)$

8. In the last 12 months, were you ever hungry but didn't eat because there wasn't enough money for food?

\section{Yes (1)}

No (0)

9. In the last 12 months, did you lose weight because there wasn't enough money for food?
Yes (1)
No (0)

10. In the last 12 months, did you ever not eat for a whole day because there wasn't enough money for food?

\section{Yes (1)}

No (0)

10a. How often did you not eat for a whole day because there wasn't enough money for food?

Almost every month (2)

Some months, but not every month (1)

In only one or two months (0) 
11. During the past 12 months, about how often did you spent money on the following instead of using the money to buy food?

$$
\text { Often (1) Sometimes (2) Never (3) }
$$

\section{Purchased alcohol instead of using money to buy food (1) \\ Purchased cigarettes instead of using money to buy food (2) \\ Purchased recreational drugs instead of using money to buy food (3) \\ Spent money on car repairs instead of using money to buy food. (4) \\ Spent money on gasoline instead of using money to buy food. (5) \\ Spent money on public transportation to school/work instead of using money to buy food.}

\section{Spent money on pet care instead of using money to buy food. (7)}

Spent money on tattoos instead of using money to buy food. (8)

11a. Did you spend money on anything else instead of using money to buy food? Please indicate: 
Below is a list of strategies that some people use to get food when their own food is low or when they have run out of food.

12. Please select how often you have used any of these strategies in the past 12 months to get food.

Often (1) Sometimes (2) Never (3)

\author{
Sold textbooks (1) \\ Sold personal possessions (2) \\ Taken fewer classes to save tuition money (3) \\ Used less utilities (e.g. electricity, water) (4) \\ Shared the rent with other people (5) \\ Held one or more part-time or full-time jobs (6) \\ Used a credit card to buy food (7) \\ Planned menus before buying food (8) \\ Cut out food coupons (9) \\ Sold your blood/plasma to buy food (10) \\ Sold your sperm/eggs to buy food (11) \\ Participated in a research study/clinical trial to buy \\ food (12) \\ Borrowed money from family or friends (13)
}


Attended on-campus or community functions where there was free food (14)

Obtained food from a food bank or food pantry (15)

Bartered (traded) services or items to get food (16)

Participated in a federal or state food assistance program (e.g. SNAP, WIC, etc.) (17)

Taken food home from on-campus dining hall (18)

Saved money on medications or medical appointments to buy food (19)

Stretched food to make it last longer (20)

Shared groceries and/or meals with roommates (21)

Obtained food from a dumpster or trash (22)

Saved a supply of food in case of emergency (23)

Ate more than normal when food was plentiful (24)

Eaten meals at places where you can "pay what you can” (e.g. FARM Café) (25)

Joined a church or other organizational group where free meals are provided (26)

Ate less healthy meals so you could eat more food

Purchased cheap, processed food (e.g. ramen noodles, frozen pizza, candy, etc.) (28) 
Visited family on the weekend in order to bring back food to school (29)

These final questions ask for information about you and your lifestyle. All of your answers will be kept confidential. Please select the answers that best apply to you.

13. Your gender is:

Male (1)

Female (2)

Other (3)

14. Which region of the country did you grow up in?

Midwest - IA, IL, IN, KS, MI, MN, MO, ND, NE, OH, SD, WI (1)

Northeast - CT, DC, DE, MA, MD, ME, NH, NJ, NY, PA, RI, VT (2)

Southeast - AL, AR, FL, GA, KY, LA, MS, NC, SC, TN, VA, WV (3)

Southwest - AZ, NM, OK, TX (4)

West - AK, CA, CO, HI, ID, MT, NV, OR, UT, WA, WY (5)

15. How old are you? (Years)

16. Which term best describes your marital status?

Not married (1)

Married (2)

17. Do you have any dependent children living with you?

Yes (1)

No (2) 
17a. How many children currently live with you?

18. About how much do you currently weigh? (Pounds)

19. About how tall are you? (Feet', inches")

20. What year are you in school?

Freshman (1)

Sophomore (2)

Junior (3)

Senior (4)

Graduate Student (5)

Other (Please indicate) (6)

21. Are you an international student?

Yes (1)

No (2)

21a. How long have you been in the United States?

22. Are you a:

Part-time student (1)

Full-time student (2)

23. What is your major?

24. How would you rate your overall progress in school including graduating on time?

Excellent (1)

Good (2)

Fair (3)

Poor (4) 
25. How would you rate your class attendance?
Excellent (1)
Good (2)
Fair (3)
Poor (4)

26. How would you rate your attention span in class?
Excellent (1)
Good (2)
Fair (3)
Poor (4)

27. How would you rate your understanding of concepts taught in class?
Excellent (1)
Good (2)
Fair (3)
Poor (4)

28. What is your current grade point average (GPA)?

29. What is your race/ethnic background? Select all that apply.

African-American, not of Hispanic origin (1)

American Indian (2)

Asian (3)

Hispanic (4)

White, not of Hispanic origin (5)

Other (Please indicate) (6) 
30. Which term best describes your employment status?

\section{Unemployed}

One or more part-time jobs

One full-time job (3)

Other (Please indicate) (4)

31. Do you live:

On-campus (1)

Off-campus (2)

32. Do you have a car?

Yes (1)

No (2)

33. Do you take public transportation such as the bus?

\section{Yes (1)}

No (2)

34. Do you currently receive income from some type of financial aid like a scholarship, grant, private or federal loan?
Yes (1)
No (2)

35. What is your personal (not family) average monthly income? (Dollars) 
36. How would you rate your current health?
Excellent (1)
Good (2)
Fair (3)
Poor (4)

37. Do you currently participate in an on-campus meal plan?
Yes (1)
No (2)

38. Do you currently have health insurance?

Yes (1)

No (2)

39. How often do you cook for yourself or others?
Often (1)
Sometimes (2)
Never (3)

40. How would you rate your cooking skills?
Excellent (1)
Good (2)
Fair (3)
Poor (4) 


\section{Appendix C: Aim 3 Survey \\ WISH4Campus Toolkit Evaluation}

We are asking for expert review of the WISH4Campus Toolkit - a guide of food security initiatives that are occurring on college campuses. The WISH4Campus Toolkit is available to download at the link below and will be used to answer questions throughout this survey. Please take some time and read through the toolkit sections before answering the questions below.

As it will take you time to read through the WISH4Campus Toolkit, this survey is set up to be closed and reopened. You can either 1) keep the survey open on the computer while you go through the toolkit, or 2) if you don't have time to complete a review of the toolkit and survey now, you can reopen the survey and it will pick up where you left off.

NOTE: to reopen the survey you must use the same computer and browser. Do not delete cookies.

1. What is your sex?

Male (1)

Female (2)

Choose not to answer (3)

2. What is your age in years?

3. What is your profession?

4. How long have you been in this profession?

5. Do you reside in the Appalachian region?

Yes (1)

No (2)

Unsure (3)

Choose not to answer (4)

5a. If no, where do you reside?

6. Optional: What higher educational institution are you a part of? 
7. Do you believe food insecurity is an issue on your university/college campus? Explain.

Yes (1)

No (2)

Choose not to answer (3)

8. Are you involved in food insecurity issues on your university/college campus? If yes, how so.

Yes (1)

No (2)

Choose not to answer (3)

9. Does your university/college measure the prevalence of food insecurity on your campus?

Yes (1)

No (2)

Unsure (3)

Choose not to answer (4)

9a. Are you aware of the screener tool used to measure the prevalence of food insecurity on campus? If yes, please explain.

Yes (1)

No (2)

Choose not to answer (3)

10. Does your university/college have resources available to students who are food insecure? If yes, what resources?

Yes (1)

No (2) 
Unsure (3)

Choose not to answer (4)

The following sections must be completed AFTER review of the WISH4Campus Toolkit.

11. What is your initial opinion of the WISH4Campus Toolkit?

12. Please rate the layout of the WISH4Campus Toolkit.

$$
\begin{array}{lllllllllll}
0 & 1 & 2 & 3 & 4 & 5 & 6 & 7 & 8 & 9 & 10
\end{array}
$$

0 (don't like the layout at all) - 10 (like the

layout a lot) ()

12a. Why did you choose this rating for the layout of the WISH4Campus Toolkit?

13. Please rate the overall content of the WISH4Campus Toolkit.

$$
\begin{array}{lllllllllll}
0 & 1 & 2 & 3 & 4 & 5 & 6 & 7 & 8 & 9 & 10
\end{array}
$$

0 (don't like the content at all) - 10 (like the

content a lot) ()

13a. Why did you choose this rating for the overall content of the WISH4Campus Toolkit?

14. Please rate the food security initiatives included in the WISH4Campus Toolkit.

$$
\begin{array}{lllllllllll}
0 & 1 & 2 & 3 & 4 & 5 & 6 & 7 & 8 & 9 & 10
\end{array}
$$

0 (don't like the initiatives at all) - 10 (like the initiatives a lot) ()

14a. Why did you choose this rating for the food security initiatives included in the WISH4Campus Toolkit? 
15. Please rank the initiatives you think are most important to last important for a college campus.

Food Pantry (1)

Campus Garden (2)

Farmer's Market (3)

Dining and Recovery Programs (4)

Mobile Apps (5)

15a. Please justify why you chose this order.

16. Is there anything important that has been left out of the toolkit? Is there anything included that should not be?

17. Do you think this type of approach is likely to be useful to the target audience (college campuses) to start a food security initiative? Why or why not?

\section{Yes (1)}

No (2)

Choose not to answer (3)

17a. If no, what would you suggest is a better approach?

18. Do you think there are barriers to using this toolkit on your campus? Please explain.

Yes (1)

No (2)

Choose not to answer (3)

19. What features of the WISH4Campus Toolkit do you think work well, and why?

20. What features of the WISH4Campus Toolkit do you think need changed and why? What suggestions for improvement do you have?

21. Are there any specific, minor or editorial type comments you wish to make?

22. Please provide your email if you would like to be entered for a chance to win one of 2, $\$ 200$ gift cards. Your email will remain separate from the rest of the survey you have completed to keep your response anonymous. 
23. Would you like to collaborate in studying food insecurity issues on college campuses moving forward?
Yes (5)
No (6)

24. If there is another individual on your campus you believe could provide expert feedback, please forward this survey to them or provide their email below. 


\section{Appendix D: College Food Insecurity Screener Paper}

\section{Abstract \\ Investigation of a 2-item Food Security Screener Among a College Population \\ RL Hagedorn ${ }^{1}$, NA Turiano ${ }^{1}$, AL Pampalone ${ }^{1}$, KP Shelnutt ${ }^{2}$, LA House ${ }^{2}$, and MD Olfert ${ }^{1}$ \\ ${ }^{1}$ West Virginia University, Morgantown, WV \\ 2 University of Florida, Gainesville, FL}

Background: Food insecurity among college students is often measured using United States Department of Agriculture (USDA) screening tools. There is a need for shortened tools to quickly screen college students in settings such as brief health clinic visits. A shortened food security screener has been proposed previously, however, no such tool has been tested in a college population. This study investigated the use of the 2-item screener in a college population and examined the sensitivity, specificity, and convergent validity of a shortened college screener.

Methods: Data from college students $(n=1610)$ were utilized to compare three screening tools: the 10-item USDA Adult Food Security Screener (USDA-AFSS), a previously proposed shortened screener (Hager short screen), and a college shortened screener (College short screen).

Results: More individuals were categorized as food insecure using the Hager (40.0\%) and the College $(54.6 \%)$ short forms when compared to the USDA-AFSS screener (33.5\%). Sensitivity was calculated at $90.9 \%$ (491/540) for the Hager and $99.1 \%$ $(535 / 540)$ for the College short forms. Specificity was calculated at $85.2 \%(915 / 1070)$ for the Hager and $67.9 \%$ (726/1070) for the College short screener. Convergent validity was also evident, in two separate analyses, with significant association between BMI and being food insecure in all three screener models.

Conclusions: The College short screen may be more appropriate for use among college students and provides a brief option for efficient food security screening.

Keywords: college; student; food insecurity; screener; survey 


\section{Introduction}

Food insecurity can be defined as the limited or uncertain availability of nutritionally adequate or safe foods [2]. In 2017, the United States Department of Agriculture (USDA) estimated that $11.8 \%$ of households in the country were classified as food insecure at some point during the year [2]. While the prevalence of food insecurity from a nationwide population has decreased steadily since 2014 [2], food insecurity among college students has been reported at levels much higher than the national population. A 2017 systematic review found prevalence of food insecurity across campuses ranging from $14-59 \%$ and averaging $42 \%$ across college campuses [3]. Therefore, college students have been identified as an at-risk population for food insecurity and associated negative outcomes [222].

Specifically, food insecurity can have a detrimental impact on college student wellbeing. Multiple studies have found food insecure students at risk for poor selfreported health outcomes [26-28, 144]. Further, these students often have higher body mass index (BMI) scores [26] and poor dietary intake [23, 26, 120], making the population more at risk for chronic disease development [108]. Beyond physical health, food insecurity has also been noted to impact students' mental health status. Specifically, within a college population, food insecurity has been found to be a major predictor for depression and anxiety in college students [25, 29, 137]. This is of great concern, as college counseling centers are already reporting increased rates of selfreported generalized anxiety, depression, social anxiety, family distress and academic distress over a five year study published in 2017[223]. Thus, food insecurity adds another level of burden to a demographic with apparent heightened mental health problems. Therefore, due to the physical and mental impairment food insecurity can have on college students, it is imperative to be able to effectively screen for individuals who may be affected.

As food insecurity among college students is a relatively recent area of investigation, methods to identify food insecure students are needed to identify individuals who may need support. Methods to classify students as food insecure vary in the literature [3], but commonly USDA published tools are utilized. The USDA offers multiple tools to identify food insecurity including an 18-item, 10-item and 6-item survey 
that can annually monitor food security status in family households or among adult or child populations within the United States [72]. While these surveys are widely used, they require algorithm analysis to determine status of food insecurity, and there is a call for an abbreviated survey for use as a tool on student clinic and campus settings for identifying at-risk students in order to provide access to food insecurity resources [82]. In 2010, a brief, 2-item food insecurity screener (termed Hager short screen in this manuscript) was developed with $97 \%$ sensitivity towards families of young children [82]. As the Hager short screen is more streamlined than the standard "short form" 6-item screener, it could be a convenient and effective tool to use among college populations and has been suggested for use as a method in college mental health clinics to quickly screen students for food insecurity issues [120]. However, the Hager short screen was developed using families in a clinical setting, calling to question its validity in a college population. The primary objective of this study was to determine the validity of the 2item screener in a college population by examining the sensitivity, specificity, and convergent validity of a shortened college screener created by identifying the two most affirmative questions as replicating Hager et al. methodology, termed College short screener.

\section{Methods}

\section{Study Design and Participants}

This study utilized secondary, cross-sectional, survey data from a sample of young adults attending one of two large, land-grant universities in fall 2016 located in West Virginia and Florida. Campus-specific methodologies have been published previously [123, 144], however, in short, both universities distributed their nonprobability, Web-based survey via email directly to students or professors to pass on to students. Raw data from both universities was combined and cleaned for secondary analysis to ensure consistency of data from both universities. For this study analysis, participants were currently enrolled college students, and all disciplines and academic years were eligible to complete the survey. Informed consent was completed online at both universities prior to participating in the study. The study was 
conducted in accordance with the Declaration of Helsinki, and the protocol was approved by the Institutional Review Board at both universities.

\section{Measures}

The data used for this study was to answer a secondary research question posed by authors; therefore, the survey at each university varied. Measures that were identical at each university were combined for analysis and shown in Table 1. Participants at both universities reported their gender, marital status, housing situation, race, school year, and grade point average. Participants also self-reported their height without shoes in feet and inches and weight in pounds. Height and weight were used to calculate BMI. Food insecurity was measured using the validated 10-item USDA Adult Food Security Survey (USDA-AFSS) pulled from the USDA Household Food Security Module [72]. This tool is commonly used with college food insecurity literature and is a shortened version of the 18-item USDA Household Food Security Screener used by Hager et al. [82]. The USDA-AFSS eliminates the household level food security questions and only identifies the individual level as appropriate for college populations. The USDA-AFSS classifies respondents who affirmatively respond to $\geq 3$ questions regarding food purchasing and consumption behaviors as food insecure.

\section{Table 1: Study Variables and Description}

\begin{tabular}{|c|c|}
\hline Variable & Description \\
\hline Gender & $\begin{array}{l}\text { 1-item } \\
\text { Male/Female }\end{array}$ \\
\hline Marital Status & $\begin{array}{l}\text { 1-item } \\
\text { Married/Not Married }\end{array}$ \\
\hline Housing & $\begin{array}{l}\text { 1-item } \\
\text { On Campus/Off Campus }\end{array}$ \\
\hline Race & $\begin{array}{l}\text { 1-item } \\
\text { White/Black/Asian/Other }\end{array}$ \\
\hline School Year & $\begin{array}{l}\text { 1-item } \\
\text { Freshman/Sophomore/Junior/Senior/Graduate }\end{array}$ \\
\hline Grade Point Average & $\begin{array}{l}\text { 1-item } \\
3.0-4.0 / 2.0-2.9 / \text { Under } 2.0\end{array}$ \\
\hline Height & $\begin{array}{l}\text { 1-item } \\
\text { Self-reported in inches }\end{array}$ \\
\hline Weight & $\begin{array}{l}\text { 1-item } \\
\text { Self-reported in pounds }\end{array}$ \\
\hline Body Mass Index (BMI) & Calculated from self-reported height and weight \\
\hline
\end{tabular}


Food Security Status

10-items

United States Department of Agriculture Adult Food

Security Screener (USDA-AFSS)

\section{Analysis}

Demographic data were categorized and combined into bivariate groups for analysis: gender (male/female), marital status (married/not married), housing situation (on campus/off campus), race (white/other), school year (undergraduate/graduate), and grade point average (GPA; > 3.0/<3.0). Data were examined for frequency responses on the USDA-AFSS to classify food insecurity. The two most affirmative questions were identified, as replicating Hager et al. methodology, and formed the College short screener[224]. We conducted a Chi-Square analysis to identify if there was a statistically significant difference between the proportions of individuals classified as food insecure using the USDA-AFSS versus using either the Hager short screener or the College short screener. To examine the sensitivity (the ability to correctly identify food-insecure households) of the Hager short screener and the adapted College short screener, we divided the number of individuals labeled as food insecure from the Hager and College screeners (separately) by the number of individuals labeled as food insecure on the USDA-AFSS. A higher sensitivity percentage represents the Hager and College screeners' ability to capture those that are indeed at risk of being food insecure according to the standard USDA-AFSS, which may be useful for faculty and healthcare workers on college campuses to identify at risk students and refer them to resources for food insecurity. Specificity (the ability to correctly identify food-secure households) was estimated by dividing the number of individuals correctly labeled as food secure on the Hager and College screeners (separately) by the number of individuals labeled as food secure on the USDA-AFSS. A higher specificity percentage represents the Hager and College screeners ability to capture those that are food secure compared to the standard USDA-AFSS and so is important for situations such as trying to estimate prevalence of food insecurity on a college campus. Lastly, to examine convergent validity (the possible affiliation between the screeners and BMI), we utilized two different analytical techniques[224]. First, we used logistic regression to determine if BMI would differentially predict the odds of being food insecure (coded $0=$ food secure; coded $1=$ 
food insecure) using the three different food insecurity screeners (Model $1=$ USDAAFSS; Model 2 = Hager short screener; Model 3 = College short screener). BMI was used as our focal predictor in this analysis as unhealthy BMI levels and food insecurity have been found to be positively correlated $[26,225]$. If predictions were similar across the models, there would be evidence of convergent validity. The Hager short screener was used as a comparison in all analyses since prior research has found utility with this shorter measure [82]. In a second analysis we utilized multinomial logistic regression to analyze BMI scores as our outcome by classifying individuals into four different weight groups $($ Underweight $=\mathrm{BMI}$ less than 18.5; Normal weight $=\mathrm{BMI}$ between 18.5 and 24.5; Overweight $=$ BMI between 25 and 29.9; Obese $=$ BMI greater than 30) . Multinomial logistic regression is an extension of logistic regression that compares multiple groups through a combination of binary logistic regressions in one unified model. We set the normal weight as our referent group and compared whether there was an increased/decreased risk of being in any of the other weight groups (Underweight, overweight, obese) based on whether or not someone was labeled as food insecure by each of the three forms. Each model included the same set of covariates, which also have known associations with BMI and food insecurity (gender, race, marital status, year in school, grade point average, and housing location). All analyses were conducted using SAS 9.4 software (SAS Institute, In., Base SAS® 9.3 Procedures Guide [computer program]. 2011, SAS Institute Inc; Cary, NC).

\section{College Short Screener}

For the 2-item screener developed by Hager et al., the two most prevalent affirmative responses from the USDA-AFSS questions are used: (1) "Within the past 12 months, we worried whether our food would run out before we got money to buy more" and (2) "Within the past 12 months, the food we bought just didn't last and we didn't have money to get more". For result comparison this 2 -item tool will be referred to as the Hager short screener. Only one of these questions was among the most prevalent affirmative responses from the USDA-AFSS in this college sample. Most food insecure college students answered affirmatively to questions 1 and 3 of the USDA-AFSS: $86.5 \%$ and $90.2 \%$, respectively. These questions asked (1) "Within the past 12 months, I 
worried whether my food would run out before I got money to buy more" and (2) "I couldn't afford to eat balanced meals." For result comparison this 2 -item tool will be referred to as the College short screener. For each tool to be considered food insecure, a respondent had to answer affirmatively to question 1 and/or question 2.

\section{Results}

\section{Sample Characteristics}

The survey was completed by 1610 college students across two campuses. Sample characteristics are represented in Table 2. The population was predominately not married $(92.2 \%)$, white $(72 \%)$, females $(72.6 \%)$ and living off campus $(72.3 \%)$. The population was spread across all academic years. Most participants had GPA's > 3.0. More college students were food secure (66.5\%) than food insecure (33.5\%) based on the USDA-AFSS criteria.

\section{Table 2: Characteristics of College Students $(n=1610)$ from Two Universities}

\begin{tabular}{ll}
\hline Demographic & Frequency (\%) \\
\hline Food Security Status & \\
Food Secure & $1070(66.5 \%)$ \\
Food Insecure & $540(33.5 \%)$ \\
Gender & \\
Male & $433(27.4 \%)$ \\
Female & $1150(72.6 \%)$ \\
Marital Status & \\
Married & $123(7.8 \%)$ \\
Not Married & $1459(92.2 \%)$ \\
Academic Year & \\
Freshman & $326(20.8 \%)$ \\
Sophomore & $207(13.2 \%)$ \\
Junior & $292(18.6 \%)$ \\
Senior & $295(18.8 \%)$ \\
Graduate & $450(28.7 \%)$ \\
GPA & $1314(90.5 \%)$ \\
3.0-4.0 & $133(9.2 \%)$ \\
2.0-2.9 & $4(0.3 \%)$ \\
Under 2.0 & \\
Housing & \\
On Campus & $429(27.7 \%)$ \\
Off Campus & $1119(72.3 \%)$ \\
Race & \\
White & $1115(72.0 \%)$ \\
Black & $74(4.8 \%)$ \\
Asian & $138(8.9 \%)$ \\
&
\end{tabular}


Other

Body Mass Index (BMI)

Underweight

Normal

Overweight

Obese
$222(14.3 \%)$

$69(4.6 \%)$

$928(61.3)$

$332(21.9)$

$18512.2)$

Note: Food insecurity is based on the USDA-AFSS with $>3$ affirmative responses. Race catergory other includes Hispanic, Pacific Islander and Bi/Multiracial.

\section{Screen Comparision}

A chi-square test of independence was performed to examine the prevalence of food insecurity when comparing the USDA-AFSS with both the Hager and the College short forms. The association with the Hager $\left.\left(\chi^{2}(2, N=1610)=872.84, p<.001\right)\right)$ and the College screeners $\left.\left(\chi^{2}(2, N=1610)=648.44, p<.001\right)\right)$ were both statistically significant. More individuals were categorized as food insecure using the Hager (40.0\%) and the College (54.6\%) short forms when compared to the USDA-AFSS screener (33.5\%). Sensitivity was calculated at $90.9 \%$ (491/540) for the Hager and $99.1 \%$ (535/540) for the College short forms. This equates to the Hager and College short forms miss-specifying 49 and 5 individuals, respectively, as food secure when the USDA-AFSS form categorizes them as food insecure. Specificity was calculated at 85.2\% (915/1070) for the Hager and 67.9\% (726/1070) for the College short screener. This equates to the Hager and College short forms miss-specifying 155 and 344 individuals, respectively, as food insecure when the USDA-AFSS categorizes them as food secure. Thus, if the College short form is used, one would only potentially miss 5 individuals that may indeed be food insecure, whereas using the Hager there may be 49 individuals missed. Thus, the College form demonstrates better sensitivity (correctly identifying those as food insecure) but worse specificity (ability to correctly identify those as food secure) when compared to the Hager form.

Table 3 displays results of the logistic regression analyses. In Model 1, every standard deviation increase in BMI was associated with a $23 \%$ increased odds of being categorized as food insecure according to the USDA-AFSS screener. Identifying as Caucasian and living on-campus were associated with a decreased odds (34\% and $38 \%$, respectively) of being food insecure. In Model 2, every standard deviation 
increase in BMI was associated with a $21 \%$ increased odds of being categorized as food insecure according to the Hager form. Identifying as Caucasian and living oncampus were also associated with a decreased odds ( $40 \%$ and $36 \%$, respectively) of being food insecure. In Model 3, every standard deviation increase in BMI was associated with a $23 \%$ increased odds of being categorized as food insecure according to the College short form. In terms of other demographic factors, being female, unmarried, and identifying as a minority was also associated with an increased odds ( $28 \%, 47 \%$, and $28 \%$, respectively) of being categorized as food insecure.

Table 3. Logistic regression analyses with three different food security forms. Model 1: USDA-AFSS Model 2: Hager Model 3: College

\begin{tabular}{|c|c|c|c|c|c|c|}
\hline & OR & $95 \% \mathrm{Cl}$ & OR & $95 \% \mathrm{Cl}$ & $O R$ & $95 \% \mathrm{Cl}$ \\
\hline BMI & $1.23^{\star \star \star}$ & $1.10-1.37$ & $1.21^{\star \star \star}$ & $1.02-1.06$ & $1.23^{\star \star \star}$ & $1.10-1.38$ \\
\hline Female & 1.11 & $0.87-1.43$ & 1.26 & $0.99-1.60$ & $1.28^{*}$ & $1.02-1.62$ \\
\hline Caucasian & $0.66^{* * *}$ & $0.51-0.83$ & $0.60^{* * *}$ & $0.48-0.76$ & $0.72^{* *}$ & $0.57-0.91$ \\
\hline Married & 0.74 & $0.47-1.15$ & 0.74 & $0.49-1.12$ & $0.53^{\star *}$ & $0.35-0.79$ \\
\hline $\begin{array}{l}\text { Graduate } \\
\text { Student }\end{array}$ & 0.93 & $0.85-1.01$ & 0.97 & $0.89-1.06$ & 1.03 & $0.95-1.13$ \\
\hline On Campus & $0.62^{* \star}$ & $0.46-0.84$ & $0.64^{\star * *}$ & $0.48-0.85$ & 0.79 & $0.60-1.04$ \\
\hline GPA & 1.07 & $0.92-1.23$ & 1.11 & $0.97-1.28$ & 1.06 & $0.92-1.22$ \\
\hline
\end{tabular}

Table 4 displays results for the multinomial logistic regression analyses. When comparing those from the normal weight group to the other three groups, the majority of significant contrasts were between normal and obese groups when examining the USDA and Hager forms. Males, Caucasians, and being labeled as food insecure were each associated with increased odds of being in the obese group versus being in the normal weight group. The USDA-AFSS showed $102 \%$ increased odds, the Hager short screener $90 \%$ increased odds and the College short screener $87 \%$ increased odds of being in the obese category versus the normal weight category for students who 
Table 4 Multinomial logistic regression results comparing three food security screeners outcomes by weight status

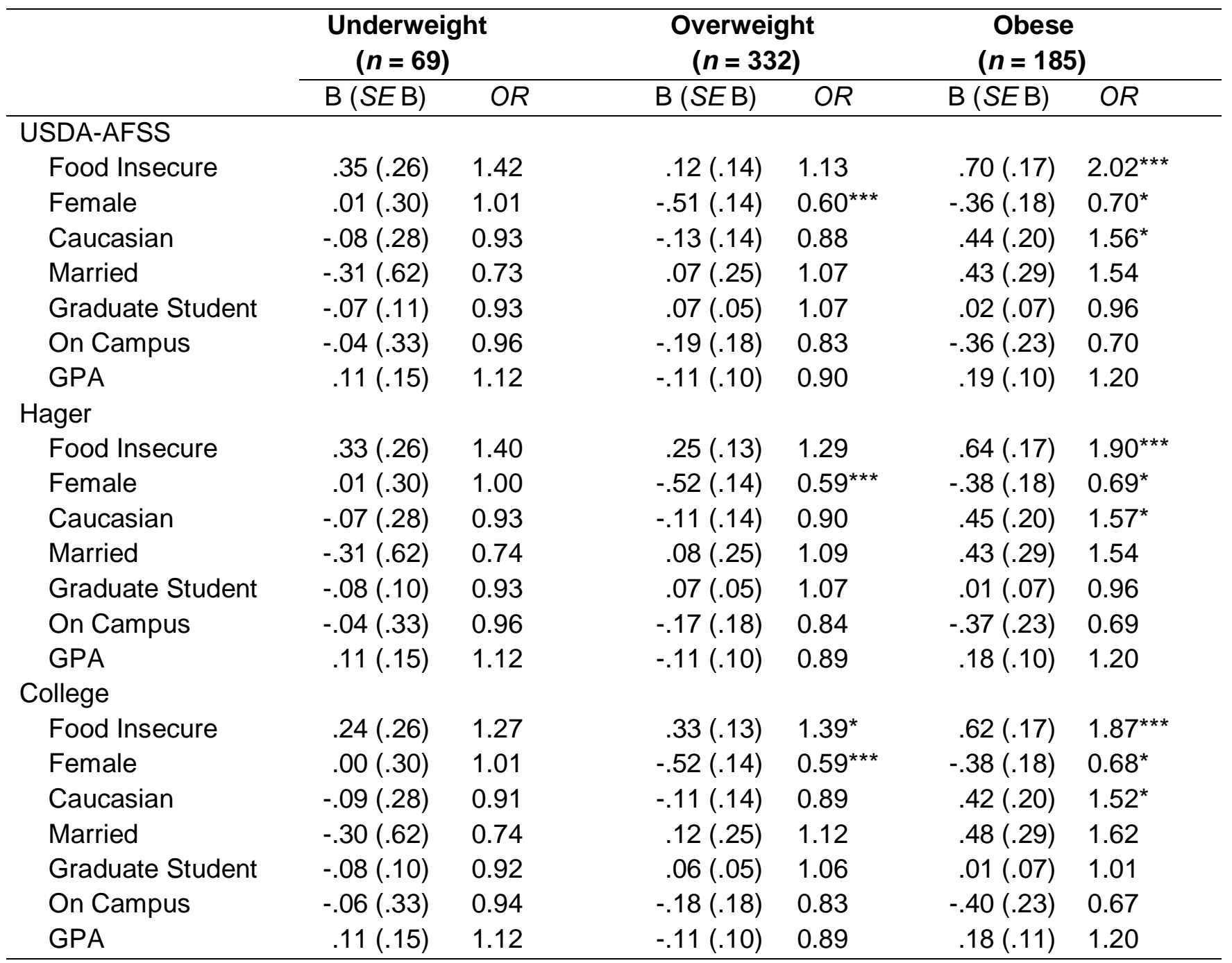

Note: Model Chi Square: $D F=21$; USDA-AFSS $=59.88^{* * *} \mathrm{Hager}=58.46^{* \star *} ;$ College $=58.91^{* * *}$. Underweight $=\mathrm{BMI}$ less than 18.5; Normal weight $=$ BMI between 18.5 and 24.5; Overweight $=$ BMI between 25 and 29.9;

Obese $=$ BMI greater than 30 .

${ }^{*} p<.05 .{ }^{\star \star *} p<.001$.

screened as food insecure. The findings were similar for the College form, but there was also a significant contrast between those in the overweight category, with food insecure students having $39 \%$ increased odds of being in the overweight category versus the normal weight category. Specifically, males and being labeled as food insecure was associated with an increased odds of being overweight versus being in the normal weight category. 


\section{Discussion}

This manuscript describes the investigation of a shortened College food security screener, compared to the 10-item USDA-AFSS and the Hager short screener. Results showed that when using the USDA-AFSS, college students are most commonly responding affirmatively to "Within the past 12 months, I worried whether my food would run out before I got money to buy more" and "I couldn't afford to eat balanced meals", which varies from the previous two questions proposed as a shortened food security screener [82]. When comparing these two questions as a College short screener, using sensitivity and specificity estimates, the College short screener has higher sensitivity in the college population than the Hager short screener. The College short screener missed less than $1 \%(n=5)$ of the individuals the full USDA-AFSS considered food insecure compared to the Hager short screener that missed 49 individuals. However, the specificity of the College short screener is less than that of the Hager short screener ( $67.9 \%$ vs. $85.2 \%$, respectively) meaning that the College short screener is more likely to classify a student as food insecure when the USDA-AFSS would classify them as food secure. When estimating prevalence of food insecurity, it may be worthwhile to use a screener that shows higher specificity, such as the longer 10-item USDA-AFSS survey. However, in terms of providing resources to potentially at-risk students, utilizing a screener with higher sensitivity would avoid potentially missing food insecure students who are in need.

The College short form was also able to show evidence of convergent validity, in two separate analyses, when compared to the USDA-AFSS and the Hager short screener. In the first analysis, using logistic regression with food security as the outcome variable, across all three screeners (Models 1-3) BMI was significantly associated with being food insecure with nearly identical size of effects and corresponding confidence intervals. All three screeners also provided significant associations between identifying as a minority and a greater likelihood of being food insecure. As with BMI, minority status and increased food insecurity risk is also consistent with what has been shown in college food insecurity literature $[36,110,150]$.

However, while the College short form showed convergent validity with our outcome variable of BMI, some variables differed across the three models. The College 
short screener was the only model to show significant results for gender and marital status, although the direction of the relationship was the same within all three models. Specifically, on the College short screener, being a female and unmarried were associated with being food insecure. Within college food insecurity literature, gender is not commonly acknowledged as significant covariate within food secure and food insecure students $[25,110]$. Similarly, marital status is not often referenced as a significant predictor within college food insecurity literature, potentially because married individuals make up such a small proportion of the college population. This relationship may be shown for the college screener related to the overestimation (low specificity) of college students who were food insecure compared to the Hager and USDA AFSS models and further testing is needed to confirm if these relationships exist in the college population.

Additionally, there was inconsistency between the USDA-AFSS and the Hager short screener models and the College short screener regarding housing (living on or off campus). Both the USDA-AFSS and the Hager short screener showed significant increase in risk of food insecurity for those who live off campus, but the College short screener did not. However, while not significant, the direction of the relation and the confidence intervals are within what would be expected compared the USDA-AFSS and the Hager short screener. Within college food security literature, housing situation and college food insecurity predominately shows association between living off campus and increased risk of food insecurity [30,110], making our results consistent with what has been found previously. A potential reason for this may be that students who live on campus, mainly in residence halls, are generally required to have a prepaid meal plan to dining halls which may protect against food insecurity by having a set payment at the start of each semester.

In the second analysis, using multinomial logistic regression with BMI as the outcome variable, the College short form was again able to demonstrate convergent validity. All screeners demonstrated that being food insecure was a risk for being obese, versus being of a normal weight. However, only with the College short screener did being food insecure predict an increased risk of being overweight versus normal weight. This finding is of importance as overweight status is a risk of subsequent obesity, and 
early identification of those at risk can be useful for targeted intervention. Specifically, college students in the transition from adolescence to adulthood are at risk for weight gain that could lead to obesity [226]. Food insecurity has been a factor that has been associated with increased weight status of college students, with food insecure students having higher BMls compared to their food secure counterparts [26]. This study confirms what has been presented previously, that food insecure college students are at risk for obesity, calling for a need for intervention to improve health outcomes in this population. Therefore, the College short screener may be able to identify food insecure students and implement an intervention before students' progress into an obese state. More research is needed to understand how both food insecurity and body mass interact as college students progress throughout young adulthood.

A notable finding of this study is the insight on the concern most predominately noted by food insecure college students - affording a balanced meal. This study sheds light on the differences that might be present between food insecurity in the general population as investigated by Hager et al. and food insecurity among the college population. As aforementioned, college students most affirmatively responded to the question "I couldn't afford to eat balanced meals" with $90 \%$ of students screened as food insecure responding affirmatively to this question. This leads us to believe that college students may be experiencing food insecurity differently. Different populations experience food insecurity in different manners and, as proposed by Wolfe, Frongillo and Valois when investigating food insecurity in the elderly [227], there is a need to fully conceptualize the food insecurity experience of a given population.

In addition, there has been no cognitive testing of college student's interpretation of the USDA food security screeners and therefore college student's interpretation of these questions might be different from that of a general population. Overall, this calls into question the validity of using previous USDA food security screeners in this population and highlights the need for a greater understanding of the college food insecurity experience, through both qualitative and quantitative research, to better define and measure food insecurity in the population.

\section{Conclusions}


The shortened food security screener, College short screen, used within this study may be more appropriate for use within a college population although further testing is needed. Future research should look to test this shortened tool on other college campuses and potentially utilize it to quickly screen students for food insecurity. Food insecurity can greatly hinder college students academic progress and impact their health, therefore, this shortened tool can provide a valuable resource for universities to identify students in need and promote student food security and well-being.

\section{Curriculum Vita}

\section{Rebecca L. Hagedorn}

820 Monongalia Ave, Morgantown, WV 26505

304.685 .8585

rlhagedorn@mix.wvu.edu

\section{Education}

Ph.D. Candidate in Animal \& Food Science

2016-Current

West Virginia University, Morgantown, WV

Current GPA: 3.93

Research focus: Food insecurity factors among college students

Anticipated Graduation: May 2019

B.S. Degree in Human Nutrition \& Foods

2012-2015

West Virginia University, Morgantown, WV

Graduated Cum Laude with 3.43 GPA

Research focus: iCook 4-H: Childhood obesity program

Applied Biostatistics Graduate Certificate

2016-2018

West Virginia University, Morgantown, WV

Dietetic Internship - ISPP

University of Arizona, Tucson, AZ

2018-Current 


\section{Experience}

Science Policy Fellow, American Society for Nutrition

2019-Current

- Represent ASN at hill visits and national meetings

- Serve as ex officio member of ASN's Committee on Advocacy and Science Policy (CASP)

- Contribute to various policy-related projects

NIH T32 Behavioral and Biomedical Sciences Trainee, West Virginia University

- Collaborate with fellow trainees in multidisciplinary environment

- Attend and present at Meetings of Behavioral and Biomedical Sciences Meetings

- Coordinate Stevenson Scholarship application process

- Advanced research training in behavioral analysis and experimental models

- Policy immersion at Center for Science in the Public Interest (CPSI)

\section{Graduate Research Assistant, West Virginia University}

https://melissa-olfert.davis.wvu.edu/our-lab-team/core-team/-becca-hagedorn

- Research Coordinator for HomeStyles - USDA Grant

- Research Coordinator for iCook 4-H - USDA Grant

2016-Current

- Lab Manager (2016-2018)

- Present at national and local meetings

- Mentor undergraduate researchers

\section{Graduate Teaching Assistant, West Virginia University}

- Community Nutrition - Fall 2018

- Maternal \& Child Nutrition - Spring 2018,2019

- Guest Lecture Nutrition Counseling - Spring 2016

Ronald E. McNair Scholar, West Virginia University

- Collaborate with fellow scholars in multidisciplinary environment

- Training in research writing and methods

- Conduct research with PI

\section{Olfert Research Lab Volunteer, West Virginia University}

- Assisted graduate students with funded research projects

- State Contact for iCook 4-H

- Coordinated dissemination throughout WV into extension and HSTA

- Attended \& presented at national meetings 
- Worked directly with patients to assess dietary choices

- Prepared \& delivered food to patients

- Presentations to hospital employees on healthful behaviors

\section{Honors \& Awards}

- Emerging Leaders Poster Competition Finalist, American Society of Nutrition National Conference, Nutrition 2018, Boston MA

- Stitzel Graduate Student Support for AGR 2018 (\$1000)

- Nancy Sanders Memorial Travel Abroad Award Recipient 2017 (\$2000)

- Second place poster presentation at Davis College Research \& Creative Scholars Day $2017(\$ 50)$

- Davis College Travel Award 2017(\$200)

- First place poster presentation Davis College Research \& Creative Scholars Day 2016 (\$200)

- $\quad$ WV Rural Health Conference Scholarship 2016 (\$300)

- Newman Travel Award 2016(\$500)

- Second place on oral presentation at the University of Delaware National McNair Research Conference 2015 (\$150)

- WVU Davis College of Agriculture, Natural Resources and Design Undergraduate Research/Creative Activity/Outreach Grant Program Recipient $2015(\$ 500)$

- West Virginia University Deans List 2012, 2015

- WV Promise Scholar Recipient 2012

- WVU Shenandoah Scholarship 2012

- Ralph \& Alma Miller Scholarship 2012

\section{Memberships}

- American Society of Nutrition

2018-Current

- Academy of Nutrition and Dietetics

- Society for Nutrition Education \& Behavior

2018-Current

- National Society of Collegiate Scholars 


\section{Certifications \& Trainings}

- Adult, Child and Infant CPR

- Smarter Lunchroom TAP Certificate

- ServSafe Food Production Manager Certificate

- Collaborative Institutional Training Initiative Program (CITI) Certificates

- Mobile Phones for Public Health Training

- Motivational Interviewing Training Certificate

\section{Peer-Reviewed Manuscript Publications}

1. Hagedorn RL, Olfert MD. Food Insecurity and Behavioral Characteristics for Academic Success in Young Adults Attending an Appalachian University. Nutrients. 2018 Mar 16;10(3):361.

https://doi.org/10.3390/nu10030361

2. Olfert MD, Famodu OA, Leary M, Hagedorn RL, Flanagan S, Smith E, Leary MP, White JA, Koenings M, Colby SE, Kattelmann KK, Franzen-Castle L, White A. The Effect of iCook 4-H, an Obesity Prevention Program, on Blood Pressure and Quality of Life in Youth and Adults. Jrnl of Childhood Obesity 2018 Mar. DOI: 10.21767/2572-5394.100044

3. Olfert, M.D., Barr, M.L., Hagedorn, R.L., Franzen-Castle, L., Colby, S.E., Kattelmann, K.K. and White, A.A., Health Disparities Score Composite of Youth and Parent Dyads from an Obesity Prevention Intervention: iCook 4-H. Healthcare. 2018 May; 6(2):51. https://doi.org/10.3390/healthcare6020051

4. Hagedorn, RL., White, JA, Franzen-Castle, L, Colby, SE, Kattelmann, KK, White, AA, \& Olfert, MD. Teens Implementing a Childhood Obesity Prevention Program in the Community: Feasibility and Perceptions of a Partnership with HSTA and iCook 4-H. International journal of environmental research and public health. 2018 May; 15(5), 934. https://doi.org/10.3390/ijerph15050934

5. White JA, Hagedorn RL, Waterland NL, Barr ML, Famodu OA, Root AE, White AA, Colby SE, Franzen-Castle L, Kattelmann KK, Olfert MD. Development of iGrow: A Curriculum for Youth/Adult Dyads to Increase Gardening Skills, Culinary Competence, and Family Meal Time for Youths and Their Adult Caregivers International journal of environmental research and public health. $2018 \mathrm{Jul}$ 3;15(7):1401. https://doi.org/10.3390/ijerph15071401

6. Olfert MD, Hagedorn RL, White JA, Baker BA, Colby SE, Franzen-Castle L, Kattelmann KK, White AA. An Impact Mapping Method to Generate Robust Qualitative Evaluation of Community-Based Research Programs for Youth and Adults. Methods and Protocols. 2018; 1(3):25. https://doi.org/10.3390/mps1030025

7. Wattick RA, Hagedorn RL, Olfert MD. Relationship between Diet and Mental Health in a Young Adult Appalachian College Population. Nutrients. 2018 Jul;10(8). https://doi.org/10.3390/nu10080957

8. Olfert M, Hagedorn R, Barr M, Famodu O, Rubino J, White J. eB4CAST: An Evidence-Based Tool to Promote Dissemination and Implementation in Community-Based, Public Health Research. International journal of environmental research and public health. 2018 Sep 29;15(10):2142. https://doi.org/10.3390/ijerph15102142

9. Olfert MD, King SJ, Hagedorn RL, Barr ML, Baker BA, Colby SE, Kattelmann KK, Franzen-Castle L, White AA. Ripple Effects Mapping Outcomes of a Childhood Obesity Prevention Program from Youth and Adult Dyads Using a Qualitative Approach: iCook 4-H. JNEB https://doi.org/10.1016/j.jneb.2018.08.002

10. Olfert MD, Hagedorn RL, Barr ML, Colby SE, Kattelmann KK, Franzen-Castle L, White AA. Dissemination Approach Using Infographic Reports Depicting Program Impact of a Community-Based Research Program: eB4CAST in iCook 4-H. JNEB. DOI: https://doi.org/10.1016/j.jneb.2018.10.013

11. Kattelmann KK, Meendering JR, Hofer E, Merfeld CM, Olfert MD, Hagedorn RL, Colby SE, FranzenCastle L, Moyer J, Mathews DR, White AA. The iCook 4-H Study: Report on physical activity and sedentary time in youth participating in a multicomponent program promoting family cooking, eating, and playing together. JNEB. DOI: https://doi.org/10.1016/j.jneb.2018.09.002 
12. Hagedorn RL, Baker K, DeJarnett SE, Hendricks T, McGowan M, Joseph L, Olfert MD. Katalyst Pilot Study: Using Interactive Activities in Anatomy and Physiology to Teach Children the Scientific Foundation of Healthy Lifestyles. Children, 2018 Dec;5(12):162. DOI: https://doi.org/10.3390/children5120162

13. Olfert MD, Hagedorn RL, Clegg EN, Ackerman S, Brown C. Choice Architecture in Appalachian High Schools: Evaluating and Improving Cafeteria Environments. Nutrients. 2019 Jan;11(1):147.

14. Baker KA, Hagedorn RL, Hendricks T, Clegg EN, McGowan M, Joseph L, Olfert MD. KATALYST Pilot Study: Development of a $5^{\text {th }}$ Grade Novel Approach to Health and Science Experiential Learning. Science Activities, 2019 Feb; https://doi.org/10.1080/00368121.2018.1561406

15. White AA, Colby S, Franzen-Castle L, Kattelmann K, Olfert M, Gould T, Hagedorn R, Mathews D, Moyer J, Wilson-Sweebe K, Yerxa K. (In Press) The iCook 4-H Study: Implementation and Dissemination of a Youth/Adult Out-Of-School Program. JNEB

16. Olfert MD, Hagedorn R, Leary MP, Eck KM, Shelnutt, Byrd-Bredbenner C. Parent and School-age Children's Food Preparation Cognitions and Behaviors Guide the Development of Recommendations for Future Interventions. (In Press) JNEB

\section{Manuscripts in Review}

17. Wattick RA, Barr ML, Hagedorn RL, Colby SE, Olfert MD. Food Insecurity and Tobacco Use of Appalachian vs. Non-Appalachian Young Adults. (In Review)

18. Hagedorn RL, McArthur LH, Hood LB, Berner M, Anderson Steeves ET, Connell CL, Wall-Bassett E, Spence M, Babatunde OT, Kelly EB, Waity JF, Lillis JP, Olfert MD. Money Expenditure, Coping and Academic Behaviors Among Food Insecure College Students at 10 Higher Education Institutes in the Appalachian and Southeastern Regions. 2018 (In review)

19. Hagedorn RL, Turiano NA, Pampalone AL, Shelnutt KP, House LA, Olfert MD. Investigation of a 2item Food Security Screener Among a College Population. (In Review)

20. Barr ML, Hagedorn RL, Olfert MD. Food Access and Obesity Relationship in the Appalachian Region (In Review)

21. Sowers M, Colby SE, Anderson Steeves E, Kavanagh K, Zhou W, Hagedorn RL, Olfert MD. Description and Comparison of Contents, Traffic, and Consumer Demographics of Vending Machines on a College Campus, (In Review).

22. Clark R, Famodu OA, Barr ML, Hagedorn RL, White JA, Warner C, Morrell A, Murray PJ, Olfert IM, McFadden JW, Cuff CF, Downes MT, Colby SE, Ruseski J, Olfert MD. Make Half Your Plate Fruits and Veggies: Cost of Following the MyPlate Diet in College Students (In Review)

23. Olfert MD, Barr ML, Hagedorn RL, Clegg EN, Wattick RA, Zhou W, Horacek TM, Mathews AE, Kattelmann KK, Kidd T, White AA, Brown ON, Morrell JS, Franzen-Castle L, Shelnutt KP, ByrdBredbenner C, Mosby TT, Greene GL, Colby SE. Feedback from a Novel Dissemination Tool: eB4CAST in Get Fruved (In Review)

24. Santella ME, Hagedorn RL, Wattick RA, Barr ML, Horacek TM, Olfert MD. Exploring the effect of a learn first, practice second style approach on West Virginia health professionals' nutrition-related knowledge, attitudes, and self-efficacy. (In review) 